Paulo Sérgio da Silva Jr.

\title{
Changes in the Equatorial Mode of the Tropical Atlantic in Different Oceanic Reanalyses
}

\author{
Master's dissertation submitted to the \\ Oceanographic Institute of the University \\ of São Paulo as partial fulfillment of the \\ requirements for the degree of Master of \\ Science in Oceanography, with emphasis on \\ Physical Oceanography.
}

Advisor: Dr. Ilana E. K. C. Wainer

São Paulo

2019 
Universidade de São Paulo

Instituto Oceanográfico

\title{
CHANGES IN THE EQUATORIAL MODE OF THE TROPICAL ATLANTIC IN DIFFERENT OCEANIC REANALYSES
}

\begin{abstract}
Paulo Sérgio da Silva Jr.
Master's dissertation submitted to the Oceanographic Institute of the University of São Paulo as partial fulfillment of the requirements for the degree of Master of Science in Oceanography, with emphasis on Physical Oceanography.
\end{abstract}

Evaluated in March 19th, 2019.

REVISED VERSION 


\section{Agradecimentos}

Gostaria de agradecer primeiramente à minha orientadora Ilana, pela confiança e por ter aceitado me orientar quando "caí de paraquedas" no laboratório, além de todo o suporte, motivação e conhecimentos transmitidos.

A todo o pessoal do OC2 pela companhia, paciência, conselhos e conhecimentos compartilhados nesses últimos dois anos: Bruno, Fernanda, Gabriel, Mineiro, Laura, Natalia e Zé. Também agradeço a todo o pessoal da pós do IO que passou pela maratona de disciplinas comigo por toda a ajuda. Muito obrigado!

Aos docentes do IO e do IAG que estiveram presentes nesses anos e contribuíram para a minha formação.

Agradeço aos meus pais por todo o suporte, carinho e apoio durante os momentos de crise. E claro, agradeço ao Pedro por ser esse ser hilário e jocoso, me encher o saco e me fazer rir. Também à Ju, Tata e Alice.

Agradeço ao Daniel, por ter estado ao meu lado nesses últimos anos, pela companhia, carinho, apoio e paciência - muita paciência (risos). Muito obrigado!

Agradeço aos amigos que estiveram comigo nesse período, mesmo que nem sempre fisicamente: Victor, Gabi e Rapha, Natalia, Iago, Renato, Camila e Rodrigo Hyago. Jag tackar också Jonas, för att alltid lyssna på mig.

Por fim, agradeço às minhas danadjinhas: Kimi, Lili, Marie, Lari e Block. Muito obrigado por terem feito parte dos meus anos de graduação, pelas longas noites de estudo feat. pizza, pelas risadas, pelas duas festas surpresa no mesmo dia, por me aguentarem (nem eu me aguentaria o tanto que vocês aguentaram, parabéns guerreiras), pelas festas, pelas noites de filme nas quais eu dormia, pelas viagens, pelos conselhos e principalmente por jamais me deixarem esquecer do dia que falei pra trancarem cálculo e que não agradeci a vocês no TCC (risos). Muito obrigado por também terem estado presentes nessa nova fase! 
O presente trabalho foi realizado com apoio da Coordenação de Aperfeiçoamento de Pessoal de Nível Superior - Brasil (CAPES) - Código de Financiamento 001.

This study was financed in part by the Coordenação de Aperfeiçoamento de Pessoal de Nível Superior - Brasil (CAPES) - Finance Code 001. 


\section{Contents}

$\begin{array}{lll}\text { List of Figures } & \text { VI }\end{array}$

List of Tables $\quad$ XIV

$\begin{array}{ll}\text { List of Acronyms } & \text { XV }\end{array}$

$\begin{array}{lll}\text { Abstract } & \text { XVIII }\end{array}$

$\begin{array}{ll}\text { Resumo XIX } & \text { X }\end{array}$

1. Introduction 1

1.1. Tropical Atlantic Climatology and Circulation . . . . . . . . . . . 2

1.1.1. Sea surface temperature and surface winds . . . . . . . . . . 2

1.1.2. Mean ocean currents . . . . . . . . . . . . . . . . . 4

1.2. Tropical Atlantic Variability . . . . . . . . . . . . . . . . 5

1.2.1. The Equatorial Mode and the Bjerknes Feedback . . . . . . . 7

2. Objectives 12

3. Methods 13

3.1. Reanalysis Products . . . . . . . . . . . . . . . . 13

3.1.1. NCEP/CFSR . . . . . . . . . . . . . 13

3.1.2. GFDL/ECDA v.3 . . . . . . . . . . . . . . 13

3.1.3. ICDC/GECCO2 . . . . . . . . . . . . . . . . 14

3.1.4. NCEP/GODAS . . . . . . . . . . . . . 14

3.1.5. JAMSTEC/K7-ODA . . . . . . . . . . . . . . . . 14

3.1.6. ECMWF/ORAS4 . . . . . . . . . . . . . 15

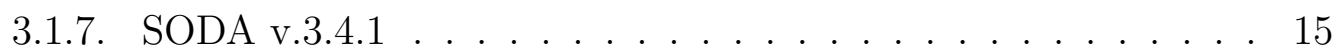

3.1.8. TropFlux . . . . . . . . . . . . . . . 15

3.1.9. 20th Century Reanalyses . . . . . . . . . . . . 16

3.2. Region of study and Variables . . . . . . . . . . . . . . . 16

3.2.1. Vertical Velocity . . . . . . . . . . . . 17

3.2.2. Thermocline Depth . . . . . . . . . . . . . . . 18

3.2.3. Net Surface Heat Flux (NSHF) . . . . . . . . . . . . . 18 
3.3. Climatologies and Anomalies . . . . . . . . . . . . . . . . . . . 19

3.4. Climate indices . . . . . . . . . . . . . . . . . . 21

3.4.1. Root Mean Square Variance (RMSV) . . . . . . . . . . . . 22

3.5. Bjerknes Feedback Analysis . . . . . . . . . . . . . . . . . 22

3.5.1. Correlations among SST, zonal wind stress and thermocline

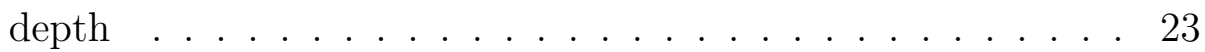

3.5.2. Bjerknes Feedback Index . . . . . . . . . . . . . . . 23

4. Reanalyses Intercomparison $\quad 27$

4.1. Mean fields and climatologies . . . . . . . . . . . . . . . . . 27

4.1.1. Sea surface temperature . . . . . . . . . . . . . 27

4.1.2. Subsurface temperature and thermocline depth . . . . . . . . 29

4.1.3. Wind stress . . . . . . . . . . . . . . 33

4.1.4. Surface currents . . . . . . . . . . . . . . . 35

4.2. Bjerknes Feedback analysis . . . . . . . . . . . . . . . . . . 37

4.2.1. Correlation patterns . . . . . . . . . . . . . 37

4.2.2. Bjerknes Feedback Index . . . . . . . . . . . . . . . . 41

5. Changes over the past decades 53

5.1. Anomaly time series . . . . . . . . . . . . . . . 53

5.1.1. Sea surface temperature, zonal wind stress and thermocline

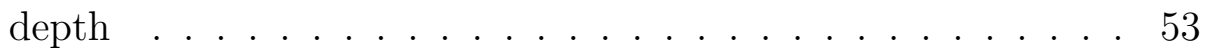

5.1.2. Net surface heat flux . . . . . . . . . . . . . . 5 56

5.2. Changes in the Bjerknes Feedback . . . . . . . . . . . . 58

5.2.1. Differences between 1980-1999 and 2000-2010 . . . . . . . 58

5.2.2. Differences between 1950-1979 and 1980-2010 . . . . . . . 63

6. Summary and conclusions $\quad 66$

$\begin{array}{ll}\text { References } & 69\end{array}$ 


\section{List of Figures}

1. Tropical Atlantic mean SST and wind fields obtained using the International Comprehensive Ocean-Atmosphere Dataset (ICOADS, data provided by the NOAA/OAR/ESRL PSD, Boulder, Colorado, USA, from their Web site at https://www.esrl.noaa.gov/psd/). . . . . . . 3

2. Simplified schematic view of the upper ocean currents in the Tropical Atlantic: North Equatorial Current (NEC), North Equatorial Counter-Current (NECC), Guiana Current (GC), North Brazil Current (NBC), northern, central and southern branches of the South Equatorial Current (nSEC, cSEC and sSEC), Equatorial Undercurrent (EUC), Benguela Current (BC), South Equatorial Counter Current (SECC) and Brazil Current (BC). Based on Stramma and Schott (1999) and Philander (2001)

3. (a) First and second EOFs of detrended SST anomalies (1900-2008) in the tropical Atlantic obtained from the HadISST data set, for which EOF1 represents the Atlantic equatorial mode, accounting for $38 \%$ of the variance, and EOF2 represents the meridional mode, accounting for $25 \%$ of variance. (b) Monthly standard deviations of the principal component time series of each EOF (dark grey for EOF1 and light grey for EOF2). Note that values for EOF1 are highest in June and July (early austral winter). Adapted from Deser et al. (2010). . . . . 6

4. Walker circulation in the tropical Atlantic. As the trade winds blow eastward in the surface, the western thermocline deepens and the eastern shoals, allowing upwelling in the eastern basin. Subsidence occurs over the cold tongue region, with compensating ascending motion over South America and Africa. Modified from Lau and Yang $(2002)$ 
5. Schematic diagrams of the recharge oscillator model, adapted from Jin (1997). (a) Warm phase, with a westerly wind anomaly forcing (black arrows), equatorial heat discharge (orange arrows) by divergent Sverdrup transport, and an anomalously shallow (blue) thermocline in the west and deep (orange) in the east; (b) Transition from the warm to the cold phase, where the SST and wind anomalies are nearly zero, with the start of the equatorial heat recharge and the anomalously shallow equatorial thermocline across the ocean basin; (c) cold phase, with an easterly wind anomaly forcing, equatorial heat recharge by convergent Sverdrup transport, and an anomalously deep thermocline in the west and shallow in the east; (d) Transition from the cold to the warm phase, where the SST and wind anomalies are nearly zero, with the start of the equatorial heat discharge and the anomalously deep equatorial thermocline across the ocean basin.

6. Synthetic time series (a) and its climatology (b) and anomalies (c). Note that the time series in (a) corresponds to the sum of (b) and (c). 20

7. SST seasonal standard deviations (1980-2010) derived from NCEP/CFSR. The delimited box indicates the ATL3 index region $\left(3^{\circ} \mathrm{N}-3^{\circ} \mathrm{S} ; 20^{\circ} \mathrm{W}\right.$ $0^{\circ}$ ), where JJA SST variability is highest.

8. Zonal wind stress seasonal standard deviations (1980-2010) derived from NCEP/CFSR. The solid line box indicates the region used to compute the mean equatorial wind stress $\left(3^{\circ} \mathrm{N}-3^{\circ} \mathrm{S} ; 40^{\circ} \mathrm{W}-0^{\circ}\right)$ and the dotted line box indicates the WATL region $\left(3^{\circ} \mathrm{N}-3^{\circ} \mathrm{S} ; 45^{\circ} \mathrm{W}-25^{\circ} \mathrm{W}\right)$, used to compute the zonal thermocline slope. . . . . . . . . . . . . 22

9. (a) Mean annual SST (1980-2010) for the reanalyses ensemble mean. (b) through (h) show the difference between each reanalysis and the ensemble mean. . . . . . . . . . . . . . . . . . . . . 28

10. Seasonal SST in the ensemble mean. Stippling indicates regions where less than 5 reanalyses are within an interval of 1 standard deviation.

11. Annual cycle of SST for the ATL3 region. The black thick line represents the ensemble mean and shading stands for the ensemble spread (1 standard deviation). 
12. (a) Mean annual thermocline depth (1980-2010), for the ensemble mean. (b) through (h) show the difference between each reanalysis and the ensemble mean. . . . . . . . . . . . . . . . . 30

13. (a) Mean annual zonal subsurface temperature (1980-2010), between $2^{\circ} \mathrm{N}$ and $2^{\circ} \mathrm{S}$, for the ensemble mean. (b) through (h) show the difference between each reanalysis and the ensemble mean. The black solid lines indicate the mean $20^{\circ} \mathrm{C}$ isotherm depth for the ensemble and the dotted lines the mean $20^{\circ} \mathrm{C}$ isotherm depth for each reanalysis. 32

14. Annual cycle of Z20 for (a) the ATL3 region and (b) the WATL region. (c) indicates the seasonal thermocline slope (difference between Z20 in ATL3 and WATL). Note that the thermocline in ATL3 is always shallower than in WATL ( $\nabla$ Z20 is always negative). A larger (smaller) value of $\nabla$ Z20 indicates a steeper (smoother) zonal slope of the thermocline. The black thick line represents the ensemble mean and shading stands for the ensemble spread (1 standard deviation). . 33

15. (a) Mean annual wind stress (1980-2010) for the reanalyses ensemble mean. (b) through (h) show the difference between each reanalysis and the ensemble mean. Shading represents the magnitude of the vectors.

16. Annual cycle of wind stress in the ensemble mean. Shading indicates the magnitude of the wind stress and vectors are plotted where at least 5 of the reanalyses are within a 1 standard deviation interval around the mean.

17. Annual cycle of zonal wind stress in the equatorial region $\left(3^{\circ} \mathrm{N}-3^{\circ} \mathrm{S}\right.$; $\left.40^{\circ} \mathrm{W}-0^{\circ}\right)$. The black thick line represents the ensemble mean and shading stands for the ensemble spread (1 standard deviation). . . . 35

18. (a) Mean annual surface currents (1980-2010) for the reanalyses ensemble mean. (b) through (h) show the difference between each reanalysis and the ensemble mean. Shading represents the magnitude of the vectors. 
19. Seasonal surface currents in the ensemble mean. Shading indicates the currents velocities and vectors are plotted where at least 5 of the reanalyses are within a 1 standard deviation interval around the mean. 37

20. Spatial pattern of the Atlantic equatorial mode for each reanalysis (ag) and the ensemble mean (h), obtained by correlating the ATL3 SST anomaly time series against SST anomalies elsewhere in the basin, for JJA (1980-2010). Only correlations significant at the 95\% level are shown. . . . . . . . . . . . . . . . . . . 38

21. Correlation between ATL3 SST anomalies and zonal wind stress anomalies elsewhere, for each reanalysis (a-h) and their ensemble mean (h), considering the whole year and the period 1980-2010. Only correlations significant at the $95 \%$ level are shown. . . . . . . . . . . . 39

22. Correlation between equatorial $\left(40^{\circ} \mathrm{W}-0^{\circ} ; 3^{\circ} \mathrm{N}-3^{\circ} \mathrm{S}\right)$ wind stress anomalies and $20^{\circ} \mathrm{C}$ isotherm depth anomalies elsewhere, for each reanalysis (a-g) and their ensemble mean (h), considering the whole year, with a one-month lag. Only correlations significant at the 95\% level are shown. .......................... 40

23. Correlation between ATL3 SST anomalies and equatorial $\left(3^{\circ} \mathrm{N}-3^{\circ} \mathrm{S}\right)$ subsurface temperature anomalies, for each reanalysis (a-g) and their ensemble mean $(\mathrm{h})$, considering the whole year. Only correlations significant at the $95 \%$ level are shown.

24. Thermal damping estimation from the regression between each reanalysis ATL3 SST anomalies and ATL3 NSHF anomalies from TropFlux. (a) CFSR: $\alpha=-13.89 \pm 2.55 \mathrm{Wm}^{-2} /{ }^{\circ} \mathrm{C}, \mathrm{R}=-0.44$; (b) ECDA: $\alpha=$ $-13.42 \pm 2.66 \mathrm{Wm}^{-2} /{ }^{\circ} \mathrm{C}, \mathrm{R}=-0.41$; (c) GECCO2: $\alpha=-12.35 \pm 2.77$ $\mathrm{Wm}^{-2} /{ }^{\circ} \mathrm{C}, \mathrm{R}=-0.37$; (d) GODAS: $\alpha=-10.41 \pm 2.31 \mathrm{Wm}^{-2} /{ }^{\circ} \mathrm{C}, \mathrm{R}=-$ 0.38; (e) K7: $\alpha=-10.62 \pm 2.38 \mathrm{Wm}^{-2} /{ }^{\circ} \mathrm{C}, \mathrm{R}=-0.37$; (f) ORAS4: $\alpha=$ $-14.15 \pm 2.36 \mathrm{Wm}^{-2} /{ }^{\circ} \mathrm{C}, \mathrm{R}=-0.47 ; \quad(\mathrm{g}) \mathrm{SODA}: \alpha=-11.09 \pm 2.16$ $\mathrm{Wm}^{-2} /{ }^{\circ} \mathrm{C}, \mathrm{R}=-0.42$. All correlations are significant at the $95 \%$ level. 
25. Equatorial zonal wind stress response to SST anomalies in the ATL3 region, estimated from the regression between ATL3 SST anomalies and mean equatorial zonal wind stress anomalies. (a) CFSR: $\mu_{\mathrm{a}}=$ $0.21 \pm 0.0810^{-2} \mathrm{~N} \cdot \mathrm{m}^{-2} /{ }^{\circ} \mathrm{C}, \mathrm{R}=0.22 ;$ (b) ECDA: $\mu_{\mathrm{a}}=0.53 \pm 0.0910^{-2}$ $\mathrm{N} \cdot \mathrm{m}^{-2} /{ }^{\circ} \mathrm{C}, \mathrm{R}=0.47$; (c) GECCO2: $\mu_{\mathrm{a}}=0.50 \pm 0.0610^{-2} \mathrm{~N} \cdot \mathrm{m}^{-2} /{ }^{\circ} \mathrm{C}$, $\mathrm{R}=0.57$; (d) GODAS: $\mu_{\mathrm{a}}=0.42 \pm 0.0710^{-2} \mathrm{~N} \cdot \mathrm{m}^{-2} /{ }^{\circ} \mathrm{C}, \mathrm{R}=0.47$; (e) K7: $\mu_{\mathrm{a}}=0.52 \pm 0.0610^{-2} \mathrm{~N} \cdot \mathrm{m}^{-2} /{ }^{\circ} \mathrm{C}, \mathrm{R}=0.59$; (f) ORAS4: $\mu_{\mathrm{a}}=0.69 \pm 0.0810^{-2} \mathrm{~N} \cdot \mathrm{m}^{-2} /{ }^{\circ} \mathrm{C}, \mathrm{R}=0.60 ;(\mathrm{g}) \mathrm{SODA}: \mu_{\mathrm{a}}=0.44 \pm 0.06$ $10^{-2} \mathrm{~N} \cdot \mathrm{m}^{-2} /{ }^{\circ} \mathrm{C}, \mathrm{R}=0.55$. All correlations are significant at the $95 \%$ level.

26. Zonal current anomalies response to equatorial wind stress anomalies, estimated from multi-linear regression between the equatorial zonal wind stress and WATL thermocline anomalies and ATL3 zonal currents. In all reanalysis only the first coefficient $\beta_{\mathrm{u}}$ is statistically significant. (a) CFSR: $\beta_{\mathrm{u}}=8.80 \pm 1.17 \mathrm{~m} \cdot \mathrm{s}^{-1} / \mathrm{N} \cdot \mathrm{m}^{-2}, \mathrm{R}=0.22$; (b) ECDA: $\beta_{\mathrm{u}}=12.89 \pm 0.88 \mathrm{~m} \cdot \mathrm{s}^{-1} / \mathrm{N} \cdot \mathrm{m}^{-2}, \mathrm{R}=0.52 ;(\mathrm{c})$ GECCO2: $\beta_{\mathrm{u}}=$ $12.11 \pm 0.84 \mathrm{~m} \cdot \mathrm{s}^{-1} / \mathrm{N} \cdot \mathrm{m}^{-2}, \mathrm{R}=0.47 ;(\mathrm{d})$ GODAS: $\beta_{\mathrm{u}}=16.16 \pm 1.45$ $\mathrm{m} \cdot \mathrm{s}^{-1} / \mathrm{N} \cdot \mathrm{m}^{-2}, \mathrm{R}=0.41 ;(\mathrm{e}) \mathrm{K} 7: \beta_{\mathrm{u}}=11.06 \pm 0.84 \mathrm{~m} \cdot \mathrm{s}^{-1} / \mathrm{N} \cdot \mathrm{m}^{-2}$, $\mathrm{R}=0.42 ;$ (f) ORAS4: $\beta_{\mathrm{u}}=11.58 \pm 0.80 \mathrm{~m} \cdot \mathrm{s}^{-1} / \mathrm{N} \cdot \mathrm{m}^{-2}, \mathrm{R}=0.42 ;(\mathrm{g})$ SODA: $\beta_{\mathrm{u}}=6.32 \pm 1.92 \mathrm{~m} \cdot \mathrm{s}^{-1} / \mathrm{N} \cdot \mathrm{m}^{-2}, \mathrm{R}=0.13$. All correlations are significant at the $95 \%$ level.

27. Cold tongue upwelling response to zonal wind stress, estimated from regression between mean equatorial zonal wind stress anomalies and ATL3 upwelling anomalies (multiplied by -1). (a) CFSR: $\beta_{\mathrm{w}}=9.24 \pm$ $1.8510^{-5} \mathrm{~m} \cdot \mathrm{s}^{-1} /\left(\mathrm{N} \cdot \mathrm{m}^{-2}\right), \mathrm{R}=0.41 ;(\mathrm{b})$ ECDA: $\beta_{\mathrm{w}}=7.88 \pm 1.32$ $10^{-5} \mathrm{~m} \cdot \mathrm{s}^{-1} /\left(\mathrm{N} \cdot \mathrm{m}^{-2}\right), \mathrm{R}=0.47 ; \quad(\mathrm{c})$ GECCO2: $\beta_{\mathrm{w}}=9.17 \pm 0.98$ $10^{-5} \mathrm{~m} \cdot \mathrm{s}^{-1} /\left(\mathrm{N} \cdot \mathrm{m}^{-2}\right), \mathrm{R}=0.64 ;(\mathrm{d})$ GODAS: $\beta_{\mathrm{w}}=9.66 \pm 2.1310^{-5}$ $\mathrm{m} \cdot \mathrm{s}^{-1} /\left(\mathrm{N} \cdot \mathrm{m}^{-2}\right), \mathrm{R}=0.38 ;(\mathrm{e}) \mathrm{K} 7: \beta_{\mathrm{w}}=8.82 \pm 0.9110^{-5} \mathrm{~m} \cdot \mathrm{s}^{-1} /(\mathrm{N} \cdot$ $\left.\mathrm{m}^{-2}\right), \mathrm{R}=0.66$; (f) ORAS4: $\beta_{\mathrm{w}}=5.47 \pm 0.7510^{-5} \mathrm{~m} \cdot \mathrm{s}^{-1} /\left(\mathrm{N} \cdot \mathrm{m}^{-2}\right)$, $\mathrm{R}=0.55 ;(\mathrm{g})$ SODA: $\beta_{\mathrm{w}}=4.72 \pm 2.8310^{-5} \mathrm{~m} \cdot \mathrm{s}^{-1} /\left(\mathrm{N} \cdot \mathrm{m}^{-2}\right), \mathrm{R}=0.15$. Correlations are significant at the $95 \%$ level for all reanalyses except SODA, for which it is significant at the $90 \%$ level only. . . . . . . . . 47 
28. Thermocline slope response to zonal wind stress, estimated from regression between mean equatorial zonal wind stress anomalies and the difference between ATL3 and WATL anomalous thermocline depths. (a) CFSR: $\beta_{\mathrm{h}}=7.98 \pm 1.7410^{2} \mathrm{~m} /\left(\mathrm{N} \cdot \mathrm{m}^{-2}\right), \mathrm{R}=0.38$; (b) ECDA: $\beta_{\mathrm{h}}=8.59 \pm 8.7210^{2} \mathrm{~m} /\left(\mathrm{N} \cdot \mathrm{m}^{-2}\right), \mathrm{R}=0.66 ;$ (c) GECCO2: $\beta_{\mathrm{h}}=$ $10.19 \pm 8.7910^{2} \mathrm{~m} /\left(\mathrm{N} \cdot \mathrm{m}^{-2}\right), \mathrm{R}=0.72 ;(\mathrm{d})$ GODAS: $\beta_{\mathrm{h}}=10.19 \pm 1.10$ $10^{2} \mathrm{~m} /\left(\mathrm{N} \cdot \mathrm{m}^{-2}\right), \mathrm{R}=0.64 ;(\mathrm{e}) \mathrm{K} 7: \beta_{\mathrm{h}}=10.48 \pm 0.7410^{2} \mathrm{~m} /\left(\mathrm{N} \cdot \mathrm{m}^{-2}\right)$, $\mathrm{R}=0.79 ;$ (f) ORAS4: $\beta_{\mathrm{h}}=9.42 \pm 0.6510^{2} \mathrm{~m} /\left(\mathrm{N} \cdot \mathrm{m}^{-2}\right), \mathrm{R}=0.79 ;(\mathrm{g})$ SODA: $\beta_{\mathrm{h}}=8.40 \pm 1.4410^{2} \mathrm{~m} /\left(\mathrm{N} \cdot \mathrm{m}^{-2}\right), \mathrm{R}=0.46$. All correlations are significant at the $95 \%$ level. . . . . . . . . . . . . . . . . 49

29. Subsurface temperature anomalies response to anomalous thermocline depth in the ATL3 region. (a) CFSR: $a_{h}=9.03 \pm 0.3210^{-2}$ ${ }^{\circ} \mathrm{C} / \mathrm{m}, \mathrm{R}=0.93$; (b) ECDA: $\mathrm{a}_{\mathrm{h}}=10.97 \pm 0.4310^{-2}{ }^{\circ} \mathrm{C} / \mathrm{m}, \mathrm{R}=0.92$; (c) GECCO2: $\mathrm{a}_{\mathrm{h}}=6.89 \pm 0.2110^{-2}{ }^{\circ} \mathrm{C} / \mathrm{m}, \mathrm{R}=0.95$; (d) GODAS: $\mathrm{a}_{\mathrm{h}}=7.64 \pm 0.3210^{-2}{ }^{\circ} \mathrm{C} / \mathrm{m}, \mathrm{R}=0.91 ;(\mathrm{e}) \mathrm{K} 7: \mathrm{a}_{\mathrm{h}}=7.75 \pm 0.2610^{-2}$ ${ }^{\circ} \mathrm{C} / \mathrm{m}, \mathrm{R}=0.94$; (f) ORAS4: $\mathrm{a}_{\mathrm{h}}=9.71 \pm 0.3910^{-2}{ }^{\circ} \mathrm{C} / \mathrm{m}, \mathrm{R}=0.91$; (g) SODA: $\mathrm{a}_{\mathrm{h}}=6.91 \pm 0.3910^{-2}{ }^{\circ} \mathrm{C} / \mathrm{m}, \mathrm{R}=0.85$. All correlations are significant at the $95 \%$ level. . . . . . . . . . . . . . 5 50

30. Dynamical damping (a), thermal damping (b), zonal advective feedback (c), Ekman feedback (d), thermocline feedback (e) and total Bjerknes Feedback Index (f), for each reanalysis and their ensemble mean. Error bars for the ensemble mean show the ensemble's standard error. . . . . . . . . . . . . . . . . . . . . 5 52

31. Time series of ATL3 SST anomalies for 1950-1980 (CHOR) and 19802010 (reanalyses ensemble). All reanalyses for the 1980-2010 period show an increasing trend in ATL3 SST anomalies (mean trend $0.0136 \pm 0.002{ }^{\circ} \mathrm{C} \mathrm{mon}^{-1}$, solid red line), significant at the $95 \%$ level. A $0.0120 \pm 0.001{ }^{\circ} \mathrm{C} \mathrm{mon}^{-1}$ trend is observed for CHOR in 1950-2010 (dotted red line). . . . . . . . . . . . . . . . . 54 54 
32. Time series of mean equatorial zonal wind stress anomalies for 19501980 (CHOR) and 1980-2010 (reanalyses ensemble). Positive trends (i.e., weakening of the trade winds) are observed in 1980-2010 in CFSR $\left(0.011 \pm 0.003 \times 10^{-2} \mathrm{~N} \cdot \mathrm{m}^{-2} \mathrm{mon}^{-1}\right), \mathrm{ECDA}\left(0.007 \pm 0.003 \times 10^{-2}\right.$ $\left.\mathrm{N} \cdot \mathrm{m}^{-2} \mathrm{mon}^{-1}\right), \operatorname{GECCO} 2\left(0.009 \pm 0.002 \times 10^{-2} \mathrm{~N} \cdot \mathrm{m}^{-2} \mathrm{mon}^{-1}\right)$ and $\mathrm{K} 7\left(0.013 \pm 0.003 \times 10^{-2} \mathrm{~N} \cdot \mathrm{m}^{-2} \mathrm{mon}^{-1}\right)$, at the $95 \%$ significance level.

33. Time series of the ATL3 thermocline depth anomalies for 1950-1980 (CHOR) and 1980-2010 (reanalyses ensemble). Negative trends (i.e, shoaling of the thermocline) are observed in K7 (-0.17 $\pm 0.03 \mathrm{~m} / \mathrm{mon}$, ORAS4 $(-0.12 \pm 0.03 \mathrm{~m} / \mathrm{mon})$ and SODA $(-0.15 \pm 0.03 \mathrm{~m} / \mathrm{mon})$ at the 95\% significance level, while a positive trend (i.e., deepening of the thermocline) is observed in ECDA $(0.06 \pm 0.03 \mathrm{~m} / \mathrm{mon})$, at the $90 \%$

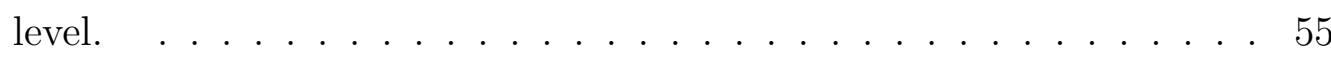

34. Root mean squared variances (21 yr window) for (a) JJA ATL3 SST anomalies, (b) MAM equatorial zonal wind stress anomalies and (c) JJA ATL3 thermocline depth anomalies. . . . . . . . . . . . 56

35. Annual climatology and seasonal cycles of NSHF in the ATL3 region for 20CR (a,b) and TropFlux (c,d), for the 1980-2010 period. . . . . . 57

36. NSHF anomaly series in the ATL3 region for 20CR (green) and TropFlux (black). An increasing trend $\left(0.06 \pm 0.02 \mathrm{~W} \cdot \mathrm{m}^{-2} / \mathrm{mon}, 95 \%\right.$ confidence level) is observed in 20CR (red dotted line). . . . . . . . . . . . 57

37. Spatial pattern of the Atlantic equatorial mode averaged in JJA for (a) 1980-1999 and (b) 2000-2010, for the ensemble mean. Stippling indicates regions where the correlations are not significant in at least 3 reanalyses, at the $95 \%$ level. . . . . . . . . . . . . . . 58

38. Dynamical damping (a), thermal damping (b), zonal advective feedback (c), Ekman feedback (d), thermocline feedback (e) and total Bjerknes Feedback Index (f), for 1980-1999 (dark blue) and 20002010 (light blue) for each reanalysis, their ensemble mean and for the 20th century ocean reanalysis (CHOR). The ensemble error bar represents the ensemble standard error. . . . . . . . . . . . . . 60 
39. Regression parameters associated with TD and TF for 1980-1999 (dark blue) and 2000-2010 (light blue) for each reanalysis, their ensemble mean and for the 20th century ocean reanalysis (CHOR): thermal damping (a), equatorial zonal wind stress response to ATL3 SST anomalies (b), equatorial thermocline slope response to zonal wind stress anomalies (c) and SST response to subsurface temperature anomalies $(\mathrm{d})$. The error bars indicate the regression standard error for each reanalysis and the ensemble standard error for the ensemble mean. . . . . . . . . . . . . . . . . . . . 61

40. Pointwise correlation of the reanalyses ensemble mean SST anomalies against TropFlux NSHF anomalies, for (a) 1980-1999 and (b) 2000-2010. Stippling indicates regions where the correlations are not significant in at least 3 reanalyses, at the $95 \%$ level. . . . . . . . . . . 62

41. Correlation of mean equatorial zonal wind stress and thermocline depth (Z20), for the ensemble mean in (a) 1980-1999 and (b) 20002010. Stippling indicates regions where the correlations are not significant in at least 3 reanalyses, at the $95 \%$ level. . . . . . . . . . . . 62

42. Individual terms and total Bjerknes Feedback Index for 1950-1979 (pink) and 1980-2010 (blue), obtained from the 20th century reanalysis $(\mathrm{CHOR}) \ldots \ldots \ldots \ldots \ldots$. . . . . . . . . . . . . . . 64

43. Regression parameters associated with ZAF and EF in 1950-1979 (pink) and 1980-2010 (blue) for the 20th century ocean reanalysis (CHOR): equatorial zonal wind stress response to ATL3 SST anomalies (a) and ATL3 zonal current (b) and upwelling (c) responses to zonal wind stress anomalies. The error bars indicate the regression standard error.

44. Correlation of mean ATL3 SST anomalies and zonal wind stress anomalies elsewhere in the basin, for CHOR in (a) 1950-1979 and (b) 1980-2010. Only correlations significant at the 95\% level are shown. 65 


\section{List of Tables}

1. Variables taken from each reanalysis and respective time periods, where: SST: sea surface temperature; POTTEMP: potential sea water temperature; $\tau_{\mathrm{x}}, \tau_{\mathrm{y}}$ : zonal and meridional wind stress; UVEL, VVEL, WVEL: zonal, meridional and vertical current velocities; NSHF: net surface heat flux; LHF: latent heat flux; SHF: sensible heat flux; $L_{W} R_{\text {down }}$ : longwave downward radiation; $\mathrm{SWR}_{\text {down }}$ : shortwave downward radiation. . . . . . . . . . . . . . . . . 17

2. Zonal $\left(\mathrm{DD}_{\mathrm{u}}\right)$, meridional $\left(\mathrm{DD}_{\mathrm{v}}\right)$, vertical $\left(\mathrm{DD}_{\mathrm{w}}\right)$ and total dynamical damping $\left(\mathrm{DD}_{\text {total }}\right)$ obtained for each reanalysis $\left(\mathrm{yr}^{-1}\right)$, their ensemble mean and standard error. . . . . . . . . . . . . . . . . . . . 42

3. Thermal damping (TD) term, in $\mathrm{yr}^{-1}$, for each reanalysis and their ensemble mean. . . . . . . . . . . . . . . . . . . . . . . . . 43

4. Zonal mean SST gradient in the ATL3 region $\left(10^{-8 \circ} \mathrm{C} / \mathrm{m}\right)$ and total ZAF in each reanalysis $\left(\mathrm{yr}^{-1}\right) \ldots \ldots \ldots$. . . . . . . . . . 46

5. Vertical mean SST gradient in the ATL3 region and from the mean thermocline depth to the surface $\left({ }^{\circ} \mathrm{C} / \mathrm{m}\right)$ and total $\mathrm{EF}$ in each reanal$\mathrm{ysis}\left(\mathrm{yr}^{-1}\right) \ldots \ldots \ldots \ldots \ldots \ldots$

6. Mean upwelling in the ATL3 region $\left(10^{-6} \mathrm{~m} / \mathrm{s}\right)$ and total TF $\left(\mathrm{yr}^{-1}\right) . \quad . \quad 51$

7. Total $\mathrm{I}_{\mathrm{BJ}}$ for each reanalysis and their ensemble mean $\left(\mathrm{yr}^{-1}\right) \ldots$. . . 51 


\section{List of Acronyms}

20CR 20th Century Reanalysis

ACT Atlantic Cold Tongue

AMSR-E Advanced Microwave Scanning Radiometer

BC Brazil Current

CCM3 Community Climate Model version 3

CFSR Climate Forecast System Reanalysis

CHOR Historical Ocean Reanalysis

CMCC Centro Euro-Mediterraneo sui Cambiamenti Climatici

CSIR Indian National Center for Ocean Information Services

DD Dynamical Damping

DJF December-January-February

EEA Eastern Equatorial Atlantic

ECDA Ensemble Coupled Data Assimilation System

ECMWF European Center for Medium-Range Weather Forecasts

EF Ekman Feedback

ENSO El Niño-Southern Oscillation

EOF Empirical Orthogonal Function

EUC Equatorial Undercurrent

GC Guinea Current

GECCO2 German Estimating the Circulation and Climate of the Ocean System version 2 
GFDL Geophysical Fluid Dynamics Laboratory

GODAS Global Ocean Data Assimilation System

GTSPP Global Temperature and Salinity Profile Program

HadISST Hadley center sea Ice and Sea Surface Temperature

IBJ Bjerknes Feedback Index

ICDC Integrated Climate Data Center

ISCCP International Cloud Climatology Project

ITCZ Intertropical Convergence Zone

JAMSTEC Japan Agency for Marine-Earth Science Technology

JJA June-July-August

LHF Latent Heat Flux

LOCEAN Laboratoire d'Océanographie

LWR Long Wave Radiation

MAM March-April-May

MEDS Canadian Marine Environmental Data Section

MOM Modular Ocean Model

NBC North Brazil Current

NCEP National Center For Environmental Prediction

NEC North Equatorial Current

NECC North Equatorial Counter-Current

NHSF Net surface heat flux

NOAA National Ocean and Atmospheric Oceanic Admnistration

NODC National Oceanographic Data Center 
OAD Ocean Data Assimilation

OISST Optimal Interpolation Sea Surface Temperature

ORA-IP Ocean Reanalysis Intercomparison Project

ORAS4 Ocean Reanalysis System 4

PMEL Pacific Marine Environmental Laboratory

POTTEMP Potential Temperature

RMSV Root Mean Square Variance

(n,c,s)SEC South Equatorial Current (northern, central or southern branch)

SHF Sensible Heat Flux

SON September-October-November

SST Sea Surface Temperature

SSTA Sea Surface Temperature Anomaly

SWR Short Wave Radiation

TAO Tropical Atmospheric and Ocean

TD Thermal Damping

TF Thermocline Feedback

UVEL Zonal velocity

VVEL Meridional velocity

WOD World Ocean Database

WVEL Vertical velocity

ZAF Zonal Advective Feedback 


\begin{abstract}
In the Tropical Atlantic Ocean, one of the main modes of SST variability is the Atlantic Equatorial Mode or Atlantic Niño, which is strongly associated with rainfall patterns in northeastern Brazil and the West Africa Monsoon. The region of largest interannual variability, where the Atlantic Cold Tongue forms, is also a region of consistent biases in climate models. In this study, we investigate the interannual variability of the Tropical Atlantic and its changes in the recent decades in terms of the Bjerknes Feedback Index in a set of seven ocean reanalyses for the periods 1980-1999 and 2000-2010 and for an XX century ocean reanalysis for 19502010. Warming trends are observed in SSTs in the cold tongue region, as well as a decrease interannual variability. These in turn are associated with a weakening in the Bjerknes Feedback in the early XXI century, resulting from a stronger thermal damping and weaker thermocline feedback, associated with a weaker response of equatorial zonal thermocline slope to equatorial zonal wind stress. However, the spread among the reanalysis products is large, which makes necessary the use of multiple products and an ensemble analysis to minimize errors and obtain more robust results. This is further reinforced as no significant shifts in the Bjerknes Feedback Index were found for the period previous to 1980, since only one reanalysis product covers this period and its individual errors are large.
\end{abstract}

Keywords: Tropical Atlantic, Atlantic Cold Tongue, Atlantic Niño, Interannual variability, Bjerknes Feedback Index. 


\section{Resumo}

No Atlântico Tropical, um dos principais modos de variabilidade da temperatura da superfície do mar é o modo equatorial, ou El Niño do Atlântico, que está fortemente associado aos padrões de precipitação no Nordeste do Brasil e à Monção Oeste-Africana. A região de maior variabilidade interanual, onde se forma a Língua Fria do Atlântico, é também uma região de consistente discordância entre modelos climáticos. Neste estudo, são investigadas a variabilidade interanual

do Atlântico Tropical e suas mudanças nas últimas décadas por meio do Índice do Feedback de Bjerknes considerando um grupo de sete reanálises oceânicas para os períodos de 1980-1999 e 2000-2010 e uma reanálise do século XX para 1950-2010. Um aquecimento é observado na região da língua fria, assim como uma diminuição na variabilidade interanual. Essas mudanças estão ligadas a um enfraquecimento do Feedback de Bjerknes no início do século XXI, como resultado de um amortecimento térmico mais intenso e um enfraquecimento do feedback da termoclina, associado a uma resposta mais fraca do gradiente zonal da termoclina equatorial à tensão de cisalhamento do vento. Contudo, a dispersão entre as reanálises é alta, o que torna necessária a análise comparativa de múltiplos produtos, visando obter resultados mais robustos. Da mesma forma, não foi possível tirar conclusões sobre mudanças no Feedback de Bjerknes no período anterior a 1980, uma vez que somente uma reanálise cobria este período e os erros individuais são grandes.

Palavras-Chave: Atlântico Tropical, Língua Fria do Atlântico, Modo Equatorial do Atlântico, Variabilidade Interanual, Índice do Feedback de Bjerknes. 


\section{Introduction}

The oceans and their interactions with the atmosphere play a key role in the regulation of the Earth's climate. This is mainly due to the ocean's thermal inertia, which results from their large heat-storage capacity. The heat stored in the ocean impacts the sea surface temperature (SST), which, coupled with atmospheric state variables such as air temperature, humidity and wind speed, control the heat fluxes between the sea surface and the atmosphere (Deser et al., 2010).

The study of SST variability is fundamental due to its influence on precipitation over surrounding regions and the consequent social and economic impacts (Lübbecke and McPhaden, 2013). Higher SSTs typically result in increased convection and shifts in the strength and direction of the trade winds in the tropical regions, while lower SSTs are responsible for subsidence and decreased rainfall (Carton et al., 1996).

Not surprisingly, a myriad of studies have been carried out to assess local and remote atmospheric responses to sea surface temperature anomalies. Enfield (1996) showed how SST anomalies (SSTA) in the Tropical Pacific and Tropical North Atlantic are associated with rainfall in the American continent, as well as the influence of the Tropical South Atlantic with rainfall in northeastern Brazil. In western Equatorial Africa, rainfall variability was linked to SST anomalies in the tropical regions of the Pacific, Atlantic and Indian Oceans but with the Atlantic playing a major role in boreal summer (Balas et al., 2007). Trends in SSTs have also been associated with rainfall changes. Chung and Ramanathan (2006) show that warming trends in the Indian Ocean in the Community Climate Model v3 (CCM3) result in a weakening of the north Indian SST gradient and consequently a decrease in associated monsoon rainfall. Xie et al. (2010), on the other hand, find that SSTA patterns have a stronger effect on rainfall changes than uniform warming trends associated, for example, with greenhouse gases emissions.

In addition to the influence on rainfall, SSTs are also associated with the development of tropical cyclones and several studies link the warming of the sea surface to an increase in tropical cyclone activity and intensity (Goldenberg et al., 2001; Hoyos et al., 2006; Vecchi and Soden, 2007; Saunders and Lea, 2008).

Of particular interest is SST variability in the Tropical Atlantic due to its in- 
fluence on the climate of the surrounding continents. Recurrent patterns of SST and wind anomalies in this region are linked to the intensity of the West African Monsoon and the distribution of rainfall in Northeast Brazil, as well as being arranged in way that they amplify each other, giving rise to positive feedback mechanisms (Xie and Carton, 2013; Brierley and Wainer, 2018). This is due to the effect of SST on sea level pressure and, consequently, on wind patterns and the position of the Intertropical Convergence Zone (ITCZ) (Carton et al., 1996). Variability in this region, particularly off the West African Coast, has also been shown to affect this

region's marine ecosystems, with an impact on local fish availability (Binet et al., 2001).

Despite the rapid progress made in the last decades in understanding these mechanisms (Xie and Carton, 2013), global climate models are known to show large biases in the Equatorial Atlantic (Deppenmeier et al., 2016). In addition, observational data in the Tropical Atlantic tends to be more sparse than in the Tropical Pacific and Indian Oceans (Xue et al., 2012) and differences among ocean reanalyses that assimilate this data using different models and assimilation methods give rise to differences among these products that are comparable to or larger than interannual variability in the region (Zhu et al., 2012). Having this in mind, this study aims to investigate Equatorial Atlantic variability in the late 20th and early 21th centuries considering a set of oceanic and atmospheric reanalyses, assessing how differently variability is represented by them as well as potential changes in the feedbacks that give rise to SST and wind anomalies in this region.

\subsection{Tropical Atlantic Climatology and Circulation}

\subsubsection{Sea surface temperature and surface winds}

The mean annual cycle is responsible for the greatest share of variability in the Tropical Atlantic Ocean (Carton and Zhou, 1997; Xie and Carton, 2013). Figure 1 shows the mean SST and wind patterns of the Tropical Atlantic. The ITCZ can be observed slightly north of the equator, where the southeasterly and northeasterly trade winds converge in a zone of warmest SSTs around $5^{\circ} \mathrm{N}$, associated with strong convection and rainfall. The mean position of the ITCZ can be regarded as the 
thermal equator (Melice and Servain, 2003).

The fact that the ITCZ is shifted northward has important implications for the annual cycle of equatorial SSTs since it causes the southern trades to cross the equator, varying in strength throughout the year (Xie, 1994). In austral autumn (MAM), temperatures are highest in the equatorial region, sometimes exceeding $27^{\circ} \mathrm{C}$, since the Sun is at its highest position this time of the year. In this period, the ITCZ is located nearly on the equator. Consequently, zonal winds are weakest and the eastern thermocline is deepest. The trades then intensify in austral winter (JJA), resulting in increased upwelling in the east, shoaling of the thermocline and minimum SSTs, forming the equatorial Atlantic Cold Tongue (ACT). The formation of the cold tongue has been associated with the onset of the West African Monsoon (Xie and Carton, 2013). As demonstrated by Li and Philander (1997), seasonal wind changes in the Gulf of Guinea - and the consequent SST changes in eastern equatorial Atlantic (EEA) - are primarily a response to seasonal variations in surface temperatures over the surrounding land.

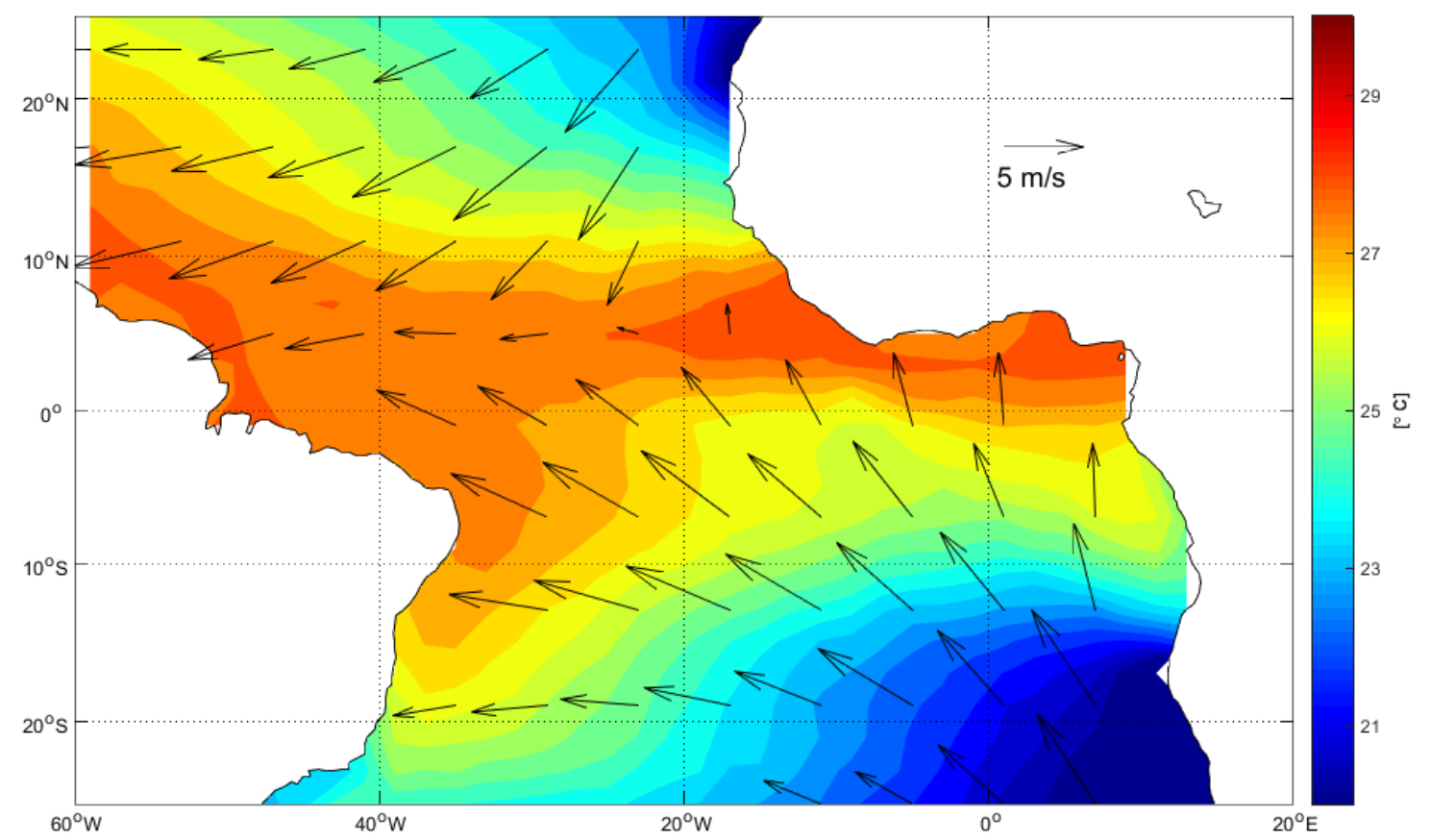

Figure 1 Tropical Atlantic mean SST and wind fields obtained using the International Comprehensive Ocean-Atmosphere Dataset (ICOADS, data provided by the NOAA/OAR/ESRL PSD, Boulder, Colorado, USA, from their Web site at https://www.esrl.noaa.gov/psd/). 


\subsubsection{Mean ocean currents}

As a result of the ITCZ being shifted northwards, so are the Tropical Atlantic wind driven current systems. As the southern trades blow across the equator, Ekman transport in opposite directions north and south of the equator results in the so-called Equatorial Divergence. On the other hand, since winds are light at the ITCZ and associated Ekman transport is weak, northward Ekman transport driven by the equator-crossing southern trades causes convergence at around $4^{\circ} \mathrm{N}$. Northward Ekman transport by the northern trades driving water away from the ITCZ results in divergence at around $10^{\circ} \mathrm{N}$. Coastal upwelling associated with divergence caused by the trade winds occurs off the African Coast (Brown et al., 2001).

A simplified schematic overview of the Atlantic Equatorial Currents is shown in Figure 2, based on Stramma and Schott (1999) and Philander (2001). The wind driven circulation involves the southern branch of the North Atlantic Subtropical Gyre and the northern branch of the South Atlantic Subtropical Gyre.

Both the North (NEC) and the South (SEC) Equatorial Currents flow westward. The NEC is located at about $20^{\circ} \mathrm{N}$, while the SEC presents three branches: a northern branch (nSEC), between the equator and $5^{\circ} \mathrm{N}$, a central branch (cSEC), between the equator and $5^{\circ} \mathrm{S}$ and a southern branch (sSEC), between $15^{\circ} \mathrm{S} 20^{\circ} \mathrm{S}$. The cold, upwelling-associated Benguela (BC) and Canary (not shown) Currents flow equatorward along the southwestern and northwestern African coasts, respectively. The Benguela Current feeds the cSEC, while the Canary Current feeds the NEC, which feeds the Gulf Stream in the North Atlantic.

In addition, an eastward North Equatorial Counter-Current (NECC) exists between the NEC and the nSEC, between $3^{\circ} \mathrm{N}$ and $10^{\circ} \mathrm{N}$, feeding the Guinea Current (GC) in the Gulf of Guinea. The NECC results from water that is pilled up in the western boundary by the trade winds and flows down the gradient pressure, since the winds at the ITCZ are light (Brown et al., 2001). This eastward pressure gradient force also results in an eastward flow centered at the equator, below the surface westward flow and near the thermocline, called the Equatorial Undercurrent (EUC). Since the Coriolis force is zero at the equator, this current flows in the direction of the pressure gradient force, losing water on its way due to the equatorial divergence at the surface. 
A South Equatorial Counter-Current (sSEC) is also observed separating the cSEC and the sSEC. The sSEC flows westward towards the Brazilian coast, where it breaks into the northward North Brazil Current (NBC) and the southward Brazil Current (BC) (Stramma and Schott, 1999).

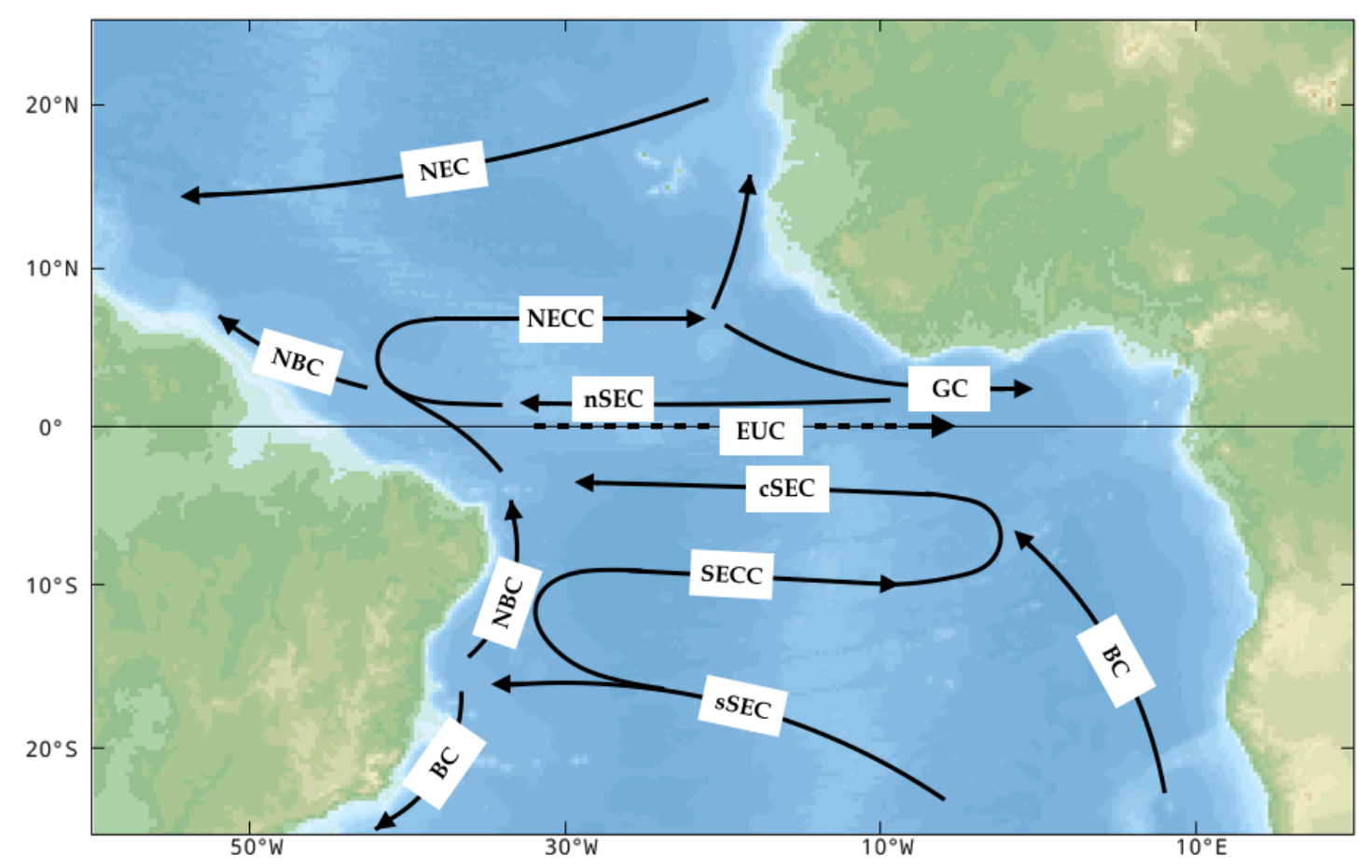

Figure 2 Simplified schematic view of the upper ocean currents in the Tropical Atlantic: North Equatorial Current (NEC), North Equatorial Counter-Current (NECC), Guiana Current (GC), North Brazil Current (NBC), northern, central and southern branches of the South Equatorial Current (nSEC, cSEC and sSEC), Equatorial Undercurrent (EUC), Benguela Current (BC), South Equatorial Counter Current (SECC) and Brazil Current (BC). Based on Stramma and Schott (1999) and Philander (2001).

\subsection{Tropical Atlantic Variability}

Besides the annual cycle, significant interannual variability is present in the Tropical Atlantic, at different time scales. The physical mechanisms of airsea interaction that occur in the Atlantic have strong similarities with those that give rise to the El Niño-Southern Oscillation (ENSO) in the Pacific. As a result, similar patterns of variability can be observed in the Tropical Atlantic (Zebiak, 1993). This variability is represented by two leading SST modes: the Atlantic Equatorial Mode, also referred to as the Atlantic Niño, and the Atlantic Meridional Mode, with generally opposite north and south polarities about the equator (Chiang and Vimont, 2004; Brierley and Wainer, 2018). The equatorial and meridional modes 
correspond to the two first empirical orthogonal functions (EOFs) of detrended monthly tropical Atlantic SST anomalies (Deser et al., 2010), shown in Figure 3. It is worth noting that the relative importance of both modes is similar, so that different studies suggest different leading modes (e.g., Servain et al., 2003; Amaya et al., 2017).
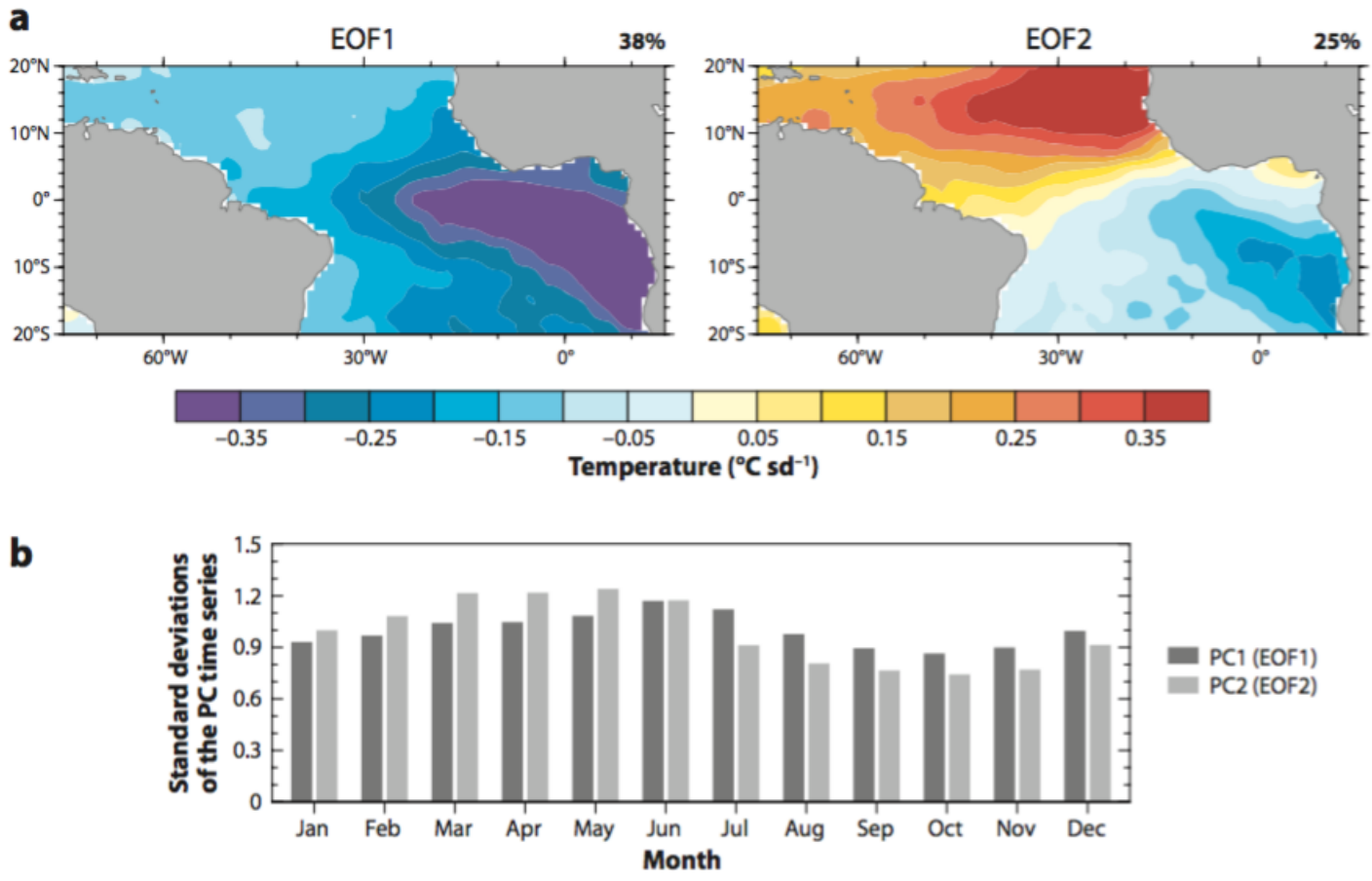

Figure 3 (a) First and second EOFs of detrended SST anomalies (1900-2008) in the tropical Atlantic obtained from the HadISST data set, for which EOF1 represents the Atlantic equatorial mode, accounting for $38 \%$ of the variance, and EOF2 represents the meridional mode, accounting for $25 \%$ of variance. (b) Monthly standard deviations of the principal component time series of each EOF (dark grey for EOF1 and light grey for EOF2). Note that values for EOF1 are highest in June and July (early austral winter). Adapted from Deser et al. (2010).

The meridional mode is characterized by a north-south interhemispheric dipole of warm and cold SST anomalies separated by the mean position of the ITCZ. This mode's evolution time scales range from interannual to decadal, and its sign is observed both in SST as well as wind fields, given its relationship with the position of the ITCZ (Servain et al., 2003). As a result, this mode is tightly linked to rainfall anomalies, for instance, in Northeastern Brazil (Nobre and Shukla, 1996; Wainer and Soares, 1997). Indeed, Foltz et al. (2012) attribute the severe flooding seen in the region in 2009 to a strong meridional mode event, with a southward shift of the ITCZ, which in turn was caused by an anomalous warming of the southern tropical Atlantic relative to its northern counterpart. Studies have also shown that 
the meridional mode plays a role in Atlantic hurricane activity (e.g., Vimont and Kossin, 2007; Smirnov and Vimont, 2011).

In this study, the focus will be on the Atlantic equatorial mode, which is reported to have weakened in the past decades (Tokinaga and Xie, 2011). Much like the Pacific El Niño, this mode is characterized by the coupling between SST anomalies in the cold tongue region, zonal wind anomalies and consequent thermocline depth and upwelling anomalies. However, it is more concentrated at the equator and displaced farther east in the basin than the Pacific mode (Zebiak, 1993). It is also weaker than its Pacific counterpart with timescales of a few months to 2-4 years, mainly due to differences in size of the oceanic basin (Zebiak, 1993; Servain et al., 1999). Its periodicity also varies considerably (Xie and Carton, 2013). Nonetheless, its signal is robust, as demonstrated by Zebiak (1993). As stated by Losada et al. (2010), the Atlantic equatorial mode is strongly coupled to West African rainfall variability. The authors show that a warming in the equatorial Atlantic in austral winter results in a weakening of the West African Monsoon by diminishing the sea level pressure gradient between the equator and the Saharan heat low. On the same note, Tokinaga and Xie (2011) show how a decrease in cold tongue SST variability in the past decades is associated with a decrease in rainfall variability over the coast of Guinea. The equatorial mode has also been shown to have teleconnections with the extropical atmosphere and the North Atlantic circulation through the impact of cold tongue anomalies on the Hadley circulation and the northern subtropical jet (Haarsma and Hazeleger, 2007) and to affect the Indian summer monsoon through perturbations in the Asian subtropical jet (Yadav et al., 2018). The air-sea interactions involved in the Atlantic equatorial mode are discussed in the following section.

\subsubsection{The Equatorial Mode and the Bjerknes Feedback}

In the Pacific, ENSO is generated by a positive coupled ocean-atmosphere feedback, first described by Bjerknes (1969). This feedback consists in three main components: the response of the zonal winds to EEA SST anomalies, the effect of this anomalous wind forcing on EEA upwelling and heat content and the response of eastern SST anomalies to the eastern upwelling and heat content anomalies. The 
three components of the Bjerknes Feedback are shown by Keenlyside and Latif (2007) to also be present in the Atlantic and to be spatially similar to their Pacific counterparts, although with a $50 \%$ weaker growth rate and peaking in austral winter, as opposed to ENSO, which peaks in austral summer.

Two Walker Circulation cells exist in the Atlantic, with subsidence over the cold tongue region and compensating ascending motion over South America and Africa (Lau and Yang, 2002). In normal conditions, the trade winds blows westward along the equator piling up warm water in the western side of the basin. This induces a zonal slope in the thermocline, which becomes deeper in the west and shallower in the east, favoring upwelling of deeper colder water and forming the ACT (Zebiak, 1993; Keenlyside and Latif, 2007). The schematic view of the Walker circulation in the Atlantic and the thermocline can be observed in Figure 4.

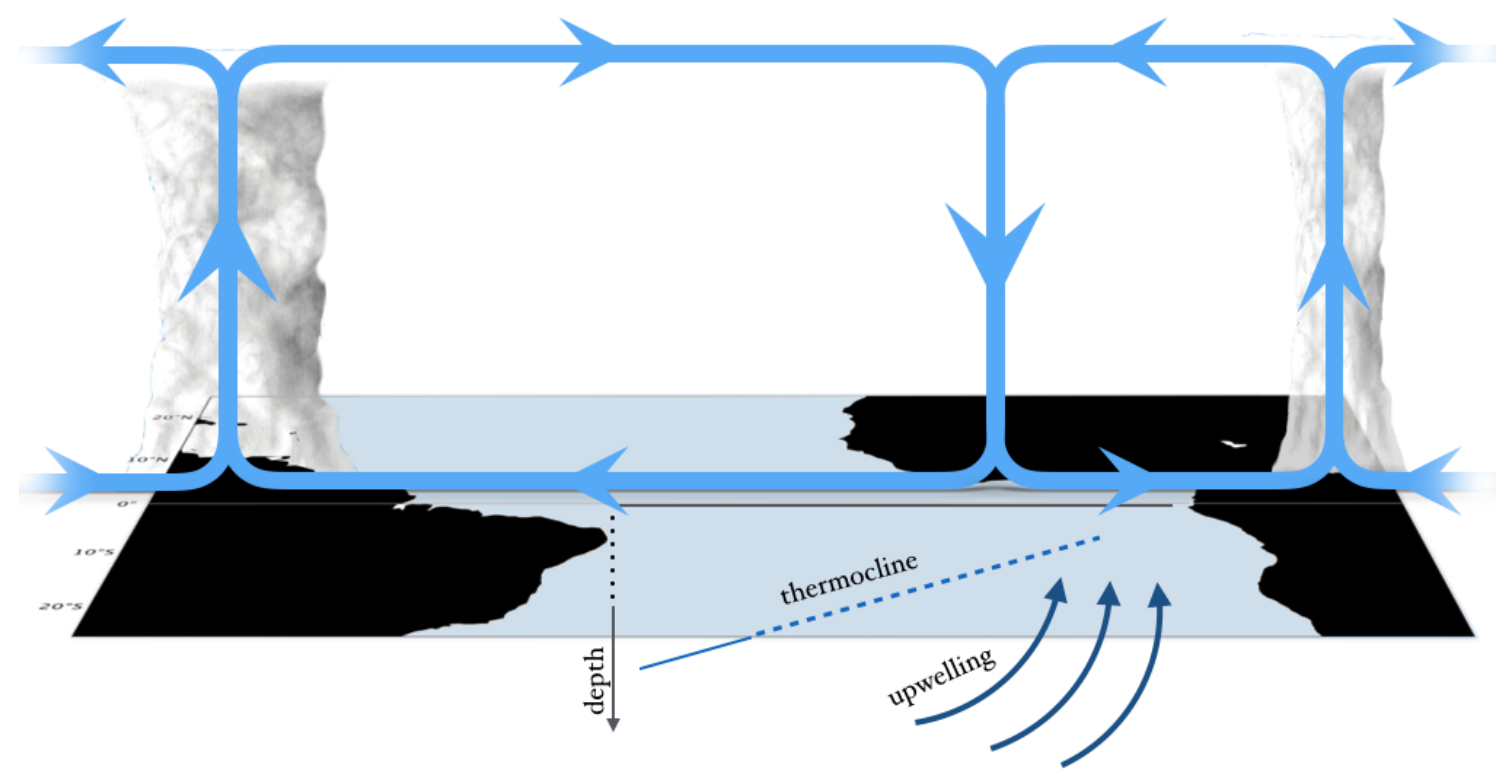

Figure 4 Walker circulation in the tropical Atlantic. As the trade winds blow eastward in the surface, the western thermocline deepens and the eastern shoals, allowing upwelling in the eastern basin. Subsidence occurs over the cold tongue region, with compensating ascending motion over South America and Africa. Modified from Lau and Yang (2002).

The growth of ENSO-related SST anomalies in the Pacific and the transition from the warm to cold phase of its equatorial mode were explained by Jin (1997) and Jin and An (1999) in terms of an oscillator model of recharge and discharge of equatorial heat content. According to Ding et al. (2010), the same framework can be applied to the Atlantic equatorial mode, since the underlying dynamics is similar.

In this model, the Bjerknes Feedback is composed of smaller components 
and damping mechanisms that enhance and limit the growth of the SST anomalies, as illustrated in Figure 5. In the warm phase (a), an initial positive SST anomaly in the east leads to the weakening of the trade winds (i.e., a westerly wind anomaly) by decreasing the surface zonal pressure gradient. The westerly wind anomaly forcing diminishes the zonal thermocline slope, by making it shallower in the west and deeper in the east. It also generates an anomalous eastward zonal current. In addition, upwelling in EEA is reduced as a response to the weaker trades. The combined effect of the anomalous thermocline depth, zonal current and upwelling results in the increase of the initial SST anomaly. These are called, respectively, the thermocline, zonal advective and Ekman feedbacks (hereafter TF, ZAF and EF). The further growth of the anomaly is limited by thermal and dynamical damping (hereafter TD and DD), which are related to the net surface heat flux exchange and the effect of the mean (climatological) currents, respectively.

During the warm phase, divergent zonal integrated Sverdrup transport leads to a discharge of equatorial heat content, which causes the mean zonal equatorial thermocline to become anomalously shallow. It also generates a meridional thermocline depth gradient such that the thermocline is shallowest at the equator. As the SST anomaly cools and disappears, so does the zonal wind anomaly and the warm phase shifts to a transition phase (Figure 5b). In this phase, the anomalous shallow thermocline allows upwelling of anomalous cold subsurface waters in the east. The meridional slope of the thermocline also gives rise to an anomalous westward flowing geostrophic current, which advects cold climatological surface waters from the east westward. These two effects combined lead to a negative SST anomaly and the mode transitions to its cold phase (Figure 5c).

In the cold phase the negative SST anomaly in the east strengthens the mean trade winds (i.e., an easterly wind anomaly) by increasing the surface zonal pressure gradient. The easterly wind forcing increases the zonal thermocline slope, making it deeper in the west and shallower in the east. This also leads to an intensification of upwelling in the east, also generating an anomalous westward zonal current. The combined effect of the TF, EF and ZAF results in the increase of the cold SST anomaly. The further growth of the anomaly once again is limited by TD and DD.

As opposed to the warm phase, in the cold phase the anomalous easterly 

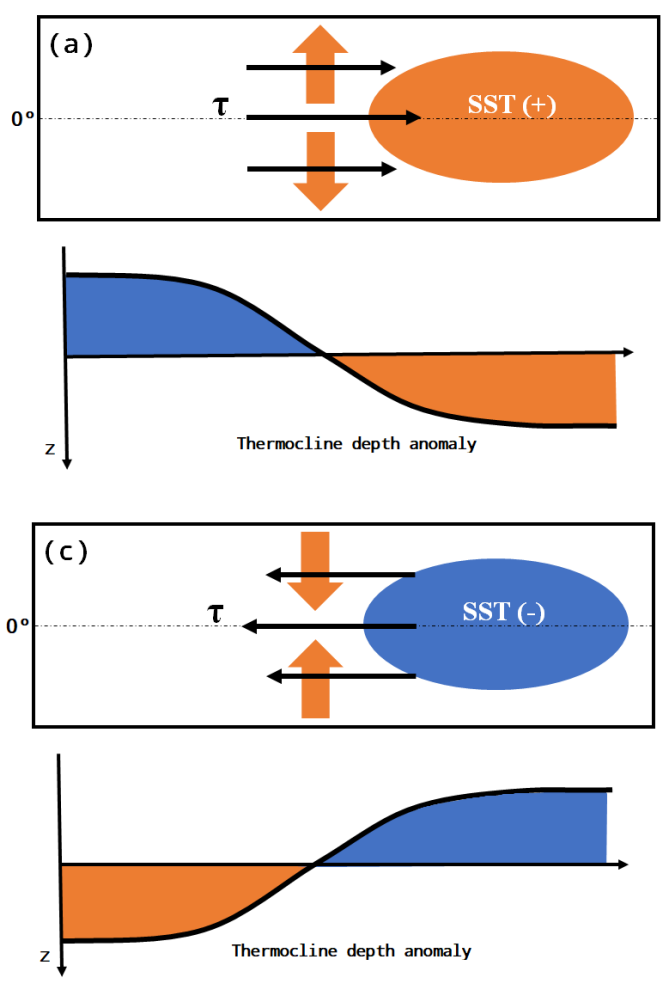
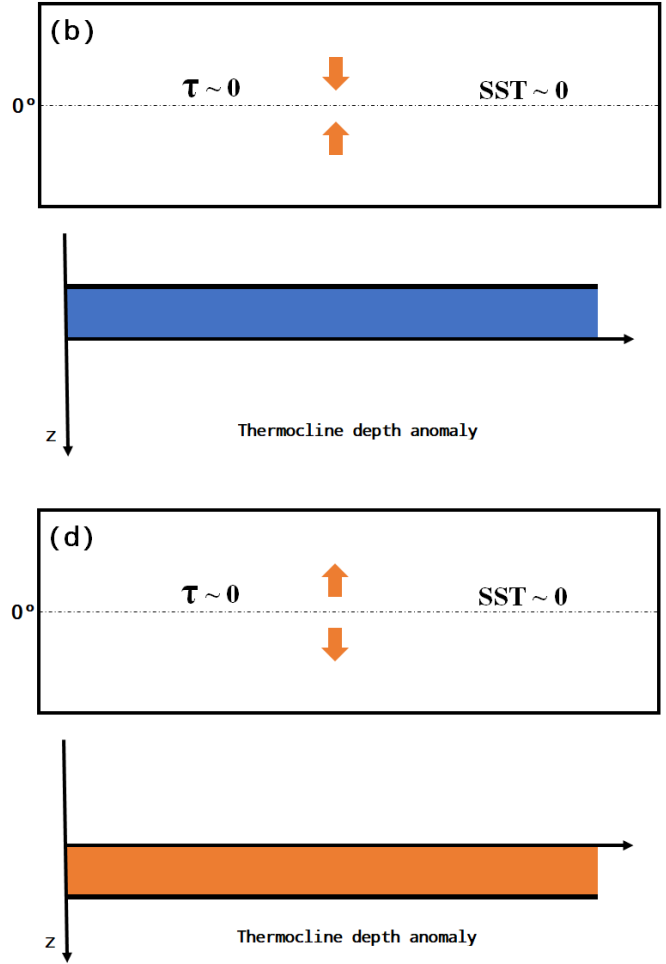

Figure 5 Schematic diagrams of the recharge oscillator model, adapted from Jin (1997). (a) Warm phase, with a westerly wind anomaly forcing (black arrows), equatorial heat discharge (orange arrows) by divergent Sverdrup transport, and an anomalously shallow (blue) thermocline in the west and deep (orange) in the east; (b) Transition from the warm to the cold phase, where the SST and wind anomalies are nearly zero, with the start of the equatorial heat recharge and the anomalously shallow equatorial thermocline across the ocean basin; (c) cold phase, with an easterly wind anomaly forcing, equatorial heat recharge by convergent Sverdrup transport, and an anomalously deep thermocline in the west and shallow in the east; (d) Transition from the cold to the warm phase, where the SST and wind anomalies are nearly zero, with the start of the equatorial heat discharge and the anomalously deep equatorial thermocline across the ocean basin. 
wind forcing leads to the recharge of equatorial heat content by convergent zonal integrated Sverdrup transport. This makes the mean zonal equatorial thermocline anomalously deep, with its depth decreasing poleward. The SST anomaly diminishes and fades and so does the wind anomaly and the system reaches another transition phase (Figure 5d). Upwelling of climatological cold waters is stifled by the deep thermocline. In addition, the meridional thermocline slope gives rise to an anomalous current, wich advects warm climatological waters eastward. The system then transitions to another warm phase.

Jin et al. (2006) developed the Bjerknes feedback index (hereafter $\mathrm{I}_{\mathrm{BJ}}$ ) based on this Recharge Oscillator Model (see section 3.5.2 for the formulation of $\mathrm{I}_{\mathrm{BJ}}$ ). The index measures the growth rate of SST anomalies associated with the Bjerknes feedback, taking its negative contributions from TD and DD and positive contributions from ZAF, EF and TF. Therefore, a positive $\mathrm{I}_{\mathrm{BJ}}$ indicates an unstable coupled system, more capable of sustaining itself with anomalies developing more promptly, while negative values indicate a damped oscillator (Lübbecke and McPhaden, 2013).

The analysis of the $\mathrm{I}_{\mathrm{BJ}}$ has been used in many studies to assess, for instance, decadal shifts in ENSO (Lübbecke and McPhaden, 2014; An and Bong, 2016) and the stability of ENSO in the CMIP models (Kim and Jin, 2011; Kim et al., 2014). For the Atlantic, Lübbecke and McPhaden (2013) compared the stability of ENSO and the Atlantic Niño using the $\mathrm{I}_{\mathrm{BJ}}$, finding that both oceans take the greatest positive contribution from TF. This feedback is twice as strong in the Pacific. Overall, the authors find that both the Atlantic and the Pacific Niños are damped oscillators, the Atlantic one being more strongly damped than the Pacific. Lübbecke and McPhaden (2014) investigate the shift in ENSO in terms of the $\mathrm{I}_{\mathrm{BJ}}$ and find weaker and more frequent events in the end of last century. To this date, no study has assessed, in terms of this index, the weakening in the ACT in recent decades as reported by i.e. Tokinaga and Xie (2011). 


\section{Objectives}

This study aims to investigate changes in the Atlantic equatorial mode and the Bjerknes feedback in the recent decades in a set of eight ocean reanalysis and assess the differences and possible biases among them. The specific goals of this study are:

- Compare the different reanalyses and evaluate how they represent the seasonal cycles of each variable related to the Bjerknes Feedback;

- Produce an ensemble of the reanalyses for the tropical Atlantic, assessing the regions where the members agree the most for each variable;

- Consider long term trends in the variables of interest for the Bjerknes Feedback and how these trends differ among the reanalysis products;

- Analyze the correlation patterns of each component of the Bjerknes Feedback for each reanalysis and investigate possible changes in the end of last century;

- Examine the variability of the Bjerknes Feedback in the Equatorial Atlantic in the last century and early 21st century in terms of the Bjerknes Feedback Index. 


\section{Methods}

\subsection{Reanalysis Products}

Seven ocean reanalyses from the Ocean Reanalysis Intercomparison Project (ORA-IP) (Balmaseda et al., 2015) are used for the period spanning from 1980 to 2010, in which all reanalysis overlap. In addition, two 20th Century reanalyses are used, one oceanic and one atmospheric, as well as one product of bias-corrected net surface heat flux. To allow comparison, all products were interpolated to a $1^{\circ}$ horizontal resolution, which is the coarser resolution among them. The datasets are described below.

\subsubsection{NCEP/CFSR}

The Climate Forecast System Reanalysis (CFSR), from the National Center For Environmental Prediction (NCEP) of the National Ocean and Atmospheric Administration (NOAA) is a coupled ocean-atmosphere-land-surface sea ice system based on the fourth version of the global Modular Ocean Model (MOM4) ocean model, GFDLSea Ice Simulator, GDAS sigma coordinate spectral atmospheric model. It uses a three-dimensional variational (3DVAR) data assimilation scheme to assimilate temperature and salinity profiles from NOAA's National Oceanographic Data Center (NODC) 1998 version of the World Ocean Database (WOD98). The atmospheric resolution is $38 \mathrm{~km}$ (T382) with 64 levels, while the global ocean resolution is $0.25^{\circ}$ at the equator and extends to $0.5^{\circ}$ beyond the tropics, with 40 vertical levels. Data is available from 1979 to present (Saha et al., 2010).

\subsubsection{GFDL/ECDA v.3}

The GFDL (Geophysical Fluid Dynamics Laboratory) Ensemble Coupled Data Assimilation System (ECDA, v.3) uses the GFDL atmosphere model AM2p12, with $2^{\circ}$ latitude by $2.5^{\circ}$ longitude horizontal resolution and 24 vertical levels and MOM4 configured with $1^{\circ} \times 1^{\circ}$ horizontal resolution and $1 / 3^{\circ}$ meridional spacing towards the equator, with 50 vertical levels (22 out of which with $10 \mathrm{~m}$ thickness each in the top 220m). It uses an Ensemble Kalman Filter to assimilate NCEP 
renalysis winds, Optimal Interpolation Sea Surface Temperature (OISST) (1980onwards), profile data from WOD09 (1960-2008) and GTSPP (Global Temperature and Salinity Profile Program) (2009-onwards). Data is available from 1960 to present (Zhang et al., 2007).

\subsubsection{ICDC/GECCO2}

The German contribution to the Estimating the Circulation and Climate of the Ocean system (GECCO2) from the Integrated Climate Data Center (ICDC) uses the MITgcm global model, with 50 levels and horizontal resolution of $1^{\circ} \mathrm{x} 1 / 3^{\circ}$. A four-dimensional variational (4DVAR) data assimilation method is used and the assimilated data consists of WOD09 climatologies, temperature and salinity profiles from EN3v2a (UK Meteorological Office), which includes XBT, CTD, Argo and Mooring data, AVISO sea surface height, Hadley Center Sea Ice and Sea Surface Temperature (HadISST) and SST from the Advanced Microwave Scanning Radiometer - Earth Observing System (AMSR-E) sensor on NASA's AQUA satellite. Data is available at a temporal resolution of 10 days, from 1948 to 2014 (Köhl, 2015).

\subsubsection{NCEP/GODAS}

The NCEP Global Ocean Data Assimilation System (GODAS) uses a quasiglobal configuration of the Modular Ocean Model 3 (MOM3), with $1^{\circ}$ zonal resolution and meridional resolution of $1 / 3^{\circ}$ within $10^{\circ}$ of the equator gradually increasing until it reaches $1^{\circ}$ at $30^{\circ}$ latitude, being fixed polewards. It has 28 levels and its temporal resolution is 5 days. It assimilates SST from NCEP's in situ and satellite blended analysis, temperature profiles from WOD98 (1980-1989) and from the Canadian Marine Environmental Data Section (MEDS) Real-time Ocean Profile Data (1990-present) as well as Tropical Atmospheric and Ocean (TAO) mooring data from the Pacific Marine Environmental Laboratory (PMEL). Data is available from 1979 until the present (Behringer, 2007).

\subsubsection{JAMSTEC/K7-ODA}

The Japan Agency for Marine-Earth Science and Technology (JAMSTEC) Ocean Data Assimilation (K7-ODA) uses a MOM3-based ocean general circulation 
model. Corrected EN3 temperature and salinity profiles, AVISO sea level height and Reynolds SST Temperature and salinity data are assimilated using 4DVAR adjoint method. The horizontal resolution is $1^{\circ} \times 1^{\circ}$ with 46 vertical levels with spacing varying from $10 \mathrm{~m}$ near the surface to $400 \mathrm{~m}$ near the bottom. Data is available from 1957 to 2011 (Masuda et al., 2010).

\subsubsection{ECMWF/ORAS4}

The European Center for Medium-Range Weather Forecasts (ECMWF) Ocean Reanalysis System 4 (ORAS4) is based on NEMO 3.0 global ocean model, with horizontal resolution of $1^{\circ} \times 1^{\circ}$ and a refined meridional resolution with a minimum $\left(0.3^{\circ}\right)$ at the equator. ORAS4 has 42 vertical levels with thickness varying between $10 \mathrm{~m}-15 \mathrm{~m}$ in the upper $200 \mathrm{~m}$. It assimilates EN3v2a profile data and AVISO sea surface height via a 3DVAR scheme. Atmospheric forcing (heat and momentum fluxes) from the ECMWF ERA-Interim Atmospheric Reanalysis (Berrisford et al., 2009) is used. ORAS4 has 10 days temporal resolution and data is available from 1958 to 2014 (Balmaseda et al., 2013).

\subsubsection{SODA v.3.4.1}

The Simple Ocean Data Assimilation (SODA, v.3.4.1) reanalysis utilizes version 5 of the GFDL Modular Ocean Model (MOM5) and the sea ice component of its CM2.5 coupled model, with horizontal resolution of $0.25^{\circ} \mathrm{x} 0.4^{\circ}$ and 50 vertical levels. Profile data from WOD and ICOADs v5.2 SST observations as well as remotely sensed SST data from L3 Pathfinder V5.2 AVHR Radiometer and NOAA Advanced Clear Sky Processor for Ocean VIIRS and MODIS L2P are assimilated. Wind data is provided by ECMWF ERA-Interim reanalysis. Data is available from 1980 to 2015 (Carton et al., 2018).

\subsubsection{TropFlux}

TropFlux consists in a product developed by the Laboratoire d'Océanographie (LOCEAN) from the Pierre Simon Laplace Institute and the Indian National Center for Ocean Information Services (CSIR), providing air-sea heat and momentum fluxes for the $30^{\circ} \mathrm{N}-30^{\circ} \mathrm{S}$ region, spanning the period from 1979 to 2013 . It uses as inputs 
ERA-Interim longwave and turbulent fluxes data and ISCCP (International Cloud Climatology Project) data for shortwave radiation fluxes. The inputs are bias and amplitude corrected based on NOAA's Global Tropical Moored Buoy Array data (Kumar et al., 2012).

\subsubsection{0th Century Reanalyses}

To investigate changes before 1980, the Historical Ocean Reanalysis (CHORRL) from the Centro Euro-Mediterraneo sui Cambiamenti Climatici (CMCC) (Yang et al., 2017) is used. It assimilates sea surface temperatures and vertical profile data using a 3D-var assimilation scheme, nudging to HadISST reconstructed SST and sea ice fields and uses NOAA's 20th Century Reanalysis (20CR v2c, hereafter 20CR) for atmospheric forcing. It spans the period from 1900 to 2010 and has $0.5^{\circ} \times 0.5^{\circ}$ horizontal resolution. For the computation of the net surface heat flux, surface albedo, heat and radiation fluxes for this period are obtained from 20CR (Compo et al., 2011), which uses an Ensemble Kalman Filter data assimilation method and an ensemble of forecasts from a global numerical weather model, with $2^{\circ} \times 2^{\circ}$ horizontal and 6-hours temporal resolutions, spanning from 1871 to the present.

\subsection{Region of study and Variables}

The region of interest in this is study is delimited by $15^{\circ} \mathrm{N}-15^{\circ} \mathrm{S}$ latitude and $60^{\circ} \mathrm{W}-20^{\circ} \mathrm{E}$ longitude. The variables taken from the ocean reanalyses products are sea surface temperature (SST), potential temperature, zonal and meridional wind stress $\left(\tau_{\mathrm{x}}\right.$ and $\left.\tau_{\mathrm{y}}\right)$, zonal and meridional currents. For CFSR and GECCO2, vertical velocity datasets are also available. For all other reanalyses, vertical velocity is calculated from the horizontal velocity fields using the mass continuity equation (see section 3.2.1). Upper ocean heat content climatologies and anomalies are calculated based on the potential temperature profiles and $20^{\circ} \mathrm{C}$ isotherm depth (see section $3.2 .2)$.

In order to allow the computation of the ensemble means, all ocean reanalysis data were interpolated to a $1^{\circ} \times 1^{\circ}$ grid. For seven of the nine reanalyses, the period ranging from 1980 to 2010 is considered, in which all of them overlap. For this period, surface net heatflux from TropFlux is used. 


\begin{tabular}{|c|c|c|c|c|c|c|c|c|c|c|}
\hline & \multicolumn{8}{|c|}{$1980-2010$} & \multicolumn{2}{|c|}{$1900-1980$} \\
\hline Reanalysis & CFSR & ECDA & GECCO2 & GODAS & K7 & ORAS4 & SODA & TropFlux & 20CR & CHOR \\
\hline SST & $\mathrm{x}$ & $\mathrm{x}$ & $\mathrm{x}$ & $\mathrm{x}$ & $\mathrm{x}$ & $\mathrm{x}$ & $\mathrm{x}$ & & & $\mathrm{x}$ \\
\hline POTTEMP & $\mathrm{x}$ & $\mathrm{x}$ & $\mathrm{x}$ & $\mathrm{x}$ & $\mathrm{x}$ & $\mathrm{x}$ & $\mathrm{x}$ & & & $\mathrm{x}$ \\
\hline$\tau_{x}, \tau_{y}$ & $\mathrm{x}$ & $\mathrm{x}$ & $\mathrm{x}$ & $\mathrm{x}$ & $\mathrm{x}$ & $\mathrm{x}$ & $\mathrm{x}$ & & & $\mathrm{x}$ \\
\hline UVEL,VVEL & $\mathrm{x}$ & $\mathrm{x}$ & $\mathrm{x}$ & $\mathrm{x}$ & $\mathrm{x}$ & $\mathrm{x}$ & $\mathrm{x}$ & & & $\mathrm{x}$ \\
\hline WVEL & $\mathrm{x}$ & & $\mathrm{x}$ & & & & & & & \\
\hline NSHF & & & & & & & & $\mathrm{x}$ & & \\
\hline LHF & & & & & & & & & $\mathrm{x}$ & \\
\hline SHF & & & & & & & & & $\mathrm{x}$ & \\
\hline $\mathrm{LWR}_{\text {down }}$ & & & & & & & & & $\mathrm{x}$ & \\
\hline$S W R_{\text {down }}$ & & & & & & & & & $\mathrm{x}$ & \\
\hline Surface Albedo & & & & & & & & & $\mathrm{x}$ & \\
\hline
\end{tabular}

Table 1: Variables taken from each reanalysis and respective time periods, where: SST: sea surface temperature; POTTEMP: potential sea water temperature; $\tau_{\mathrm{x}}, \tau_{\mathrm{y}}$ : zonal and meridional wind stress; UVEL, VVEL, WVEL: zonal, meridional and vertical current velocities; NSHF: net surface heat flux; LHF: latent heat flux; SHF: sensible heat flux; $L_{W} R_{\text {down }}$ : longwave downward radiation; $\mathrm{SWR}_{\text {down }}$ : shortwave downward radiation.

\subsubsection{Vertical Velocity}

Vertical velocity fields were calculated for the datasets for which this variable was not available, based on the horizontal velocity fields using mass continuity (equation 1). We note that despite this being a rough approximation, the main features of vertical velocity (such as the equatorial uppwelling associated with the equatorial divergence and the cold tongue-associated upwelling) are visible in the resulting fields. In addition, we are mostly interested in the mean uppwelling in the ATL3 region used to compute the Bjerknes Feedback Index (see 3.4 and 3.5.2), so that there are not significant differences between the region means obtained from the calculated fields and the fields provided by the other reanalyses. From the continuity equation:

$$
\frac{\partial \mathrm{u}}{\partial \mathrm{x}}+\frac{\partial \mathrm{v}}{\partial \mathrm{y}}+\frac{\partial \mathrm{w}}{\partial \mathrm{z}}=0
$$

From which we obtain:

$$
\frac{\partial \mathrm{w}}{\partial \mathrm{z}}=-\left(\frac{\partial \mathrm{u}}{\partial \mathrm{x}}+\frac{\partial \mathrm{v}}{\partial \mathrm{y}}\right)
$$

Which can be written in discrete form as: 


$$
\Delta \mathrm{w}=-\left(\frac{\Delta \mathrm{u}}{\Delta \mathrm{x}}+\frac{\Delta \mathrm{v}}{\Delta \mathrm{y}}\right) \Delta \mathrm{z}
$$

The gradients of $u$ and $v$ are obtained using central finite differences, as follows:

$$
\begin{aligned}
& \left(\frac{\Delta \mathrm{u}}{\Delta \mathrm{x}}\right)_{(\mathrm{i}, \mathrm{j}, \mathrm{k})}=\frac{\mathrm{u}_{(\mathrm{i}+1, \mathrm{j}, \mathrm{k})}-\mathrm{u}_{(\mathrm{i}-1, \mathrm{j}, \mathrm{k})}}{2 \Delta \mathrm{x}} \\
& \left(\frac{\Delta \mathrm{v}}{\Delta \mathrm{y}}\right)_{(\mathrm{i}, \mathrm{j}, \mathrm{k})}=\frac{\mathrm{v}_{(\mathrm{i}, \mathrm{j}+1, \mathrm{k})}-\mathrm{v}_{(\mathrm{i}, \mathrm{j}-1, \mathrm{k})}}{2 \Delta \mathrm{y}}
\end{aligned}
$$

The vertical velocity in each point is then calculated as:

$$
\mathrm{w}_{(\mathrm{i}, \mathrm{j}, \mathrm{k})}=\mathrm{w}_{(\mathrm{i}, \mathrm{j}, \mathrm{k}-1)}+\Delta \mathrm{w}_{(\mathrm{i}, \mathrm{j}, \mathrm{k})}
$$

\subsubsection{Thermocline Depth}

The $20^{\circ} \mathrm{C}$ isotherm depth (Z20) is chosen as a proxy for thermocline depth as it usually is located near the center of the thermocline in the equatorial oceans (Yang and Wang, 2009). Although the authors note that during the cold season in coastal and upwelling regions Z20 may outcrop to the surface, this is not observed in the in the $15^{\circ} \mathrm{S}-15^{\circ} \mathrm{N}$ region considered in this study.

\subsubsection{Net Surface Heat Flux (NSHF)}

For the period before 1980, which is not covered by TropFlux, NSHF is calculated based on radiation and heat fluxes provided by 20CR. NSHF is computed as in Kumar et al. (2012) (equations 7 to 9).

$$
\begin{aligned}
& \mathrm{LWR}_{\text {net }}=\varepsilon \sigma \mathrm{T}_{\mathrm{S}}^{4}-\mathrm{LWR}_{\text {down }} \\
& \mathrm{SWR}_{\text {net }}=(1-\mathrm{a}) \mathrm{SWR}_{\text {down }} \\
& \mathrm{NET}=\mathrm{SWR}_{\text {net }}-\left(\mathrm{LWR}_{\text {net }}+\mathrm{LHF}+\mathrm{SHF}\right)
\end{aligned}
$$


Where $\mathrm{LWR}_{\text {net }}, \mathrm{LWR}_{\text {down }}, \mathrm{SWR}_{\text {net }}, \mathrm{SWR}_{\text {down }}, \mathrm{LHF}, \mathrm{SHF}$ and NET are, respectively, the net longwave, downwards longwave, net shortwave, downwards shortwave, latent heat, sensible heat and net surface heat fluxes $\left(\mathrm{W} / \mathrm{m}^{2}\right), \varepsilon=0.98$ is the Earth's emissivity, $\sigma=5.67 \times 10^{-8} \mathrm{~W} / \mathrm{m}^{2} \cdot \mathrm{K}^{4}$ is the Stefan-Boltzmann constant, $\mathrm{T}_{\mathrm{S}}$ is surface temperature $(\mathrm{K})$ and $a$ is the surface albedo.

\subsection{Climatologies and Anomalies}

Calculating climatologies and anomalies is a simple but highly important technique in meteorologic and oceanographic studies (Taschetto, 2001), since it provides an overview of the long-term mean behavior of a certain climatic element in the region of interest, as well as the deviation from this mean over time.

The climatology can be understood as the mean state of a climate variable, computed based on a sufficiently long time series (usually 30 years or longer). Here climatologies are computed based on the 1980-2010 period. Anomalies, on the other hand, result from the subtraction of the climatology from the original time series. Therefore, the time series of a certain variable consists in the sum of two main components: one cyclic and predictable (climatology), related to the mean annual cycle, and a component with no specific pattern, resultant from the combined effect of variability in different time scales (anomalies) (Figure 6): 
(a) Time Series

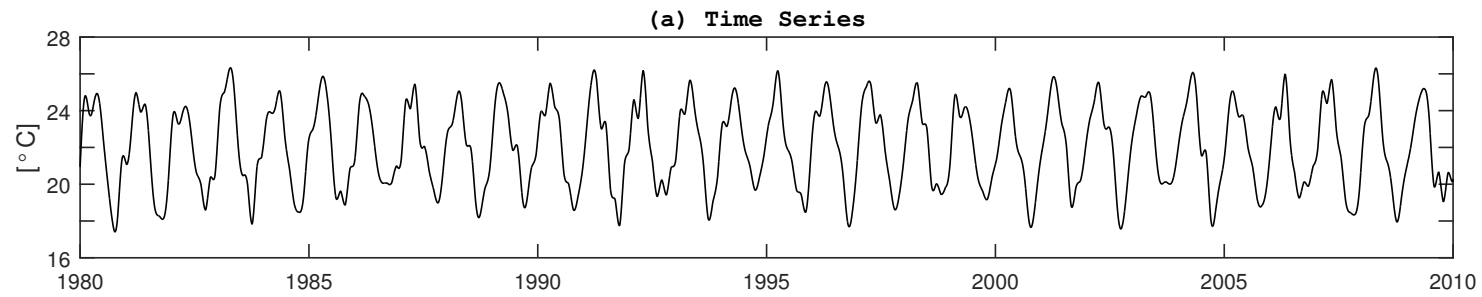

(b) Climatology

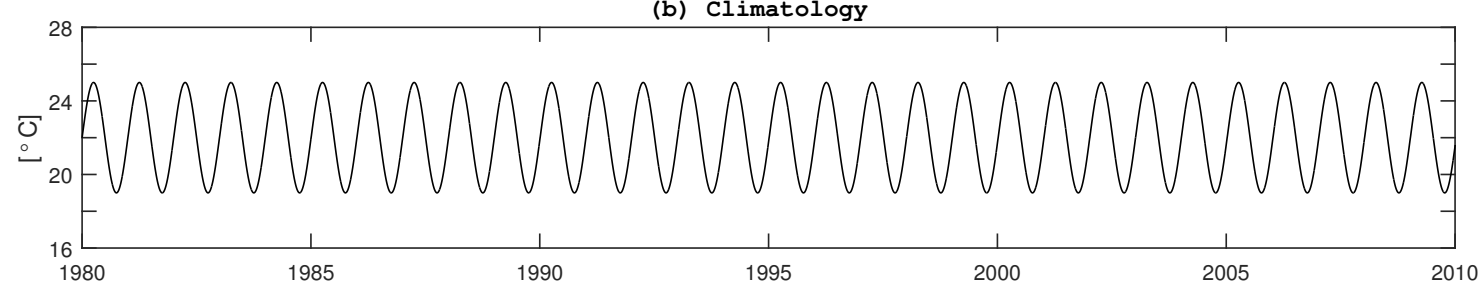

(c) Anomaly

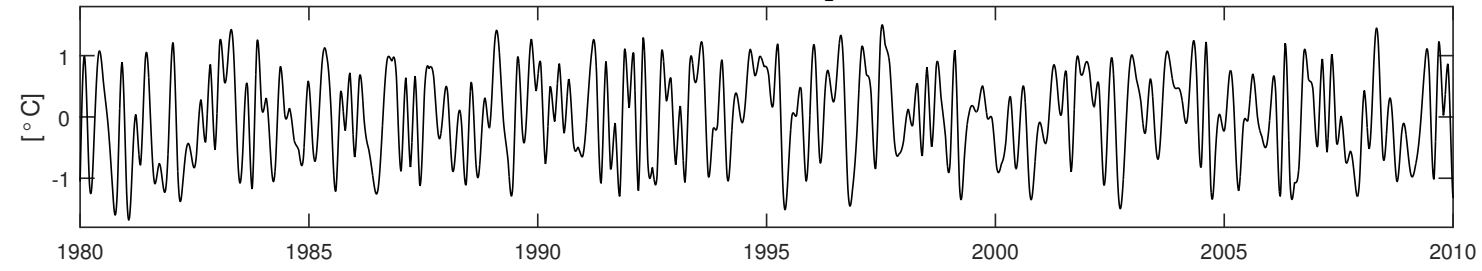

Figure 6 Synthetic time series (a) and its climatology (b) and anomalies (c). Note that the time series in (a) corresponds to the sum of (b) and (c).

The monthly climatology for the reanalysis data is obtained by computing the arithmetic mean of each month's time series, in each grid point, for the whole period, according to equation 10 :

$$
\overline{\mathrm{x}}(\mathrm{i})=\frac{1}{\mathrm{n}} \sum_{\mathrm{j}=0}^{\mathrm{n}-1} \mathrm{x}_{\mathrm{i}+12 \mathrm{j}}
$$

Where $\mathrm{i}=1,2, \ldots, 12$ and $\mathrm{n}=$ number of years of the time series.

The seasonal climatology is obtained by averaging the climatologies of the months referent to each season: December, January and February (DJF); March, April and May (MAM); June, July and August (JJA); and September, October and November (SON).

The monthly anomaly series is calculated by subtracting from each monthly data the climatology of the corresponding month, as in equation 11:

$$
\mathrm{d}_{\mathrm{j}}=\mathrm{x}_{\mathrm{j}}-\overline{\mathrm{x}}_{\mathrm{i}}
$$

Where $d_{j}$ is the anomaly of the $j$-th month of the time series, $x_{j}$ is the value 
of the variable in the $\mathrm{j}$-month and $\mathrm{x}_{\mathrm{i}}$ is the climatology of the corresponding month. Here, the mean state of each variable (i.e., its climatology) is assessed comparatively for each reanalysis by analysing the spatial patterns of their difference from the reanalyses ensemble mean.

\subsection{Climate indices}

A number of indices can be computed to describe the Atlantic Equatorial Mode. Similarly to the indices used to describe ENSO (Rasmusson and Carpenter, 1982; Bamston et al., 1997), the Atlantic Niño can be described by the ATL3 index, which is the mean SST anomaly over $3^{\circ} \mathrm{N}-3^{\circ} \mathrm{S} ; 20^{\circ} \mathrm{W}-0^{\circ}$ in the ACT. This is where the largest interannual SST variability occurs (Zebiak, 1993). It peaks in June-JulyAugust (JJA) (Richter et al., 2012), as shown in Figure 7. This region is also used to assess the average thermocline depth associated with the cold tongue.
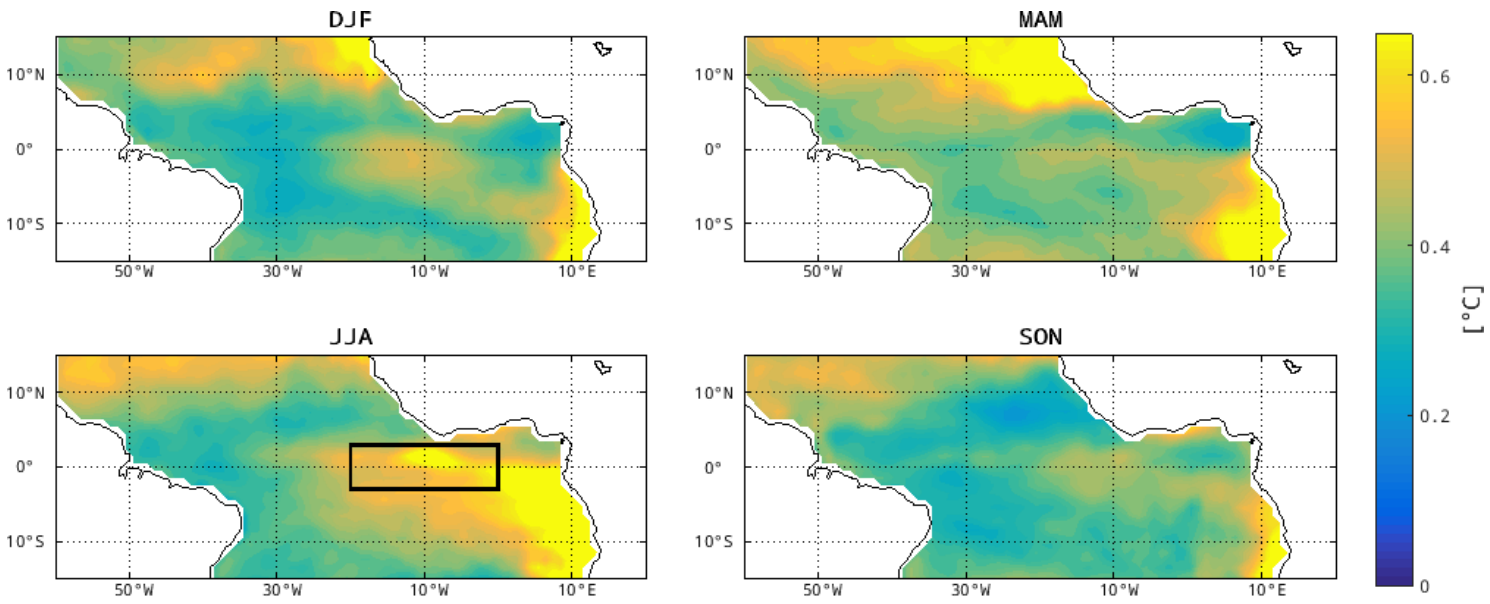

Figure 7 SST seasonal standard deviations (1980-2010) derived from NCEP/CFSR. The delimited box indicates the ATL3 index region $\left(3^{\circ} \mathrm{N}-3^{\circ} \mathrm{S} ; 20^{\circ} \mathrm{W}-0^{\circ}\right)$, where JJA SST variability is highest.

SST variability is suggested to be driven by zonal wind stress variability (Keenlyside and Latif, 2007), which peaks in March-April-May (MAM) (Richter et al., 2012), as can be observed in Figure 8. The region used here to average the zonal wind stress anomalies extends farther east $\left(3^{\circ} \mathrm{N}-3^{\circ} \mathrm{S} ; 40^{\circ} \mathrm{W}-0^{\circ}\right)$. This is the averaging region required for consistency of the Bjerknes Feedback index equation (Lübbecke and McPhaden, 2013, see section 3.5.2). The WATL region (dotted line in MAM wind stress depicted in figure 8) for $3^{\circ} \mathrm{N}-3^{\circ} \mathrm{S} ; 45^{\circ} \mathrm{W}-25^{\circ} \mathrm{W}$ (Tokinaga and Xie, 2011) is used to compute the zonal thermocline slope. It is the same region used 
by the authors, combined with the ATL3 region, to compute the zonal equatorial SST gradient for the Tropical Atlantic.
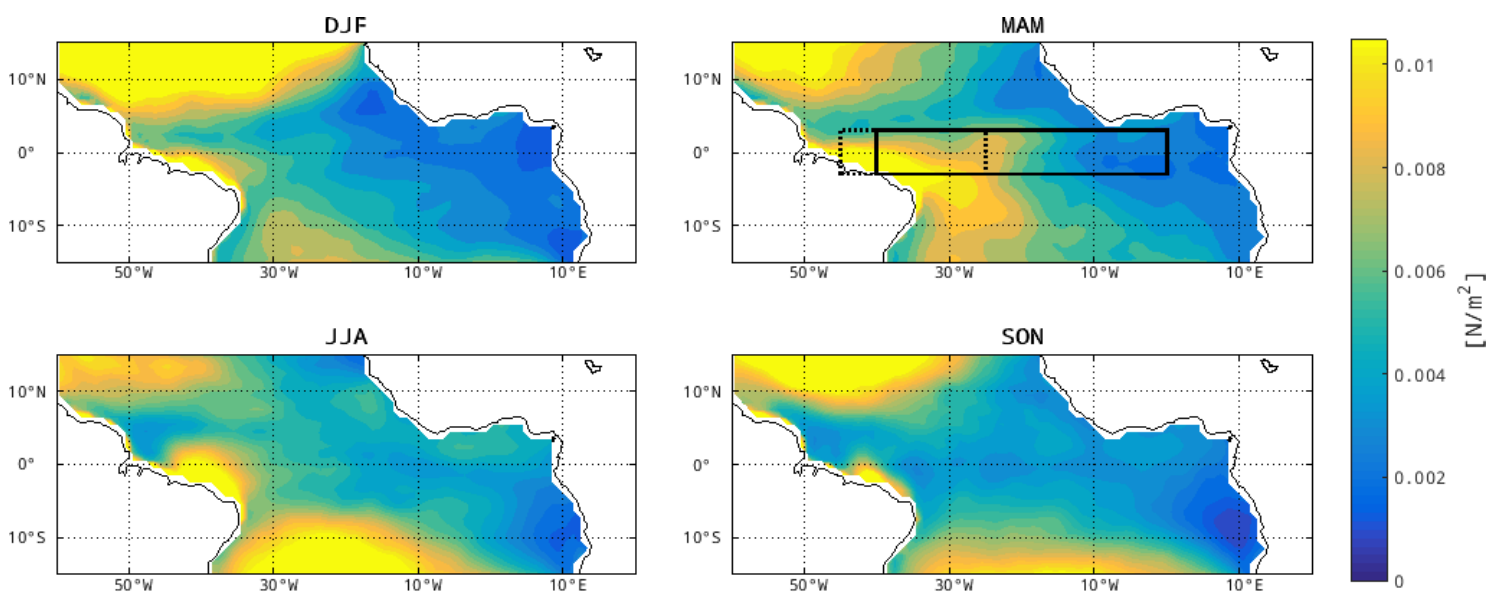

Figure 8 Zonal wind stress seasonal standard deviations (1980-2010) derived from NCEP/CFSR. The solid line box indicates the region used to compute the mean equatorial wind stress $\left(3^{\circ} \mathrm{N}-3^{\circ} \mathrm{S}\right.$; $\left.40^{\circ} \mathrm{W}-0^{\circ}\right)$ and the dotted line box indicates the WATL region $\left(3^{\circ} \mathrm{N}-3^{\circ} \mathrm{S} ; 45^{\circ} \mathrm{W}-25^{\circ} \mathrm{W}\right)$, used to compute the zonal thermocline slope.

\subsubsection{Root Mean Square Variance (RMSV)}

The variability of the aforementioned climate indices can be assessed by computing a moving-window standard deviation analysis (root mean square variance - RMSV), addapted from Tokinaga and Xie (2011). The RMSV for year $i$ of a variable $X$, considering a time window of $n+1$ years, is defined as the standard deviation of the anomalies between years $i-n / 2$ and $i+n / 2$, according to equation (12):

$$
\operatorname{RMSV}_{i}=\sqrt{\frac{\sum_{j=i-n / 2}^{i+n / 2}(X-\bar{X})^{2}}{n+1}}
$$

\subsection{Bjerknes Feedback Analysis}

The strength of the Bjerknes Feedback is obtained by computing the correlation patterns among sea surface temperature, zonal wind stress and Z20 anomalies and by calculating the Bjerknes Feedback Index. 


\subsubsection{Correlations among SST, zonal wind stress and thermocline depth}

- The influence of SST in the eastern equatorial Atlantic on zonal wind stress over the equatorial Atlantic is evaluated by averaging SST anomalies over the ATL3 region and correlating the resulting time series with $\tau_{\mathrm{x}}$ anomalies elsewhere in the ocean basin;

- The influence of $\tau_{\mathrm{x}}$ anomalies in equatorial Atlantic on thermocline depth anomalies is evaluated by correlating the averaged $\tau_{\mathrm{x}}$ anomalies in the equatorial region against thermocline depth anomalies elsewhere in the basin;

- The influence of subsurface temperature anomalies in overlying SST anomalies in the cold tongue region is evaluated by correlating subsurface temperature anomalies in the equatorial region $\left(3^{\circ} \mathrm{N}-3^{\circ} \mathrm{S}\right)$ with ATL3 SST anomalies.

\subsubsection{Bjerknes Feedback Index}

The Bjerknes Feedback Index (hereafter $\mathrm{I}_{\mathrm{BJ}}$ ) was developed by Jin et al. (2006) from the linear equation for mixed layer SST anomalies (equation 13):

$$
\frac{\partial \tilde{\mathrm{T}}}{\partial \mathrm{t}}=-\left(\overline{\mathrm{u}} \frac{\partial \tilde{\mathrm{T}}}{\partial \mathrm{x}}+\overline{\mathrm{v}} \frac{\partial \tilde{\mathrm{T}}}{\partial \mathrm{y}}+\overline{\mathrm{w}} \frac{\partial \tilde{\mathrm{T}}}{\partial \mathrm{z}}+\tilde{\mathrm{u}} \frac{\partial \overline{\mathrm{T}}}{\partial \mathrm{x}}+\tilde{\mathrm{v}} \frac{\partial \overline{\mathrm{T}}}{\partial \mathrm{y}}+\tilde{\mathrm{w}} \frac{\partial \overline{\mathrm{T}}}{\partial \mathrm{z}}\right)+\tilde{\mathrm{Q}}
$$

Where T represents temperature, $\mathrm{u}, \mathrm{v}$ and $\mathrm{w}$ represent zonal, meridional and vertical velocities, the overbar denotes the climatological mean and tilde stands for anomaly. The equation is averaged in the region of highest SST variability, which corresponds to the ATL3 region in the Equatorial Atlantic:

$$
\frac{\partial \tilde{\mathrm{T}}}{\partial \mathrm{t}}=2 \mathrm{I}_{\mathrm{BJ}}\langle\tilde{\mathrm{T}}\rangle_{\mathrm{E}}-\left\langle\frac{\partial \overline{\mathrm{T}}}{\partial \mathrm{x}}\right\rangle_{\mathrm{E}} \beta_{\mathrm{uh}}+\left\langle\frac{\mathrm{H}(\overline{\mathrm{w}}) \overline{\mathrm{w}}}{\mathrm{H}_{\mathrm{m}}} \mathrm{a}_{\mathrm{h}}\right\rangle_{\mathrm{E}}
$$

Where $\mathrm{H}_{m}$ is the effective depth for vertical advection, which is the first vertical level showing high vertical velocities; \langle\rangle$_{\mathrm{E}}$ denotes the average over the ATL3 region; $\mathrm{H}(\mathrm{x})$ represents the Heaviside function so only upwards advection is considered; $a_{h}$ is the response of SST to subsurface temperature anomalies in the ATL3 region (equation 21) and $\beta_{\mathrm{uh}}$ is the second coefficient of the multilinear regression between 
averaged ATL3 zonal current anomalies, averaged equatorial wind stress anomalies and averaged western (3S-3N; 45W-25) thermocline depth anomalies (equation 18). Equation 14 shows that the evolution of SST anomalies is dependant: 1) on the basic state, represented by the second and third terms on the right side of the equation, which are associated with the equatorial heat content recharge and discharge in the transition phase of the equatorial mode; 2) on an anomalous term (first term on the right side of the equation), where $\mathrm{I}_{\mathrm{BJ}}$ is the growth rate of $\mathrm{SST}$ anomalies (equation $15)$ :

$$
\begin{aligned}
2 \mathrm{I}_{\mathrm{BJ}}=\underbrace{-\left(\frac{\langle\overline{\mathrm{u}}\rangle_{\mathrm{E}}}{\mathrm{L}_{\mathrm{x}}}+\frac{\langle-2 \mathrm{y} \overline{\mathrm{v}}\rangle_{\mathrm{E}}}{\mathrm{L}_{\mathrm{y}}^{2}}+\frac{\langle\overline{\mathrm{w}}\rangle_{\mathrm{E}}}{\mathrm{H}_{\mathrm{m}}}\right)}_{\mathrm{DD}} \overbrace{-\alpha}^{\mathrm{TD}} \underbrace{+\mu_{\mathrm{a}} \beta_{\mathrm{u}}\left\langle\frac{-\partial \overline{\mathrm{T}}}{\partial \mathrm{x}}\right\rangle_{\mathrm{E}}}_{\mathrm{ZAF}} \\
\underbrace{+\mu_{\mathrm{a}} \beta_{\mathrm{w}}\left\langle\frac{-\partial \overline{\mathrm{T}}}{\partial \mathrm{z}}\right\rangle_{\mathrm{E}}}_{\mathrm{EF}} \underbrace{+\mu_{\mathrm{a}} \beta_{\mathrm{h}}\left\langle\frac{\mathrm{H}(\overline{\mathrm{w}}) \overline{\mathrm{w}}}{\mathrm{H}_{\mathrm{m}}} \mathrm{a}_{\mathrm{h}}\right\rangle_{\mathrm{E}}}_{\mathrm{TF}}
\end{aligned}
$$

Where $\mathrm{L}_{\mathrm{x}}$ and $\mathrm{L}_{\mathrm{y}}$ stand for the zonal and meridional extent of the averaging region and $\mathrm{y}$ is the distance from the equator. In equation 15, each term on the right side corresponds to a mechanism within the Bjerknes Feedback: dynamical damping (DD), thermal damping (TD), zonal advective (ZAF), Ekman (EF) and thermocline (TF) feedbacks, from left to right. Positive values for the $\mathrm{I}_{\mathrm{BJ}}$ indicate an unstable coupled system, more capable of sustaining itself with anomalies developing more promptly, while negative values indicate a more damped oscillator. Therefore, negative terms (thermal and dynamical damping) have a dampening effect on the oscillator whereas positive terms (ZAF, EF and TF) act to enhance the oscillator (Lübbecke and McPhaden, 2014). The parameters $\alpha, \mu_{\mathrm{a}}, \beta_{\mathrm{u}}, \beta_{\mathrm{w}}, \beta_{\mathrm{h}}$ and $\mathrm{a}_{\mathrm{h}}$ are obtained through linear regression, according to Jin et al. (2006) and Lübbecke and McPhaden (2013), and are detailed below. All data are detrended prior to regression.

- $\alpha$ (Thermal damping)

The thermal damping term $\alpha$ represents the influence of net surface heat flux anomalies on SST anomalies over the cold tongue region. It is obtained from the linear regression between the averaged net anomalous heat flux over the 
ATL3 region and the ATL3 index (averaged SST anomalies over the ATL3 region, hereafter denoted as $\left.\langle\tilde{\mathrm{T}}\rangle_{\mathrm{E}}\right)$, as in equation 16 .

$$
\left\langle\tilde{\mathrm{Q}}_{\mathrm{net}}\right\rangle_{\mathrm{E}}=\alpha\langle\tilde{\mathrm{T}}\rangle_{\mathrm{E}}
$$

Where $\alpha$ is given in $\mathrm{W} /{ }^{\circ} \mathrm{C} \cdot \mathrm{m}^{2}$ and multiplied by $\frac{30758400 \mathrm{~s} \cdot \mathrm{yr}^{-1}}{\langle\mathrm{Z} \overline{2} 0\rangle_{\mathrm{E}} \cdot \mathrm{c}_{\mathrm{p}} \cdot \rho}$ for conversion to $\mathrm{yr}^{-1}$.

- $\mu_{\mathrm{a}}$

The parameter $\mu_{\mathrm{a}}$ represents the response of equatorial zonal wind stress to SST anomalies and is needed to calculate the ZAF, EK and TF terms. It is obtained from the linear regression between zonal wind stress anomalies $\left[\tilde{\tau}_{\mathrm{x}}\right]$ averaged over the Equatorial Atlantic $\left(3^{\circ} \mathrm{S}-3^{\circ} \mathrm{N} ; 40^{\circ} \mathrm{W}-0^{\circ}\right)$ and the ATL3 index (equation 17):

$$
\left[\tilde{\tau}_{x}\right]=\mu_{a}\langle\tilde{T}\rangle_{E}
$$

Where $\mu_{\mathrm{a}}$ is given in $\mathrm{N} /{ }^{\circ} \mathrm{C} \cdot \mathrm{m}^{2}$.

- $\beta_{\mathrm{u}}$

The parameter $\beta_{u}$ represents the effect of equatorial wind stress anomalies and geostrophic adjustment to thermocline depth gradient on zonal surface currents anomalies and is needed in the computation of the ZAF term. It is obtained as the first coefficient of the multilinear regression between averaged EEA zonal current anomalies, averaged equatorial wind stress anomalies and averaged western $\left(3^{\circ} \mathrm{S}-3^{\circ} \mathrm{N} ; 45^{\circ} \mathrm{W}-25^{\circ}\right)$ thermocline depth anomalies (equation 18):

$$
\langle\tilde{u}\rangle_{\mathrm{E}}=\beta_{\mathrm{u}}\left[\tilde{\tau}_{\mathrm{x}}\right]+\beta_{\mathrm{uh}}\langle\mathrm{Z} \tilde{2} 0\rangle_{\mathrm{W}}
$$

Where $\beta_{\mathrm{u}}$ is given in $\mathrm{ms}^{-1} / \mathrm{Nm}^{-2}$. 
- $\beta_{\mathrm{w}}$

The parameter $\beta_{\mathrm{w}}$ represents the relationship between mean upwelling in the ATL3 region and zonal wind stress across the equatorial Atlantic. It is used in the computation of the EF term and is obtained from linear regression between zonal wind stress anomalies over the equatorial Atlantic and averaged upwelling anomalies in the ATL3 region (equation 19):

$$
\langle\mathrm{H}(\overline{\mathrm{w}}) \tilde{\mathrm{w}}\rangle_{\mathrm{E}}=-\beta_{\mathrm{w}}\left[\tilde{\tau}_{\mathrm{x}}\right]
$$

Where $\beta_{\mathrm{w}}$ is given in $\mathrm{ms}^{-1} / \mathrm{Nm}^{-2}$.

- $\beta_{\mathrm{h}}$ and $\mathrm{a}_{\mathrm{h}}$

The terms $\beta_{\mathrm{h}}\left(\mathrm{m} /\left(\mathrm{N} \cdot \mathrm{m}^{-2}\right)\right)$ and $\mathrm{a}_{\mathrm{h}}\left({ }^{\circ} \mathrm{C} / \mathrm{m}\right)$ are associated with the thermocline feedback. The first represents the effect of equatorial wind stress anomalies on the zonal thermocline slope (equation 20):

$$
\langle\mathrm{Z} \tilde{2} 0\rangle_{\mathrm{E}}-\langle\mathrm{Z} \tilde{2} 0\rangle_{\mathrm{W}}=\beta_{\mathrm{h}}\left[\tilde{\tau}_{\mathrm{x}}\right]
$$

Where \langle\rangle$_{\mathrm{W}}$ denotes the average over the WATL region. The term $\mathrm{a}_{\mathrm{h}}$ reflects the effect of thermocline depth anomalies on subsurface temperature anomalies $(21)$ :

$$
\left\langle\mathrm{H}(\overline{\mathrm{w}}) \tilde{\mathrm{T}}_{\mathrm{sub}}\right\rangle_{\mathrm{E}}=\mathrm{a}_{\mathrm{h}}\langle\mathrm{Z} \tilde{2} 0\rangle_{\mathrm{E}}
$$

Where $\mathrm{T}_{\text {sub }}$ is the mean temperature from the surface to the $20^{\circ} \mathrm{C}$ isotherm. 


\section{Reanalyses Intercomparison}

In this section we compare the mean climatological fields of the variables of interest in the 7 oceanic reanalyses spanning the period 1980-2010. Next, we investigate how well the Bjerknes Feedback is represented in each product by spatial correlation analysis. Lastly, the strength of the feedback is estimated by computing the Bjerknes Feedback Index.

\subsection{Mean fields and climatologies}

\subsubsection{Sea surface temperature}

The mean SST field for the reanalyses ensemble and the difference between each reanalysis from the mean can be observed in Figure 9. The mean pattern in the ensemble (Figure 9a) shows a band of SSTs exceeding $27^{\circ} \mathrm{C}$ just north of the equator associated with the ITCZ. A region of lower SSTs off the coast of Africa and below the equator, associated with coastal upwelling and the cold tongue formation is also observed, as described by Xie and Carton (2013). The subsequent panels in Figure 9 show that GODAS and SODA have overall lower SSTs in the northern tropical Atlantic and in the cold tongue region, while CFSR has a colder northern tropical Atlantic but SSTs in the cold tongue region do not deviate much from the mean. ECDA and ORAS4 show the smallest deviation from the mean overall, with exception of the southern African coast $\left(0^{\circ}-15^{\circ} \mathrm{S}\right)$, where ECDA shows significantly higher SSTs. The largest differences are observed for GECCO2 and $\mathrm{K} 7$, the former showing higher SSTs in most of the basin (being more than $0.5^{\circ} \mathrm{C}$ warmer), in particular off the southern African coast. The latter displays a region of SSTs $0.5-1^{\circ} \mathrm{C}$ warmer in the central region of the basin and between $15^{\circ} \mathrm{N}-10^{\circ} \mathrm{S}$, with surrounding SSTs that can be $1^{\circ} \mathrm{C}$ colder than the mean. 

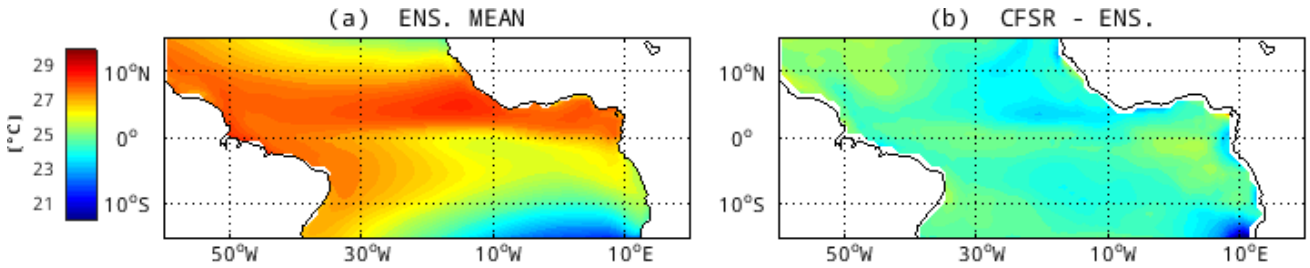

(c) ECDA - ENS.
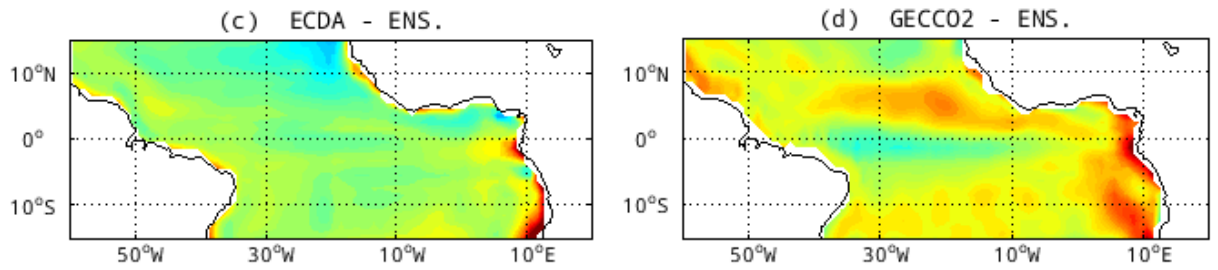

(e) GODAS - ENS.

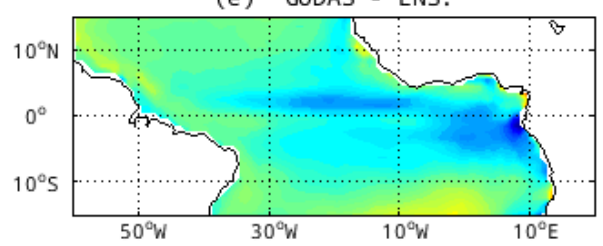

f) $\mathrm{K} 7-$ ENS.

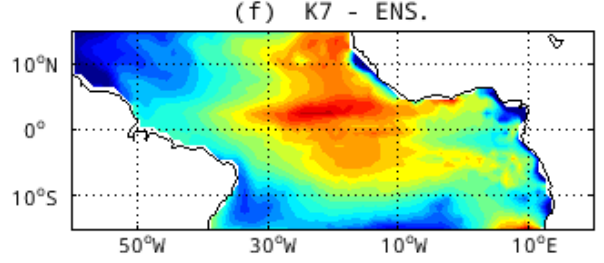

(h) SODA - ENS.
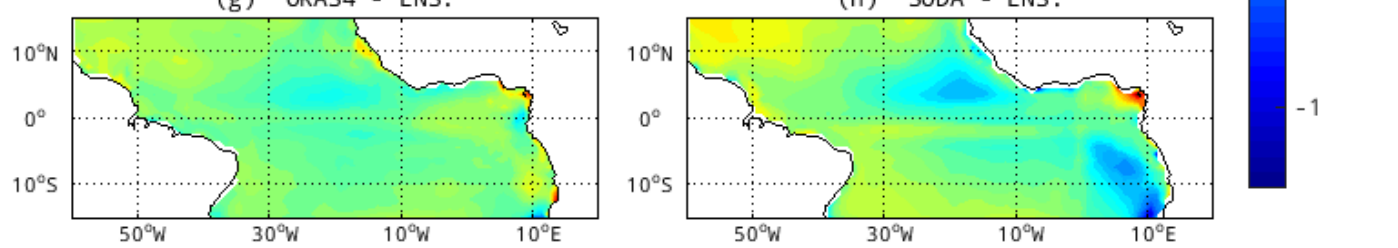

Figure 9 (a) Mean annual SST (1980-2010) for the reanalyses ensemble mean. (b) through (h) show the difference between each reanalysis and the ensemble mean.

The annual cycle of SSTs is shown in Figure 10. The band of highest SSTs associated with the ITCZ is more centered on the equator in DJF and MAM. The highest SSTs in EEA are observed in MAM, associated with the period when the southern trades are weakest (Xie and Carton, 2013). The band of warmest SSTs shifts north in JJA, when the cold tongue appears in the east. The cold tongue then starts to retreat in SON. There is a larger spread in SSTs among the reanalyses in the western equatorial Atlantic and in the cold tongue region, in all seasons. In the ATL3 region, GECCO2, K7 and GODAS are outside of the ensemble spread throughout the year, the first two having warmer and the last colder SSTs (Figure 11). Note that the spread is largest in JJA, when the cold tongue peaks. 

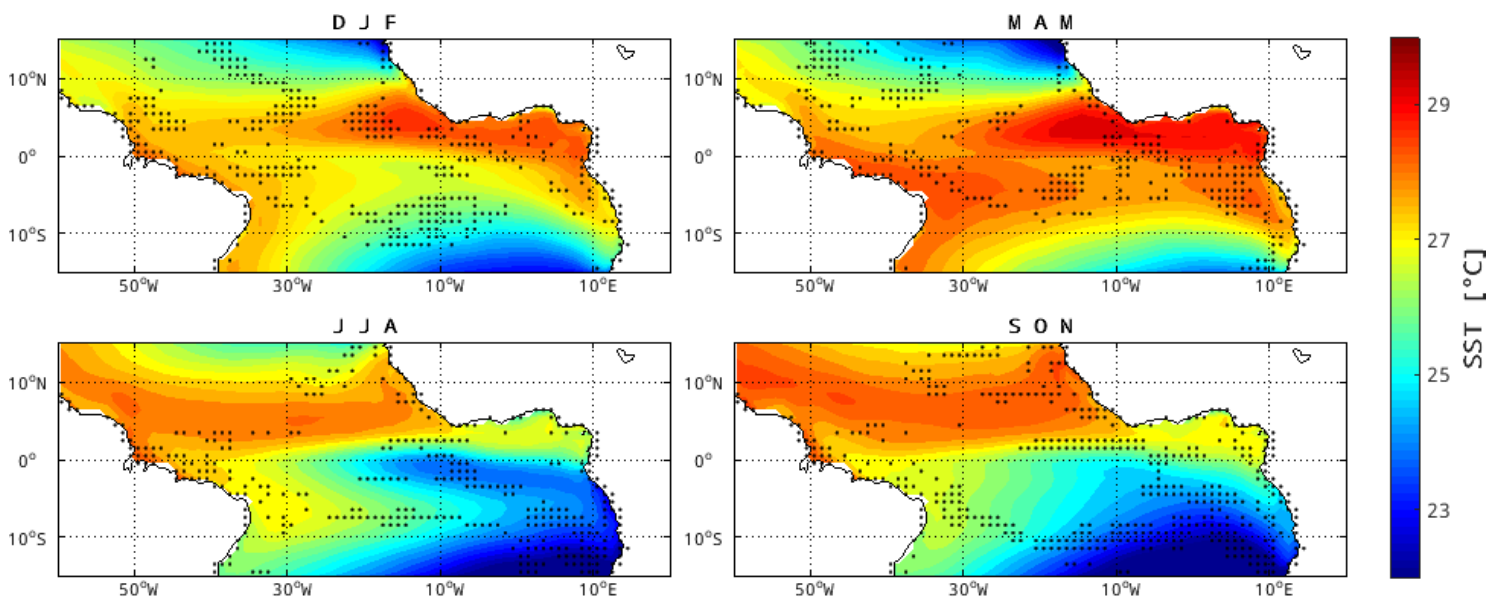

Figure 10 Seasonal SST in the ensemble mean. Stippling indicates regions where less than 5 reanalyses are within an interval of 1 standard deviation.

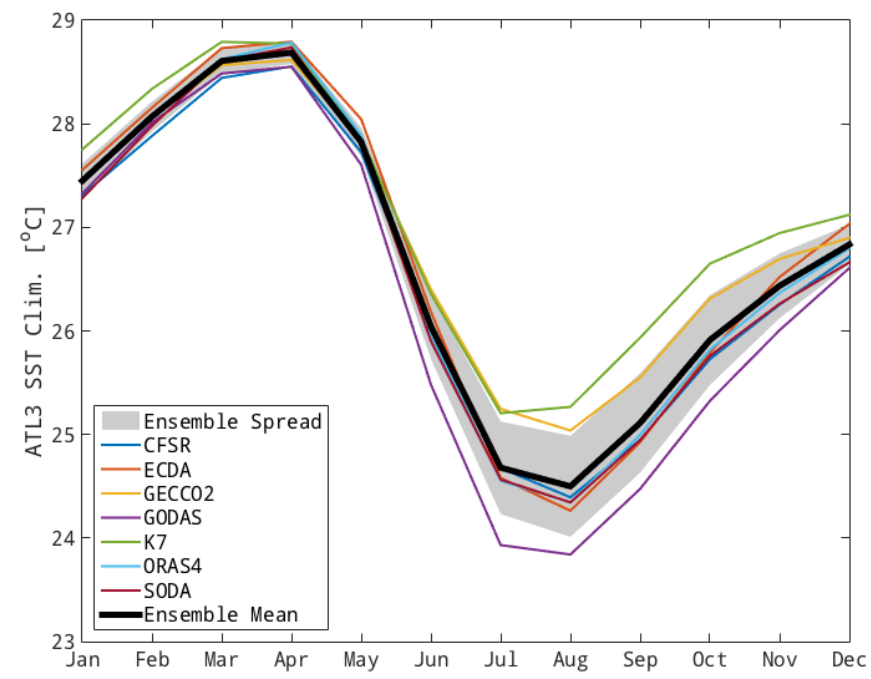

Figure 11 Annual cycle of SST for the ATL3 region. The black thick line represents the ensemble mean and shading stands for the ensemble spread (1 standard deviation).

\subsubsection{Subsurface temperature and thermocline depth}

The annual climatology of the depth of the $20^{\circ} \mathrm{C}$ isotherm in the ensemble mean and the differences between the mean and each of the reanalyses is shown in Figure 12. The mean field in Figure 12a shows a zonal gradient throughout the basin, with a deeper thermocline in the west (115-170+ $\mathrm{m}$ deep) and shallower in the east (5-60 $\mathrm{m}$ deep), as a result of the mean westward wind stress (Keenlyside and Latif, 2007). ECDA, GODAS and SODA deviate the least from the mean, while ORAS4 shows a mean equatorial thermocline around $10 \mathrm{~m}$ shallower. CFSR displays a shallower thermocline in the southeastern portion of the basin (10-25m), and a dipole-like feature in the northwest of shallower and deeper thermocline. The 
largest differences are observed again in GECCO2 and K7, wich show a deeper equatorial thermocline. The region of deeper equatorial thermocline (around $10 \mathrm{~m}$ deeper) in GECCO2 however is concentrated in the cold tongue region, while K7's equatorial thermocline is deeper than the mean $(15-25 \mathrm{~m})$ throughout the basin. This is consistent with the fact that both reanalyses also show the warmest SSTs compared to the mean.

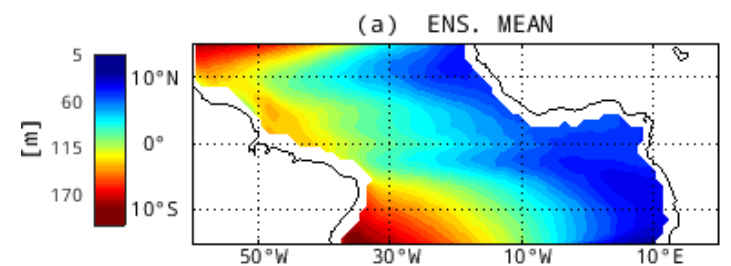

(c) ECDA - ENS.

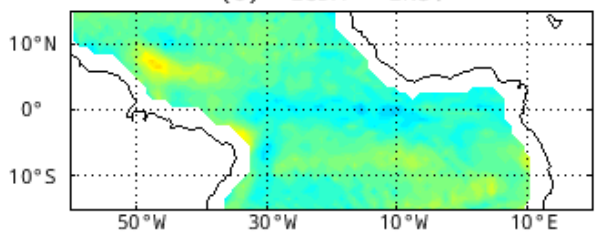

(e) GODAS - ENS.

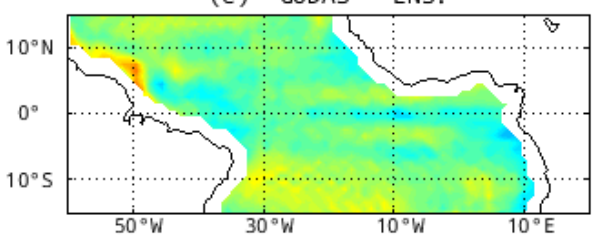

(g) ORAS4 - ENS.

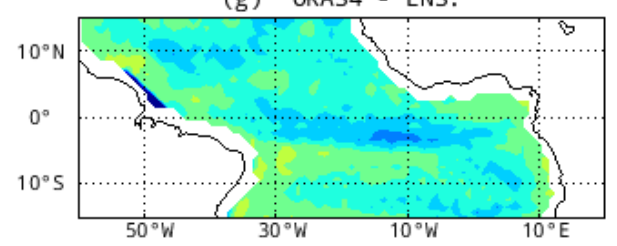

(b) CFSR - ENS.

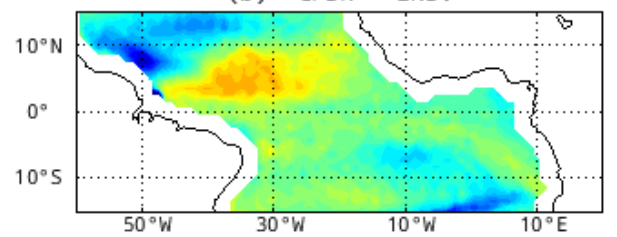

(d) GECCO2 - ENS.

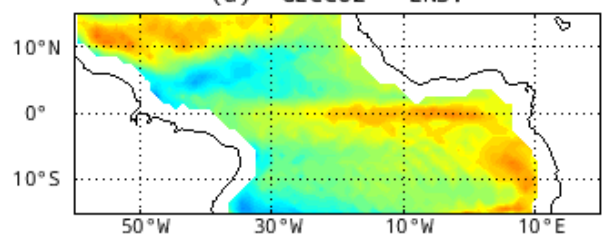

(f) $\mathrm{K} 7$ - ENS.

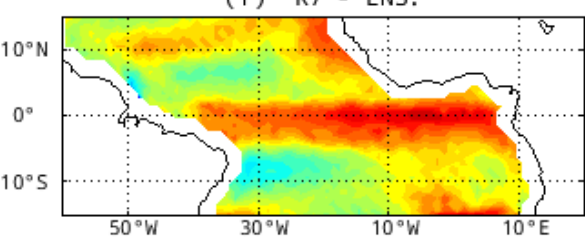

(h) SODA - ENS.

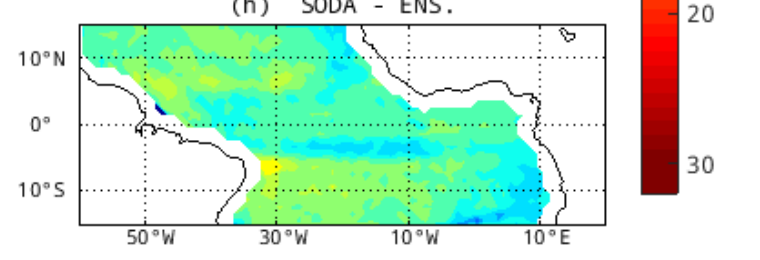

Figure 12 (a) Mean annual thermocline depth (1980-2010), for the ensemble mean. (b) through (h) show the difference between each reanalysis and the ensemble mean.

The patterns for mean subsurface temperature in the equatorial region $\left(2^{\circ} \mathrm{N}\right.$ $2^{\circ} \mathrm{S}$ ) are shown in Figure 13. The equatorial zonal slope of the thermocline is visible in Figure 13a. There is overall more variability among the reanalysis in terms of subsurface temperature than surface temperature. Note that the $20^{\circ} \mathrm{C}$ isotherm depth used to define the thermocline is the first vertical level showing a $20^{\circ} \mathrm{C}$ temperature. Differences in the subsurface temperature below Z20 therefore indicate a thermocline that is thicker than the mean (if temperatures are warmer) or shallower than the mean (if temperatures are cooler). Consistent with Figure 12, the majority of the reanalyses agree in the mean equatorial $20^{\circ} \mathrm{C}$ isotherm depth. ECDA and 
GODAS show the coolest subsurface temperatures below Z20 $\left(1-1.5^{\circ} \mathrm{C}\right.$ cooler than the mean), which indicates a sharper temperature gradient and a shallower thermocline. On the other hand, GECCO2 displays warmer temperatures $\left(1-1.5^{\circ} \mathrm{C}\right.$ warmer than the mean) below Z20, indicating a smoother temperature gradient and thicker thermocline. Despite this, the position of the $20^{\circ} \mathrm{C}$ isotherm depth does not differ much from the ensemble mean. $\mathrm{K} 7$ shows the deepest $20^{\circ} \mathrm{C}$ isotherm of all $(25 \mathrm{~m}$ deeper than the mean in the eastern half of the basin), whose underlying temperatures can be more than $2^{\circ} \mathrm{C}$ warmer, indicating its thermocline is also thicker and the vertical temperature gradient smoother. The annual cycle of the thermocline in eastern and western Atlantic is depicted in Figure 14. The equatorial thermocline in K7 is deeper both in the east (Figure 14a) and west (Figure 14b) and is a consistent outlier in the spread. Nonetheless, its seasonal zonal thermocline slope is overall within the ensemble spread, except in June-September. CFSR shows a small seasonal variation in ATL3 thermocline depth, leading to a reduced amplitude of the seasonal cycle of the equatorial thermocline slope. 

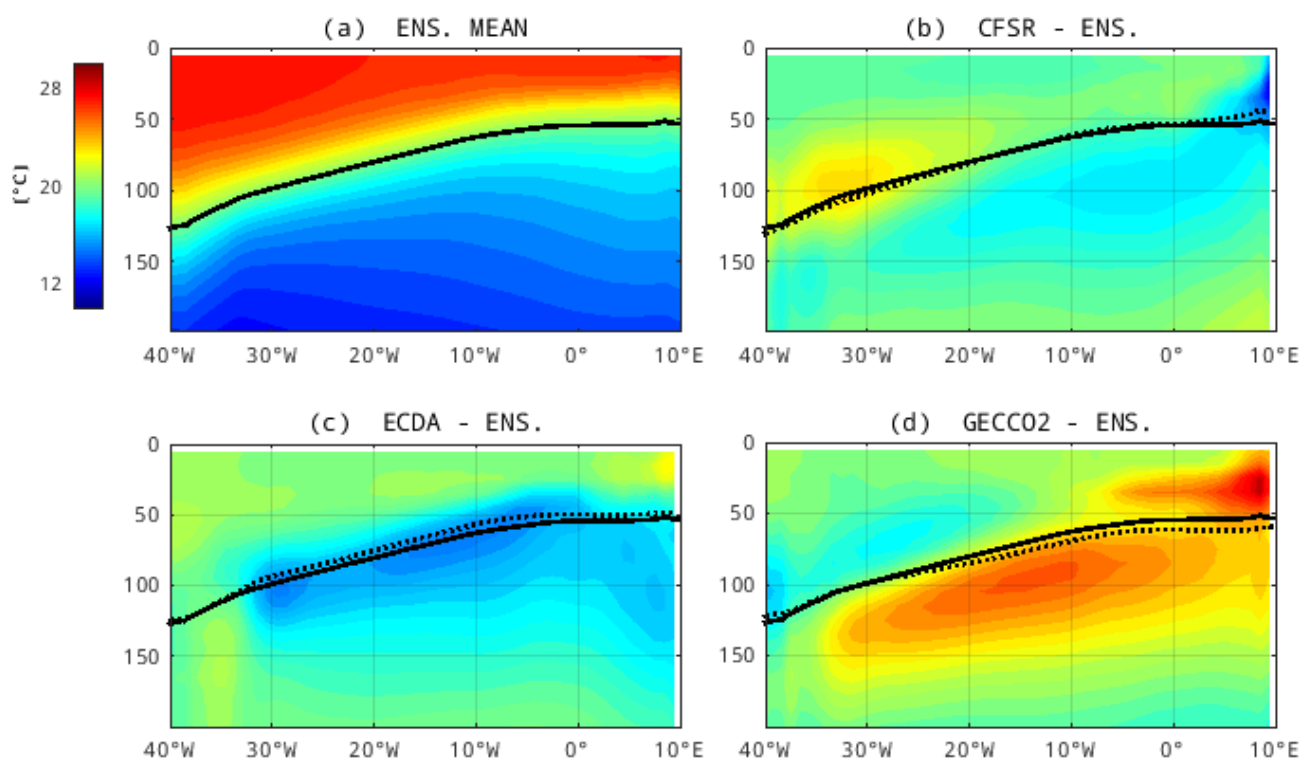

$-1.5$

(e) GODAS - ENS.
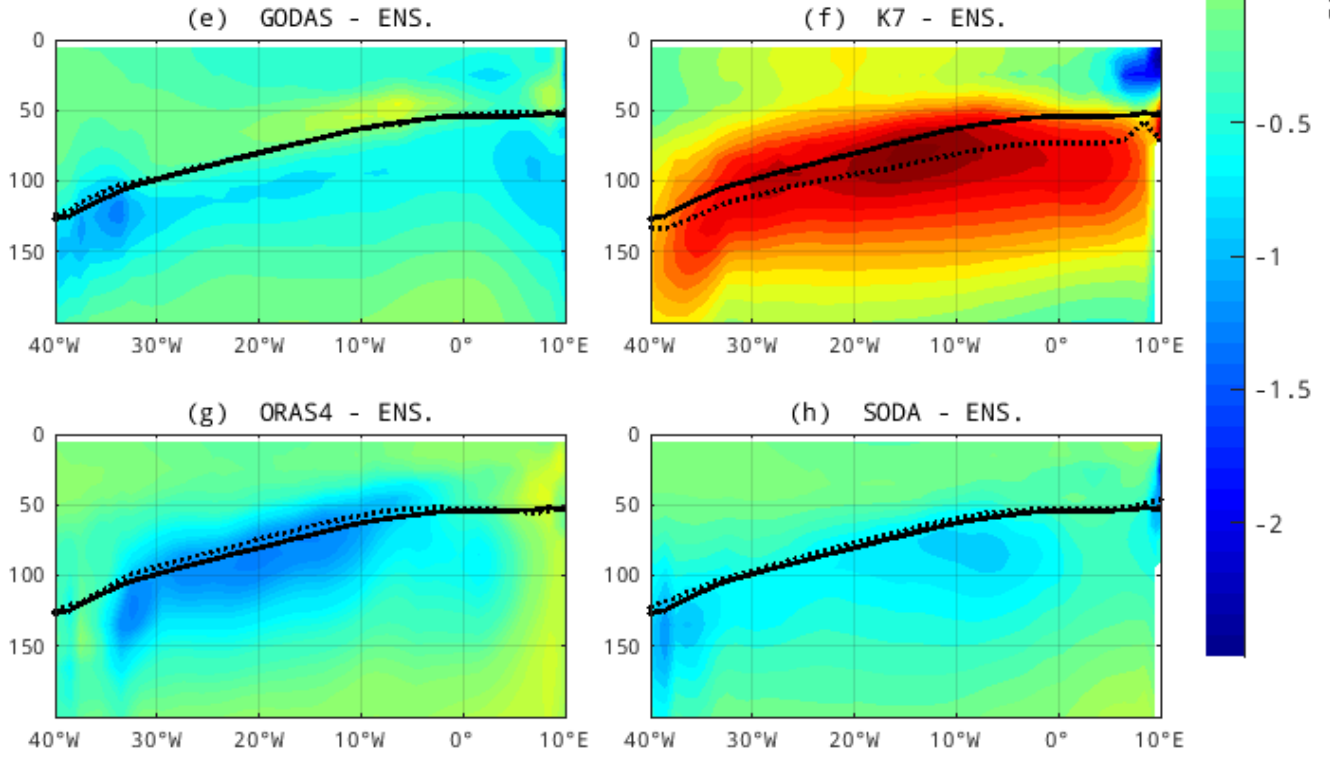

Figure 13 (a) Mean annual zonal subsurface temperature (1980-2010), between $2^{\circ} \mathrm{N}$ and $2^{\circ} \mathrm{S}$, for the ensemble mean. (b) through (h) show the difference between each reanalysis and the ensemble mean. The black solid lines indicate the mean $20^{\circ} \mathrm{C}$ isotherm depth for the ensemble and the dotted lines the mean $20^{\circ} \mathrm{C}$ isotherm depth for each reanalysis. 

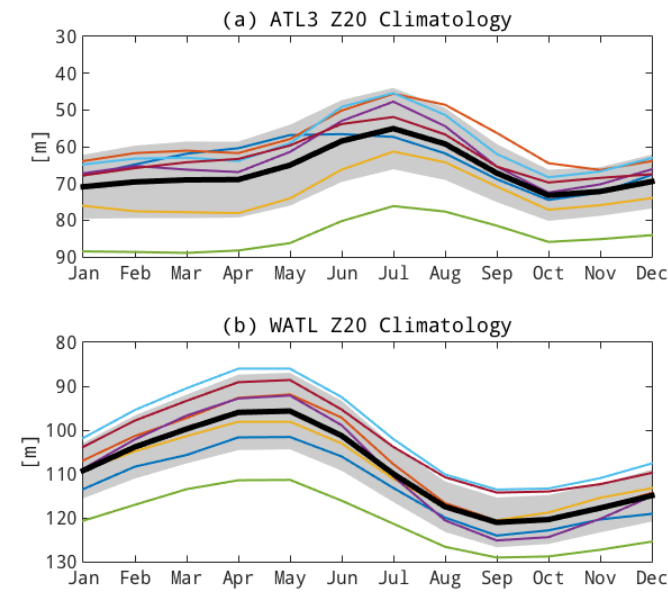

(c) $\nabla Z 20$ (ATL3-WATL)

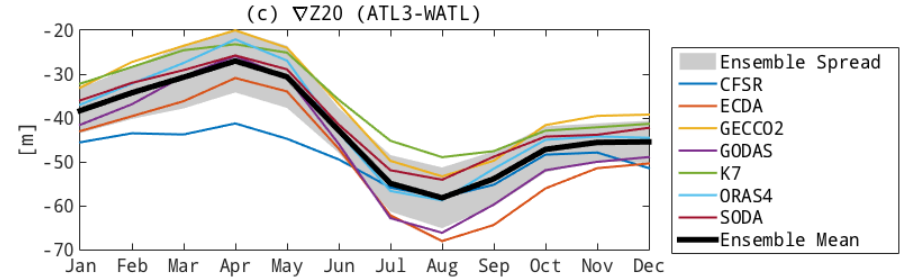

Figure 14 Annual cycle of Z20 for (a) the ATL3 region and (b) the WATL region. (c) indicates the seasonal thermocline slope (difference between Z20 in ATL3 and WATL). Note that the thermocline in ATL3 is always shallower than in WATL ( $\nabla$ Z20 is always negative). A larger (smaller) value of $\nabla Z 20$ indicates a steeper (smoother) zonal slope of the thermocline. The black thick line represents the ensemble mean and shading stands for the ensemble spread (1 standard deviation).

\subsubsection{Wind stress}

The mean annual wind stress for the ensemble mean and the difference between the mean and each reanalysis are displayed in Figure 15. The mean ITCZ can be observed slightly north of the equator, where winds are lightest and predominantly zonal (Figure 15a). The spread among the reanalysis products is lowest at the equator and increases poleward. CFSR, GECCO2, GODAS and K7 show stronger southern trades in most of the southern tropical Atlantic. In ECDA the northern trades are intensified, while the southern trades are weaker. GODAS also displays more intense northern trades. Both northern and southern trades are weaker in SODA. In ORAS4 the southern trades are weaker only along the African coast and the northern are weaker in most of the northern tropical Atlantic. 

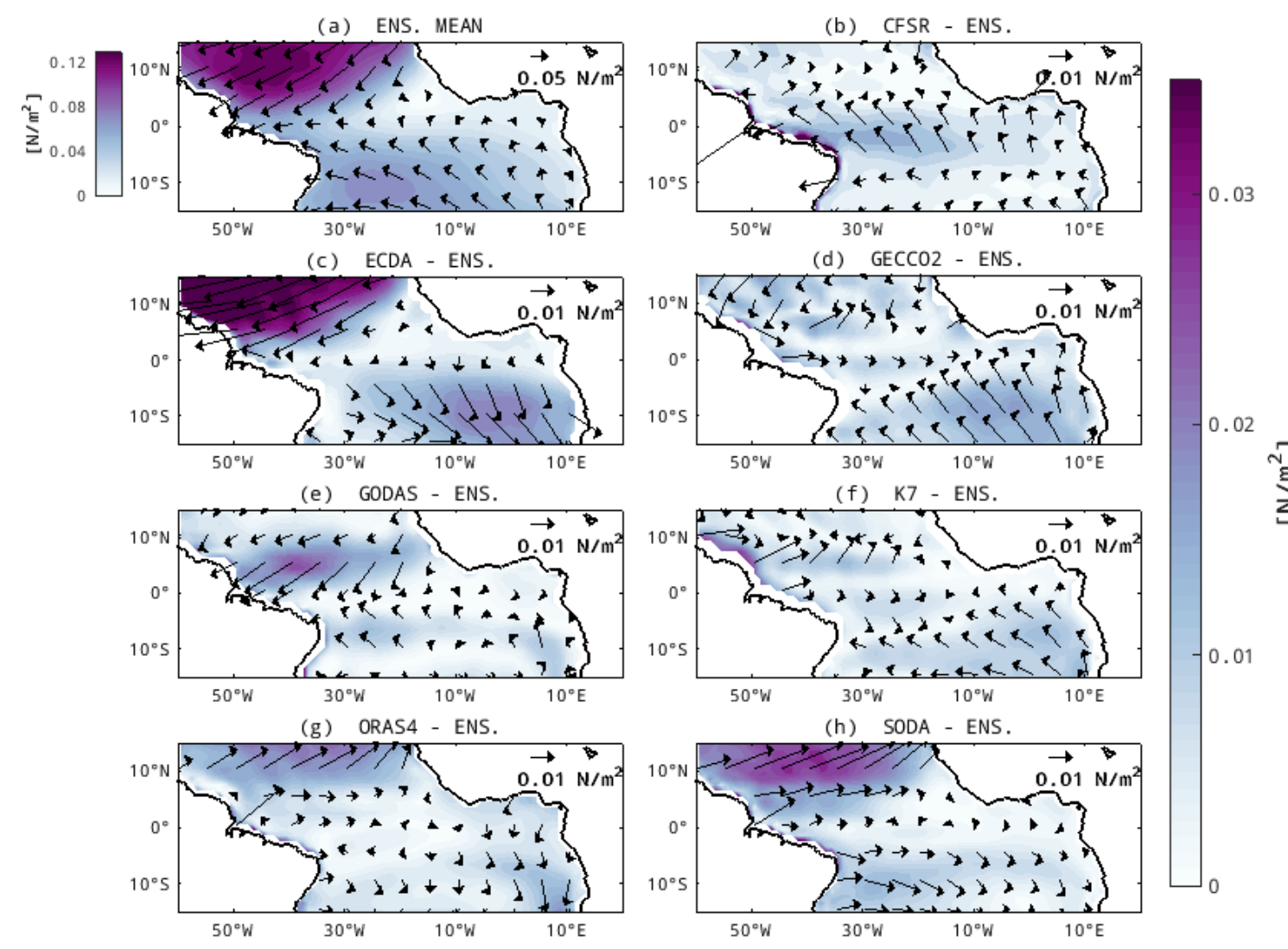

Figure 15 (a) Mean annual wind stress (1980-2010) for the reanalyses ensemble mean. (b) through (h) show the difference between each reanalysis and the ensemble mean. Shading represents the magnitude of the vectors.

By analyzing the seasonal cycle of the wind stress (Figure 16), it is observed that there is overall more agreement among the products in DJF and MAM. However, the southwestern tropical Atlantic shows more disagreement among the reanalyses for all the seasons, particularly in JJA and SON, when the southern trades are also strongest. In DJF, the ITCZ is shifted southward, and the southern, equatorcrossing trades are weaker. This begins to reverse in MAM, when the equatorial zonal winds are weakest, and in JJA, when the ITCZ can be observed further north around $10^{\circ} \mathrm{N}$, the southern trades are stronger (Li and Philander, 1997; Keenlyside and Latif, 2007; Xie and Carton, 2013). In the equatorial averaging region $\left(3^{\circ} \mathrm{N}\right.$ $\left.3^{\circ} \mathrm{S} ; 40^{\circ} \mathrm{W}-0^{\circ}\right)$, most of the reanalyses are within the spread throughout the year. The exceptions are CFSR between January-June, GODAS in June-November and GECCO2, which is outside the spread throughout the year (Figure 16). 

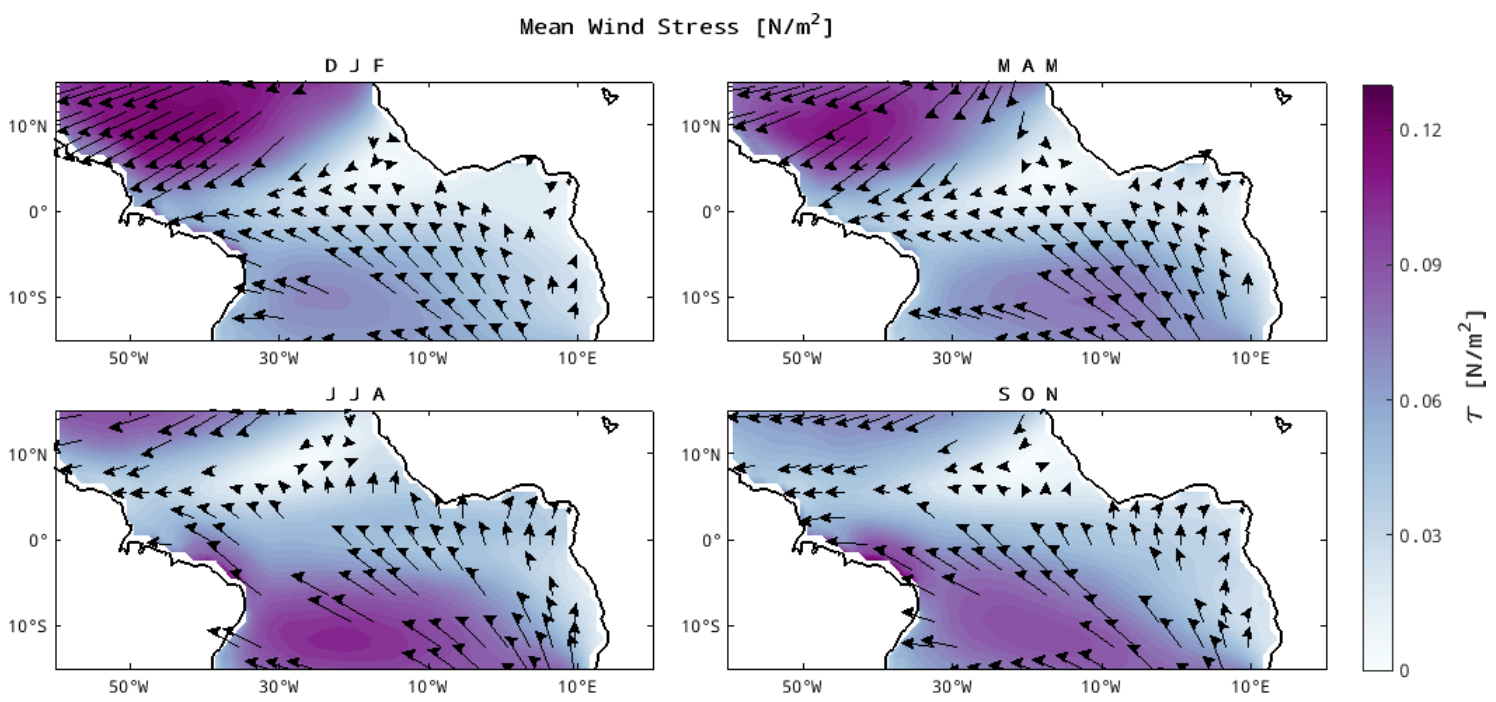

Figure 16 Annual cycle of wind stress in the ensemble mean. Shading indicates the magnitude of the wind stress and vectors are plotted where at least 5 of the reanalyses are within a 1 standard deviation interval around the mean.

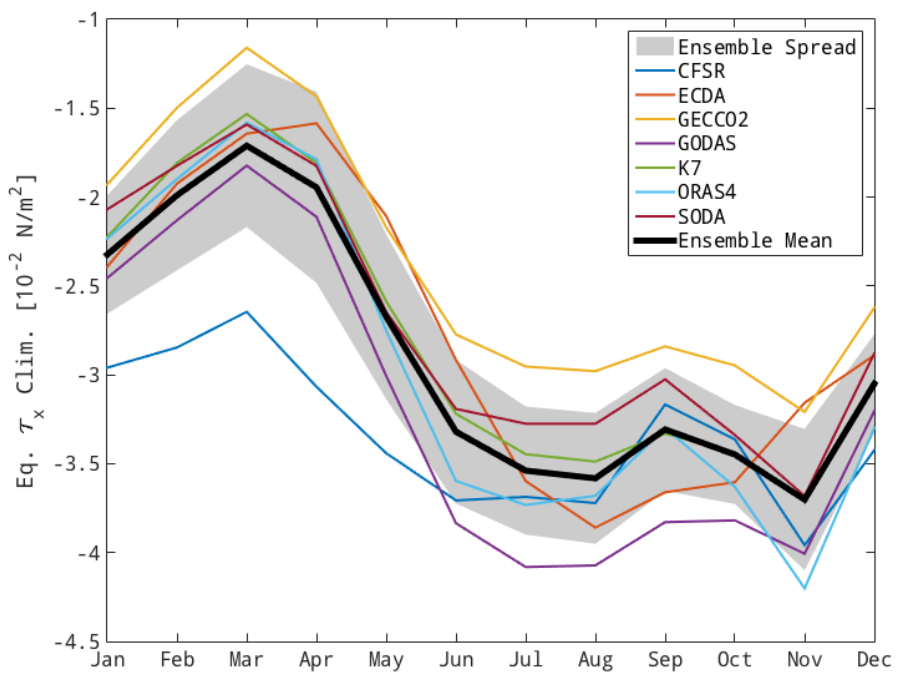

Figure 17 Annual cycle of zonal wind stress in the equatorial region $\left(3^{\circ} \mathrm{N}-3^{\circ} \mathrm{S} ; 40^{\circ} \mathrm{W}-\right.$ $\left.0^{\circ}\right)$. The black thick line represents the ensemble mean and shading stands for the ensemble spread (1 standard deviation).

\subsubsection{Surface currents}

The mean surface currents in the ensemble and the deviation from the ensemble mean for each reanalysis product is presented in Figure 18. The highest velocities are observed in the North Brazil Current (exceeding $0.6 \mathrm{~m} / \mathrm{s}$ ). The North Equatorial Counter-current can be observed between $5^{\circ} \mathrm{N}-10^{\circ} \mathrm{N}$, flanking into the Guinea Current as it reaches the African coast. The northern and central branches of the South Equatorial Current can be observed between $5^{\circ} \mathrm{N}-5^{\circ} \mathrm{S}$, as discussed in Stramma and Schott (1999). The North Brazil Current presents the most variability 
among the products. GECCO2 is overall closest to the mean for the entire ocean basin. CFSR displays a weaker South Equatorial Current in the west, while in this region it is stronger for ECDA. GODAS and K7 show more intense equatorial currents, while the northern branch of the southern Subtropical Gyre is stronger in K7. In SODA (v3.4.1), right at the equator, the currents reverse in direction. This is due to the Equatorial Undercurrent extending all the way up to the surface, which was also noted by Lübbecke and McPhaden (2013) for SODA v2.0.2-4.
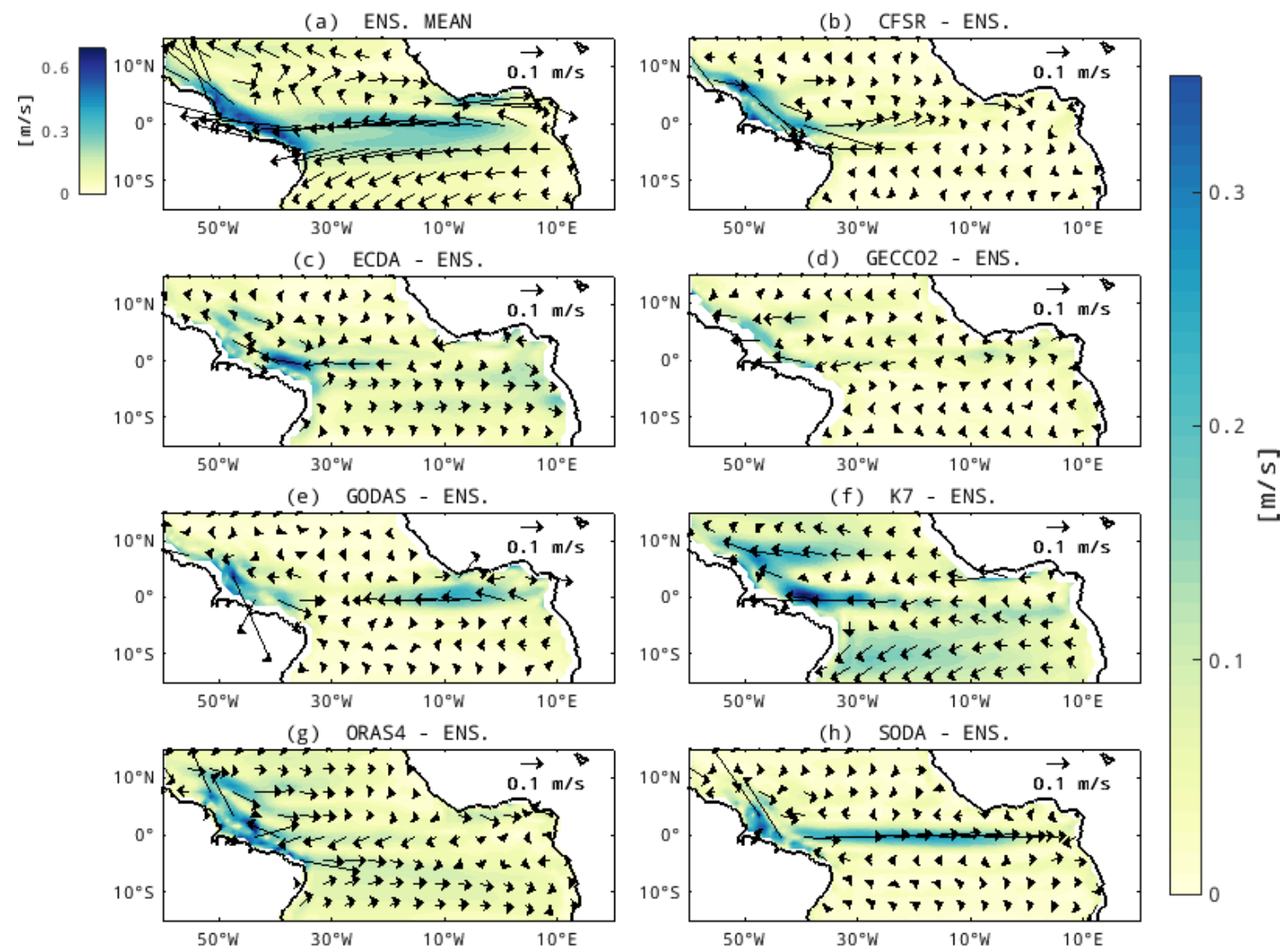

Figure 18 (a) Mean annual surface currents (1980-2010) for the reanalyses ensemble mean. (b) through (h) show the difference between each reanalysis and the ensemble mean. Shading represents the magnitude of the vectors.

The seasonality of the surface currents are shown in Figure 18. Despite the differences described above, the reanalyses in general agree well on the magnitude of the currents in each season, particularly in JJA, when the currents are most intense and the Equatorial Counter-Current and Guinea Currents are most prominent. 

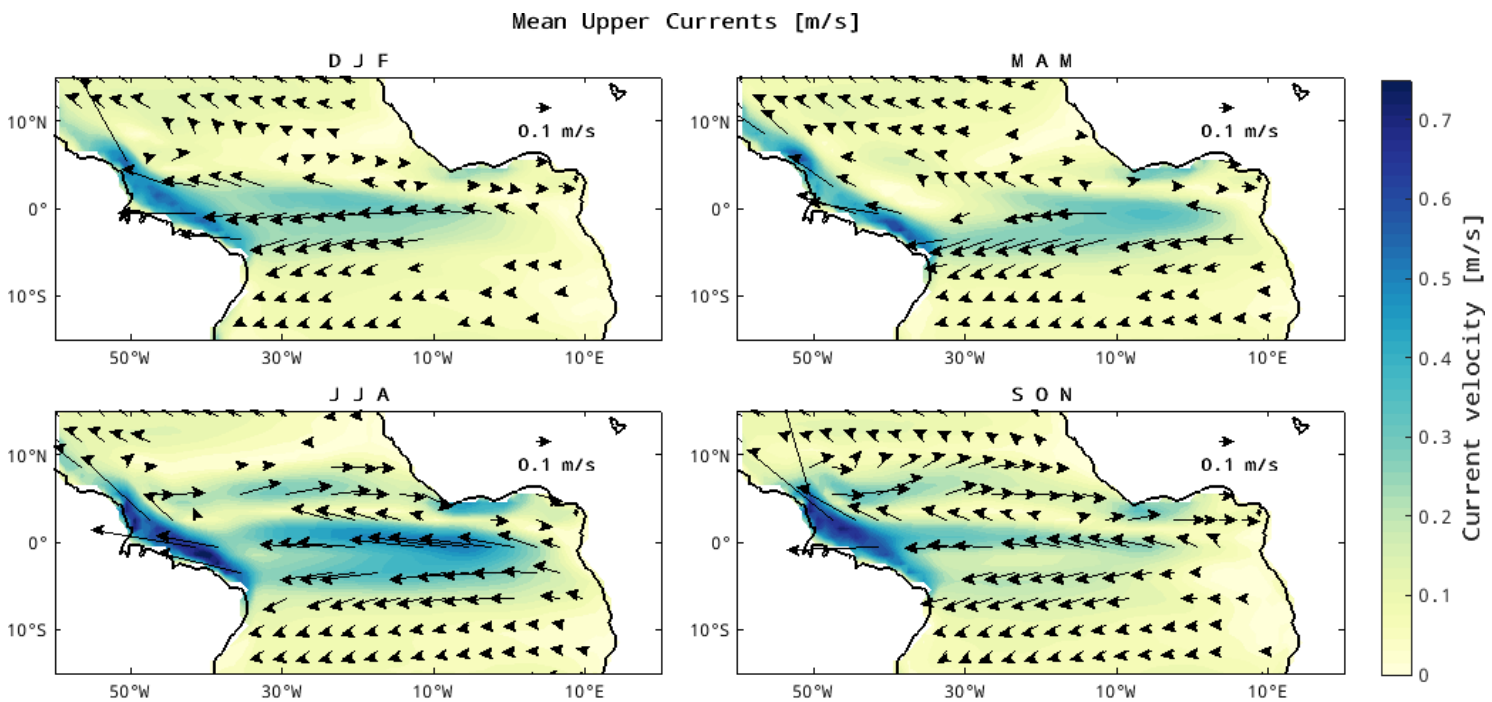

Figure 19 Seasonal surface currents in the ensemble mean. Shading indicates the currents velocities and vectors are plotted where at least 5 of the reanalyses are within a 1 standard deviation interval around the mean.

\subsection{Bjerknes Feedback analysis}

\subsubsection{Correlation patterns}

The mean spatial pattern of the Atlantic equatorial mode can be obtained by correlating the time series of the ATL3 index against SST anomalies in the basin (e.g., Zebiak, 1993). The mean JJA pattern is shown in Figure 20 for each reanalysis and for the ensemble mean. As can be observed, the pattern is centered around the equator and is strongest in EEA, where the cold tongue forms. These patterns are similar among the reanalysis in shape and strength and agree with the correlations obtained by Zebiak (1993) and Deppenmeier et al. (2016). 

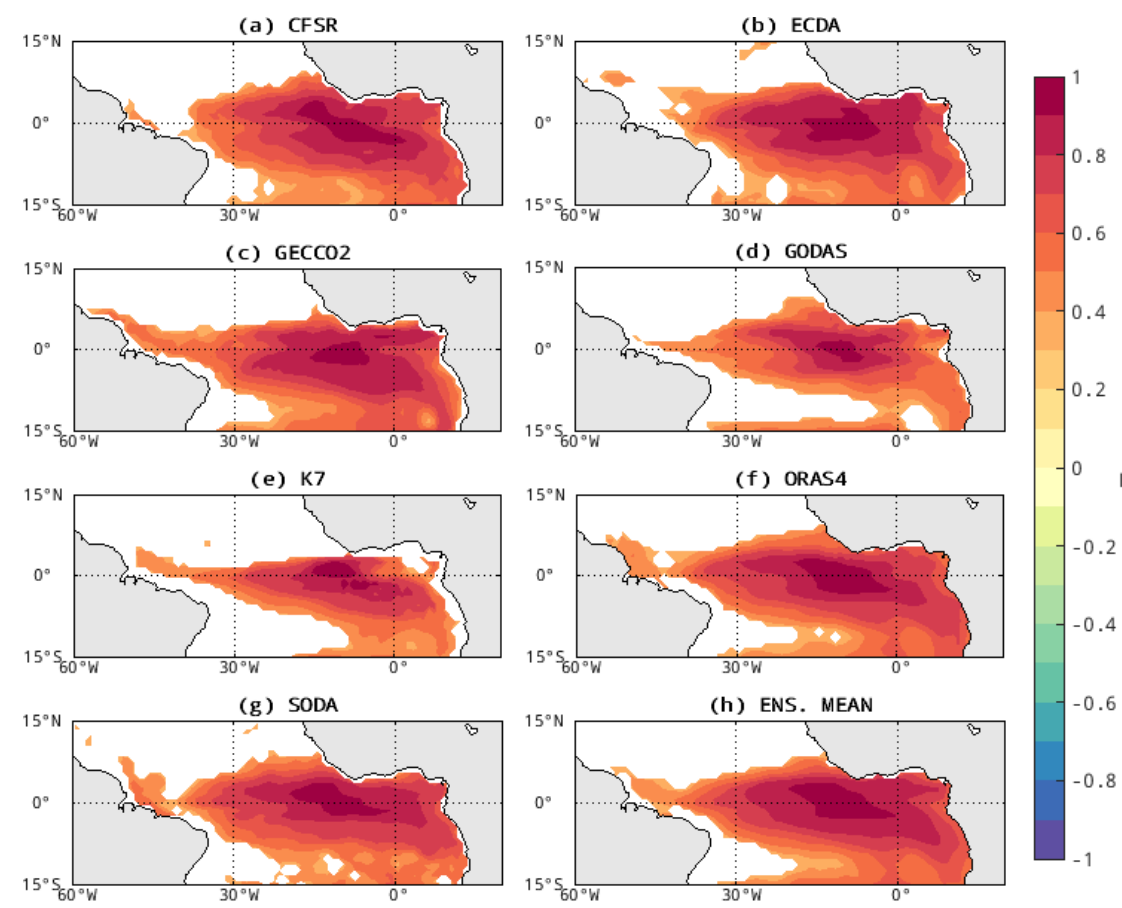

Figure 20 Spatial pattern of the Atlantic equatorial mode for each reanalysis (a-g) and the ensemble mean (h), obtained by correlating the ATL3 SST anomaly time series against SST anomalies elsewhere in the basin, for JJA (1980-2010). Only correlations significant at the $95 \%$ level are shown.

The manner in which the Bjerknes Feedback acts across the ocean basin can be analyzed by performing the spatial correlation of the anomaly time series of a certain variable against the anomaly field of a second variable, as in Keenlyside and Latif (2007) and Deppenmeier et al. (2016).

The first component taken into consideration is the influence of SST anomalies in the ATL3 region on zonal wind stress anomalies elsewhere in the ocean basin, as shown in Figure 21. In all reanalyses, a dipole pattern is noticed, with a large area of positive correlations in the western and central Equatorial Atlantic and a smaller area of negative correlations in the east. This reveals the role of positive (negative) SST anomalies in the eastern basin in weakening (intensifying) the prevailing easterly winds. The regions of negative correlation off the African coast could be related to the relationship between the formation of the cold tongue in JJA and the onset of the West African Monsoon, so that positive (negative) anomalies would weaken (strengthen) the winds flowing into the continent. Variations in the correlation patters are observed among the products. The area of influence of the eastern SSTs on equatorial winds has a larger meridional extent in ECDA, while for the other reanalyses it is more concentrated on the equator. In CFSR the response of zonal 
wind anomalies is more focused on the west.
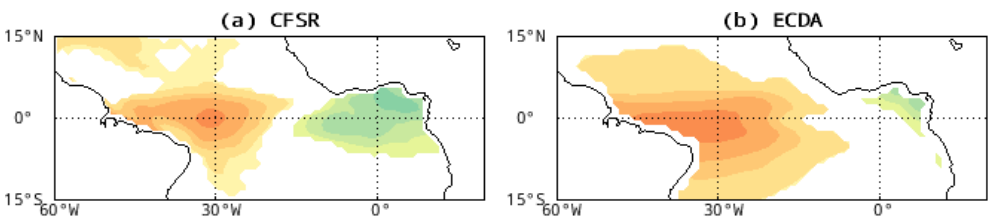

(c) GECCO2
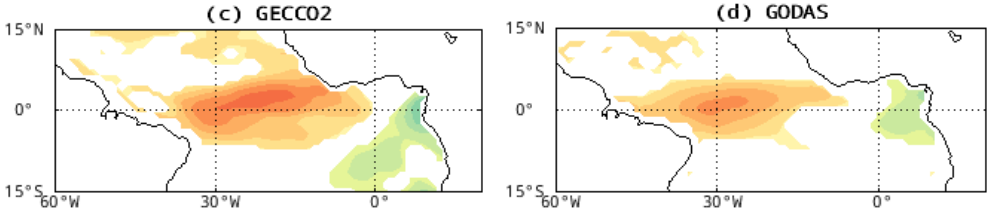

(e) $\mathrm{K7}$
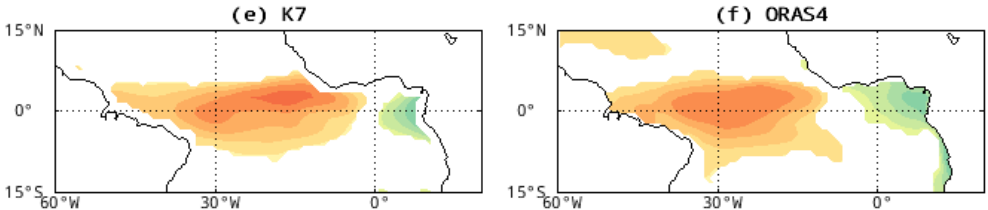

(g) SODA
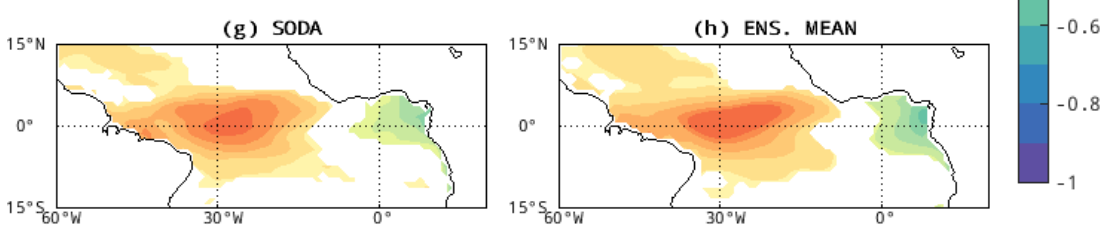

Figure 21 Correlation between ATL3 SST anomalies and zonal wind stress anomalies elsewhere, for each reanalysis (a-h) and their ensemble mean (h), considering the whole year and the period 1980-2010. Only correlations significant at the $95 \%$ level are shown.

The response of thermocline depth to such SST driven equatorial wind anomalies is shown in Figure 22. Here, correlations are computed with a one-month lag. This is done to take into account the time it takes for an equatorial Kelvin wave, generated by the zonal wind stress anomaly in the west, to travel all the way to the eastern side of the basin, as in Deppenmeier et al. (2016).

A dipole pattern is again observed, but with negative correlations in the west and positive in the east. This illustrates the response of the zonal thermocline slope to zonal wind anomalies: positive (i.e., easterly) wind anomalies shoal the thermocline in the west (negative thermocline depth anomaly), and deepens it in the east (i.e., a positive thermocline anomaly), reducing the zonal thermocline slope. Negative (i.e., westerly) wind anomalies have the opposite effect. The pattern in the east is similar in shape and extension among the reanalyses, but relatively weaker in SODA, indicating this product captures less the response of the eastern thermocline to changes in wind. There is more variation in the western pattern, with K7 showing negative correlations spanning all the western region between $15^{\circ} \mathrm{N}-15^{\circ} \mathrm{S}$ and SODA displaying the smallest correlations. By computing the correlations at different 
time lags (not shown), it is observed that they peak with one month lag and start to weaken afterwards. After four months, the positive signal in the east vanishes almost completely. Negative correlations remain in the west, although weaker (around -0.3).
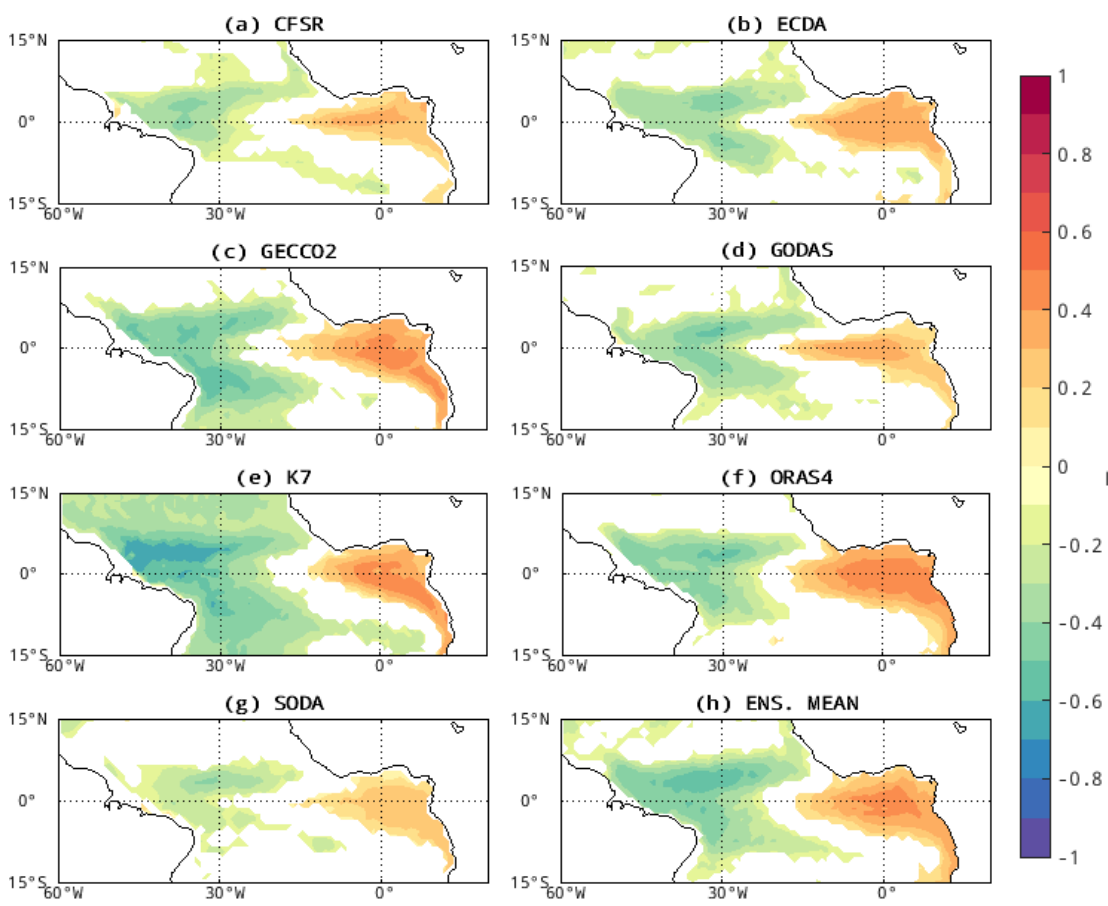

Figure 22 Correlation between equatorial $\left(40^{\circ} \mathrm{W}-0^{\circ} ; 3^{\circ} \mathrm{N}-3^{\circ} \mathrm{S}\right)$ wind stress anomalies and $20^{\circ} \mathrm{C}$ isotherm depth anomalies elsewhere, for each reanalysis (a-g) and their ensemble mean (h), considering the whole year, with a one-month lag. Only correlations significant at the $95 \%$ level are shown.

The final element of the feedback is the effect of subsurface anomalies driven by the anomalous wind on surface temperatures in the eastern basin. The correlations of subsurface temperature anomalies between $3^{\circ} \mathrm{N}-3^{\circ} \mathrm{S}$ and ATL3 SST anomalies are shown in Figure 23. The strongest couplings between surface and subsurface temperatures are observed in ECDA, GECCO2, K7 and ORAS4, with high correlations extending all the way to $200 \mathrm{~m}$ deep. Despite capturing the effect of wind anomalies on thermocline depth well, CFSR shows the weakest coupling with the subsurface, with higher correlations concentrated near the surface. 
(a) CFSR
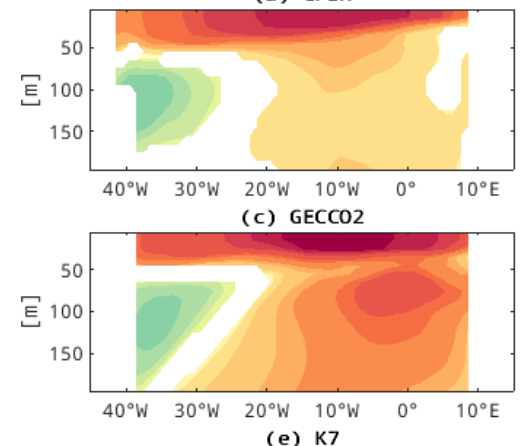

(e) $\mathrm{K} 7$

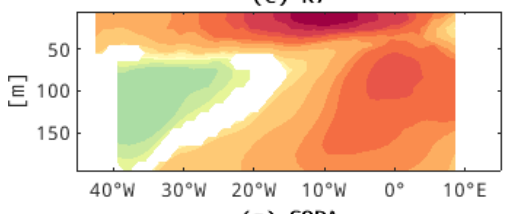

(g) SODA

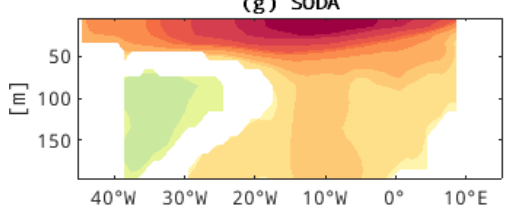

(b) ECDA

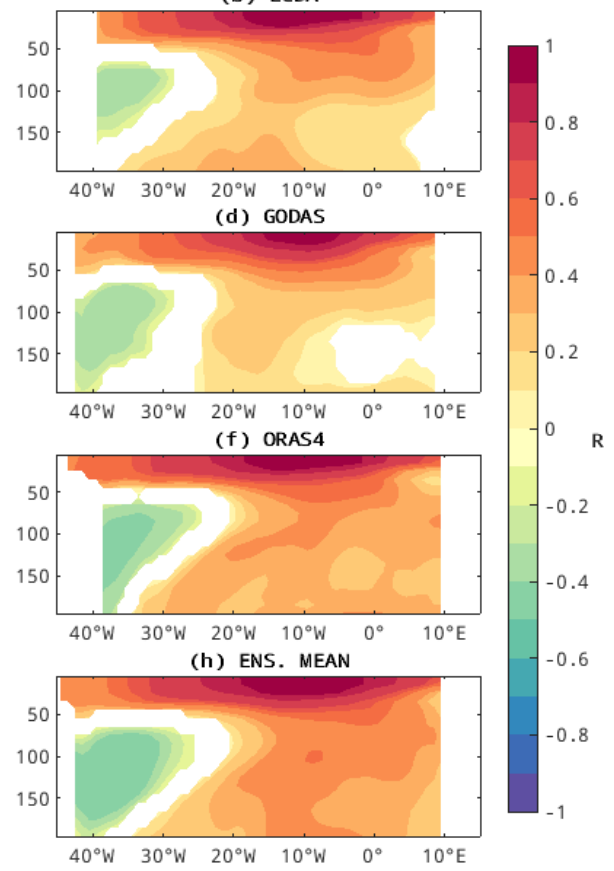

Figure 23 Correlation between ATL3 SST anomalies and equatorial $\left(3^{\circ} \mathrm{N}-3^{\circ} \mathrm{S}\right)$ subsurface temperature anomalies, for each reanalysis (a-g) and their ensemble mean (h), considering the whole year. Only correlations significant at the $95 \%$ level are shown.

\subsubsection{Bjerknes Feedback Index}

Dynamical damping (DD). The dynamical dampings obtained for each reanalysis are shown in table 2. All terms are computed based on the mean currents in the ATL3 region and from the mean ATL3 thermocline depth up to the surface. Although the ultimate effect of the mean currents is to damp the anomalies (negative total DD term in all reanalyses), differences are observed among the zonal $\left(\mathrm{DD}_{\mathrm{u}}\right)$, meridional $\left(\mathrm{DD}_{\mathrm{v}}\right)$ and vertical $\left(\mathrm{DD}_{\mathrm{w}}\right)$ components. In EEA, mean westward (eastward) currents act to enhance (damp) SST anomalies, as do mean upward (downward) vertical velocities and meridional velocities directed away from (towards the center of) the anomaly. Therefore, given the mean surface circulation in the Tropical Atlantic (e.g., Stramma and Schott, 1999), zonal, meridional and vertical contributions are expected to be positive, negative and negative, respectively. This holds true for $\mathrm{DD}_{\mathrm{v}}$ and $\mathrm{DD}_{\mathrm{w}}$ in all reanalyses. In contrast, there is more disagreement regarding $\mathrm{DD}_{\mathrm{u}}$. Four of the reanalyses (GECCO2, K7, ORAS4 and SODA) yield a negative $\mathrm{DD}_{\mathrm{u}}$. This can be related to a shallower Equatorial Undercurrent in these products. In fact, SODA displays the largest negative value of $\mathrm{DD}_{\mathrm{u}}\left(-0.77 \mathrm{yr}^{-1}\right)$, since, as discussed previously, its Equatorial Undercurrent ex- 
tends all the way up to the surface (Figure 18h). GODAS, on the other hand, has the highest positive value for this term $\left(1.24 \mathrm{yr}^{-1}\right)$, since it displays stronger westward currents in EEA (Figure 18e). In all reanalyses the meridional term has the smallest contribution, while the vertical term dominates, resulting in a net damping effect. However, the total dynamical damping is much larger than the obtained by Lübbecke and McPhaden (2013) for SODA v2.0.2-4 and NEMO-ORCA05 global circulation model. This is due to the fact that $\mathrm{DD}_{\mathrm{u}}$ is not positive and/or large enough to balance the meridional and zonal terms.

\begin{tabular}{ccccc}
\hline & $\mathrm{DD}_{\mathrm{u}}$ & $\mathrm{DD}_{\mathrm{v}}$ & $\mathrm{DD}_{\mathrm{w}}$ & $\mathrm{DD}_{\text {total }}$ \\
\hline CFSR & 0.53 & -0.68 & -2.31 & $-2.46 \pm 0.06$ \\
ECDA & 0.88 & -0.62 & -2.70 & $-2.44 \pm 0.07$ \\
GECCO2 & -0.09 & -0.46 & -1.73 & $-2.29 \pm 0.04$ \\
GODAS & 1.24 & -0.73 & -2.07 & $-1.55 \pm 0.09$ \\
K7 & -0.32 & -0.40 & -2.31 & $-3.03 \pm 0.04$ \\
ORAS4 & -0.18 & -0.62 & -2.45 & $-3.25 \pm 0.07$ \\
SODA & -0.77 & -0.55 & -0.95 & $-2.27 \pm 0.11$ \\
\hline & & & ENS. MEAN & $-2.47 \pm 0.21$ \\
\hline
\end{tabular}

Table 2: Zonal $\left(\mathrm{DD}_{\mathrm{u}}\right)$, meridional $\left(\mathrm{DD}_{\mathrm{v}}\right)$, vertical $\left(\mathrm{DD}_{\mathrm{w}}\right)$ and total dynamical damping $\left(\mathrm{DD}_{\text {total }}\right)$ obtained for each reanalysis $\left(\mathrm{yr}^{-1}\right)$, their ensemble mean and standard error.

Thermal damping (TD). The regressions performed between ATL3 SST anomalies in each reanalysis and net surface heat flux (NSHF) anomalies from TropFlux in this region to obtain the thermal damping term are shown in Figure 24. The correlation between NSHF and SST anomalies is negative, i.e., a positive (negative) SST anomaly in the ATL3 region leads to a negative (positive) NSHF anomaly, which acts to damp the SST anomaly (Frankignoul and Kestenare, 2002; Frankignoul et al., 2004). Correlations range from $R=-0.37$ to $R=-0.47$, all of which are significant at the $95 \%$ level. The smallest correlations are observed for GECCO2 and K7. The latter also has the smallest regression coefficient $\left(-10.62 \pm 2.38 \mathrm{~W} / \mathrm{m}^{2} \cdot{ }^{\circ} \mathrm{C}\right)$. The largest thermal damping is obtained from ORAS4 $\left(-14.15 \pm 2.36 \mathrm{~W} / \mathrm{m}^{2} \cdot{ }^{\circ} \mathrm{C}\right)$, which also yields the largest correlation $(R=-0.47)$. This is consistent with the re- 
sults obtained by Lübbecke and McPhaden (2013), who found a thermal damping in the ATL3 region ranging from -12.4 to $-16.5 \mathrm{~W} / \mathrm{m}^{2} \cdot{ }^{\circ} \mathrm{C}$. Results converted to $\mathrm{yr}^{-1}$ are summarized in table 3 .

\begin{tabular}{cc}
\hline & TD \\
\hline CFSR & $-1.66 \pm 0.31$ \\
ECDA & $-1.77 \pm 0.35$ \\
GECCO2 & $-1.30 \pm 0.29$ \\
GODAS & $-1.26 \pm 0.28$ \\
K7 & $-0.93 \pm 0.22$ \\
ORAS4 & $-1.79 \pm 0.30$ \\
SODA & $-1.34 \pm 0.26$ \\
\hline ENS. MEAN & $-1.44 \pm 0.12$
\end{tabular}

Table 3: Thermal damping (TD) term, in $\mathrm{yr}^{-1}$, for each reanalysis and their ensemble mean.
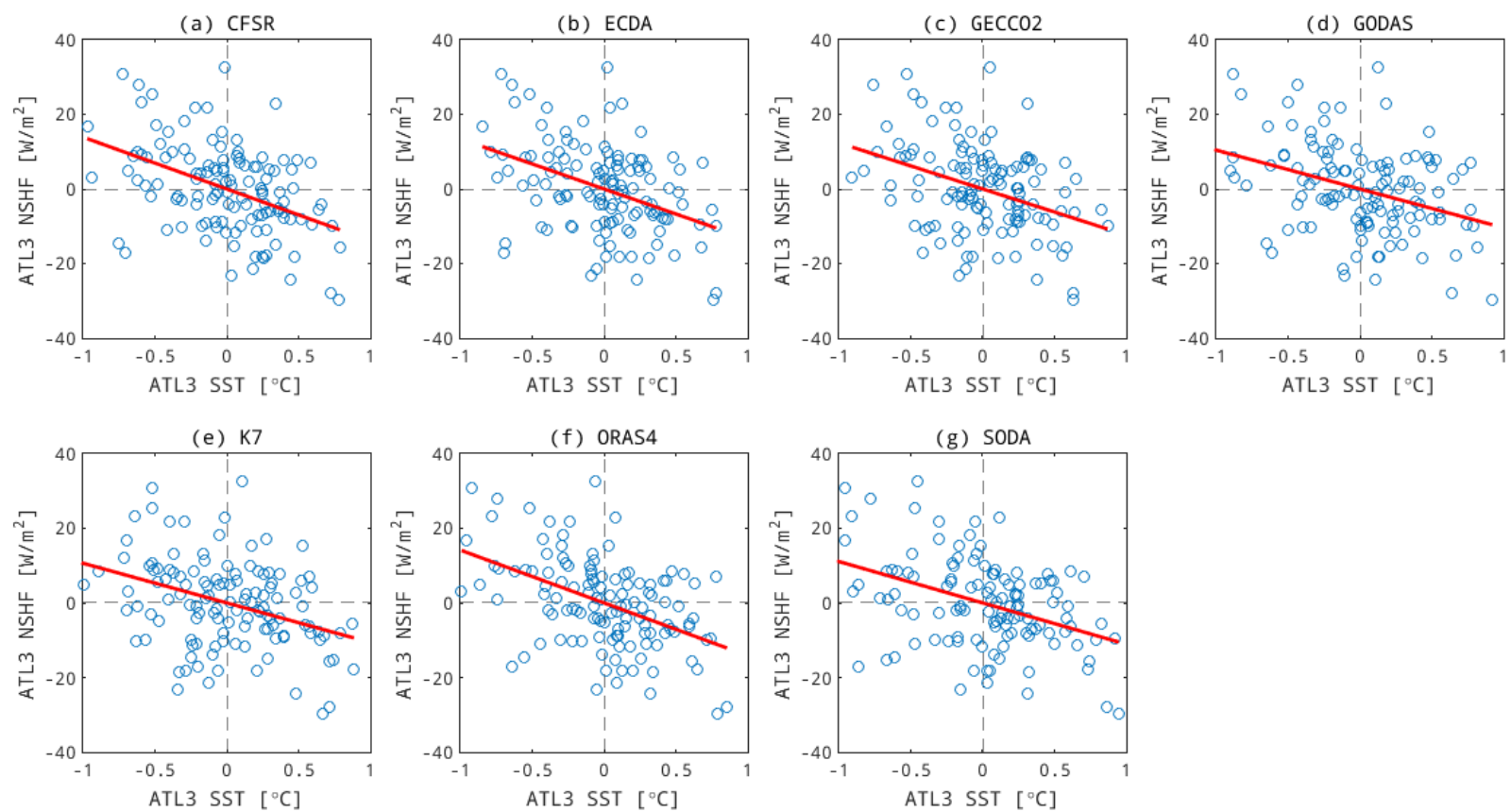

Figure 24 Thermal damping estimation from the regression between each reanalysis ATL3 SST anomalies and ATL3 NSHF anomalies from TropFlux. (a) CFSR: $\alpha=-13.89 \pm 2.55 \mathrm{Wm}^{-2} /{ }^{\circ} \mathrm{C}, \mathrm{R}=-$ 0.44 ; (b) ECDA: $\alpha=-13.42 \pm 2.66 \mathrm{Wm}^{-2} /{ }^{\circ} \mathrm{C}, \mathrm{R}=-0.41$; (c) GECCO2: $\alpha=-12.35 \pm 2.77 \mathrm{Wm}^{-2} /{ }^{\circ} \mathrm{C}$, $\mathrm{R}=-0.37$; (d) GODAS: $\alpha=-10.41 \pm 2.31 \mathrm{Wm}^{-2} /{ }^{\circ} \mathrm{C}, \mathrm{R}=-0.38$; (e) $\mathrm{K} 7: \alpha=-10.62 \pm 2.38 \mathrm{Wm}^{-2} /{ }^{\circ} \mathrm{C}$, $\mathrm{R}=-0.37$; (f) ORAS4: $\alpha=-14.15 \pm 2.36 \mathrm{Wm}^{-2} /{ }^{\circ} \mathrm{C}, \mathrm{R}=-0.47 ;(\mathrm{g}) \mathrm{SODA}: \alpha=-11.09 \pm 2.16 \mathrm{Wm}^{-2} /{ }^{\circ} \mathrm{C}$, $\mathrm{R}=-0.42$. All correlations are significant at the $95 \%$ level.

Zonal advective feedback (ZAF). The zonal advective feedback term 
depends on the parameters $\mu_{\mathrm{a}}$ and $\beta_{\mathrm{u}}$, which describe, respectively, the effect of SST anomalies on zonal wind anomalies and the effect of these wind anomalies on zonal current anomalies.

The regressions performed between ATL3 SST anomalies and zonal wind stress anomalies averaged in the equatorial region are shown in Figure 25. Correlations are in general high in all products (0.47-0.60), except in CFSR, which displays the lowest correlation $(R=0.22)$ and the lowest value for $\mu_{\mathrm{a}}\left(0.21 \pm 0.0810^{-2}\right.$ $\mathrm{N} \cdot \mathrm{m}^{-2} /{ }^{\circ} \mathrm{C}$ ). The strongest relationship is observed in ORAS4, with $\mathrm{R}=0.60$ correlation and $\mu_{\mathrm{a}}=0.69 \pm 0.0810^{-2} \mathrm{~N} \cdot \mathrm{m}^{-2} /{ }^{\circ} \mathrm{C}$. These values are similar to those found by Keenlyside and Latif $(2007)\left(0.7510^{-2} \mathrm{~N} \cdot \mathrm{m}^{-2} /{ }^{\circ} \mathrm{C}\right)$ and Lübbecke and McPhaden (2013) $\left(0.47-0.8610^{-2} \mathrm{~N} \cdot \mathrm{m}^{-2} /{ }^{\circ} \mathrm{C}\right)$.
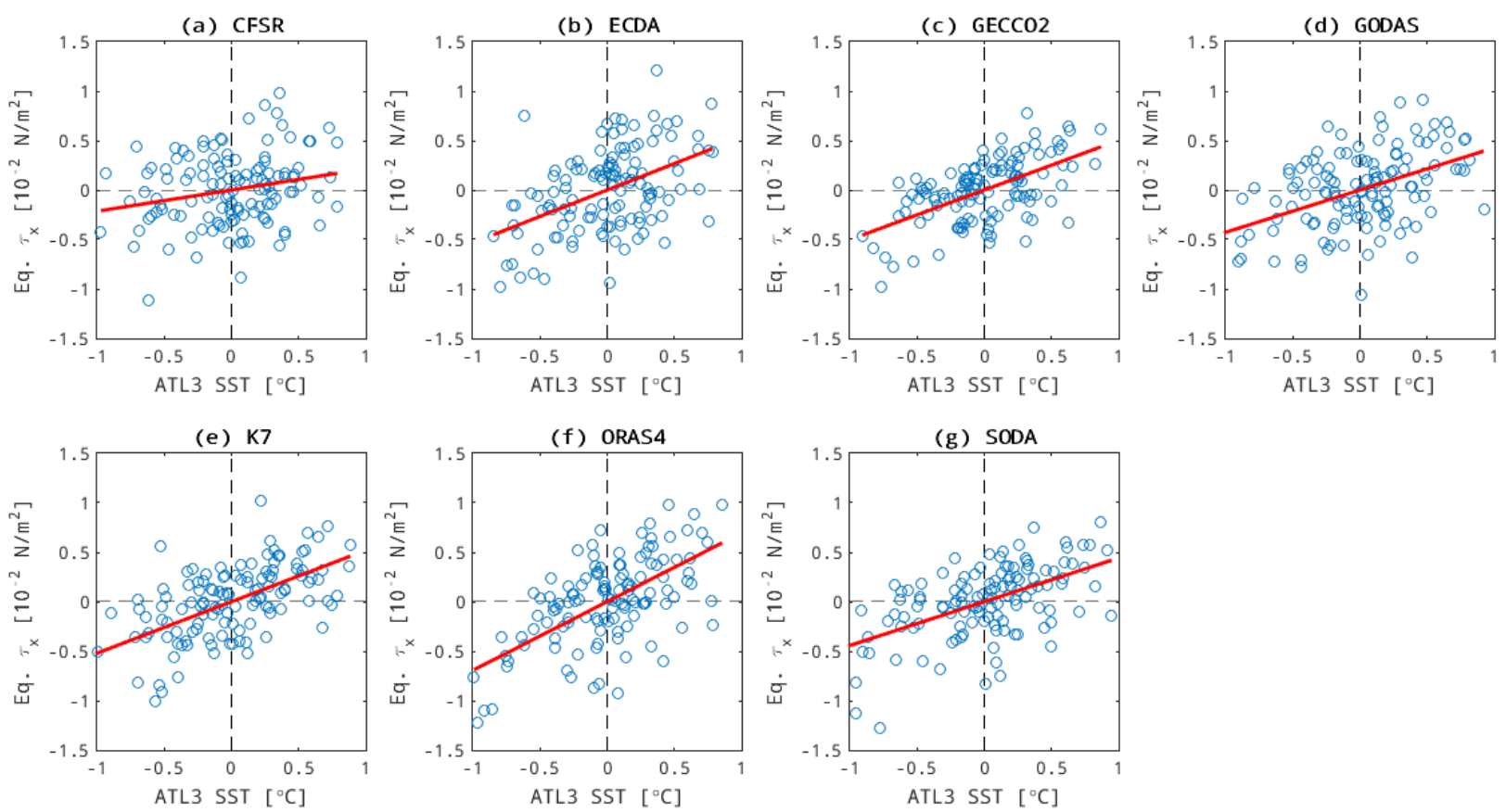

Figure 25 Equatorial zonal wind stress response to SST anomalies in the ATL3 region, estimated from the regression between ATL3 SST anomalies and mean equatorial zonal wind stress anomalies. (a) CFSR: $\mu_{\mathrm{a}}=0.21 \pm 0.0810^{-2} \mathrm{~N} \cdot \mathrm{m}^{-2} /{ }^{\circ} \mathrm{C}, \mathrm{R}=0.22$; (b) ECDA: $\mu_{\mathrm{a}}=0.53 \pm 0.0910^{-2} \mathrm{~N} \cdot \mathrm{m}^{-2} /{ }^{\circ} \mathrm{C}$, $\mathrm{R}=0.47 ;(\mathrm{c})$ GECCO2: $\mu_{\mathrm{a}}=0.50 \pm 0.0610^{-2} \mathrm{~N} \cdot \mathrm{m}^{-2} /{ }^{\circ} \mathrm{C}, \mathrm{R}=0.57$; (d) GODAS: $\mu_{\mathrm{a}}=0.42 \pm 0.0710^{-2}$ $\mathrm{N} \cdot \mathrm{m}^{-2} /{ }^{\circ} \mathrm{C}, \mathrm{R}=0.47$; (e) K7: $\mu_{\mathrm{a}}=0.52 \pm 0.0610^{-2} \mathrm{~N} \cdot \mathrm{m}^{-2} /{ }^{\circ} \mathrm{C}, \mathrm{R}=0.59 ;$ (f) ORAS4: $\mu_{\mathrm{a}}=0.69 \pm 0.08$ $10^{-2} \mathrm{~N} \cdot \mathrm{m}^{-2} /{ }^{\circ} \mathrm{C}, \mathrm{R}=0.60 ;(\mathrm{g}) \mathrm{SODA}: \mu_{\mathrm{a}}=0.44 \pm 0.0610^{-2} \mathrm{~N} \cdot \mathrm{m}^{-2} /{ }^{\circ} \mathrm{C}, \mathrm{R}=0.55$. All correlations are significant at the $95 \%$ level.

The regressions performed between the equatorial zonal wind stress and WATL thermocline depth anomalies against ATL3 zonal current anomalies are shown in Figure 26. Since the second regression coefficient $\beta_{u h}$ is not statistically significant in any of the products, only the first coefficient $\beta_{u}$ is shown. Correlations 
vary greatly among the reanalyses. SODA displays the lowest correlation $(\mathrm{R}=0.13)$, as well as the lowest regression slope $\left(\beta_{\mathrm{u}}=6.32 \pm 1.92 \mathrm{~m} \cdot \mathrm{s}^{-1} / \mathrm{N} \cdot \mathrm{m}^{-2}\right)$, as the scatter is concentrated around the vertical axis (fig. 26g). The second smallest correlation and regression slope are observed in CFSR $\left(\mathrm{R}=0.22, \beta_{\mathrm{u}}=8.80 \pm 1.17\right.$ $\left.\mathrm{m} \cdot \mathrm{s}^{-1} / \mathrm{N} \cdot \mathrm{m}^{-2}\right)$. All other products display relatively large correlations (0.41-0.52) and regression coefficients $\left(11.06-16.16 \mathrm{~m} \cdot \mathrm{s}^{-1} / \mathrm{N} \cdot \mathrm{m}^{-2}\right)$. Lübbecke and McPhaden (2013) obtain a similar value for SODA v2.0.2-4 $\left(18.76 \pm 6.04 \mathrm{~m} \cdot \mathrm{s}^{-1} / \mathrm{N} \cdot \mathrm{m}^{-2}\right)$.
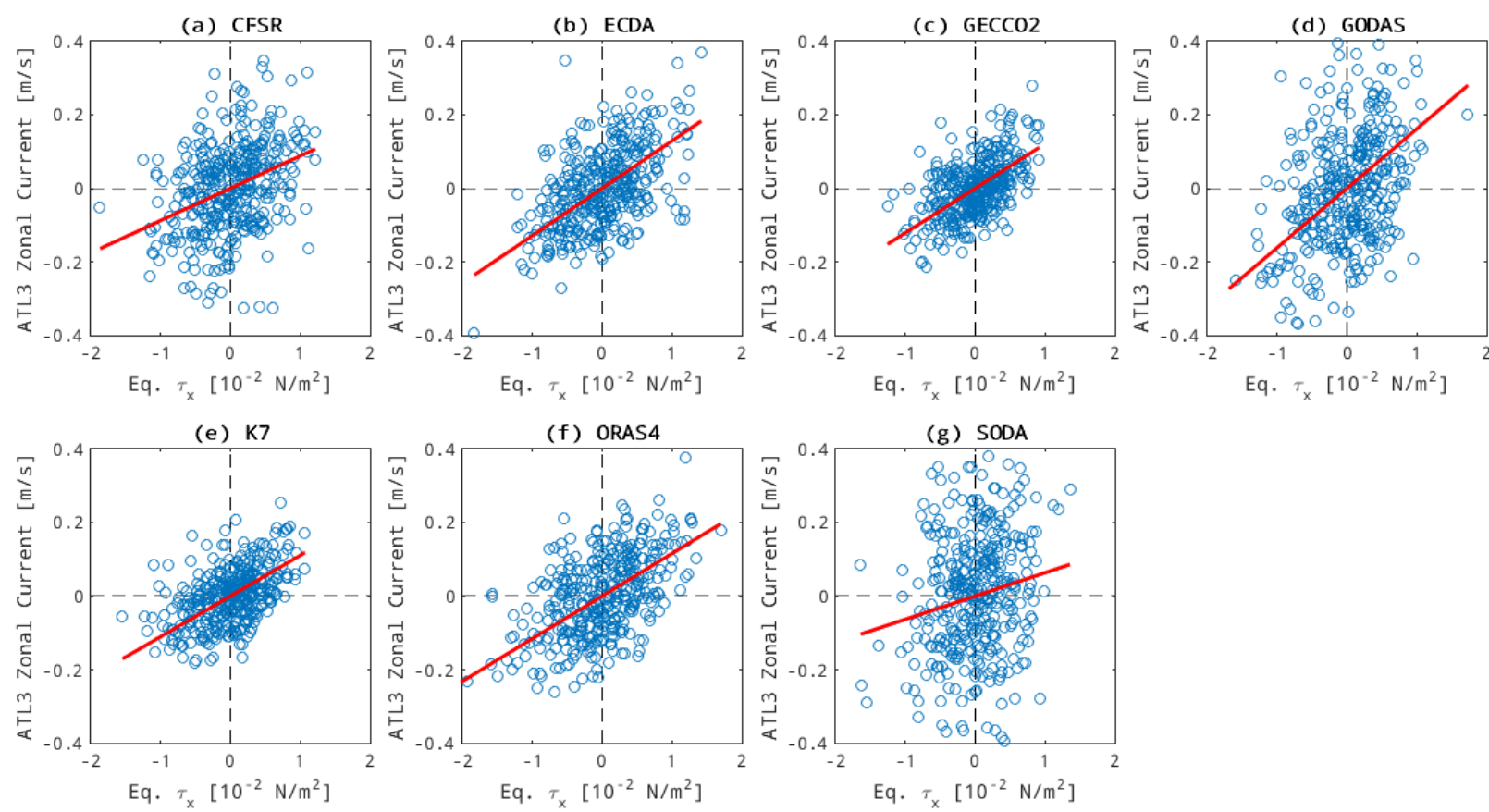

Figure 26 Zonal current anomalies response to equatorial wind stress anomalies, estimated from multi-linear regression between the equatorial zonal wind stress and WATL thermocline anomalies and ATL3 zonal currents. In all reanalysis only the first coefficient $\beta_{u}$ is statistically significant. (a) CFSR: $\beta_{\mathrm{u}}=8.80 \pm 1.17 \mathrm{~m} \cdot \mathrm{s}^{-1} / \mathrm{N} \cdot \mathrm{m}^{-2}, \mathrm{R}=0.22$; (b) ECDA: $\beta_{\mathrm{u}}=12.89 \pm 0.88 \mathrm{~m} \cdot \mathrm{s}^{-1} / \mathrm{N} \cdot \mathrm{m}^{-2}$, $\mathrm{R}=0.52 ;$ (c) GECCO2: $\beta_{\mathrm{u}}=12.11 \pm 0.84 \mathrm{~m} \cdot \mathrm{s}^{-1} / \mathrm{N} \cdot \mathrm{m}^{-2}, \mathrm{R}=0.47 ;$ (d) GODAS: $\beta_{\mathrm{u}}=16.16 \pm 1.45$ $\mathrm{m} \cdot \mathrm{s}^{-1} / \mathrm{N} \cdot \mathrm{m}^{-2}, \mathrm{R}=0.41 ;(\mathrm{e}) \mathrm{K} 7: \beta_{\mathrm{u}}=11.06 \pm 0.84 \mathrm{~m} \cdot \mathrm{s}^{-1} / \mathrm{N} \cdot \mathrm{m}^{-2}, \mathrm{R}=0.42$; (f) ORAS4: $\beta_{\mathrm{u}}=$ $11.58 \pm 0.80 \mathrm{~m} \cdot \mathrm{s}^{-1} / \mathrm{N} \cdot \mathrm{m}^{-2}, \mathrm{R}=0.42 ;(\mathrm{g}) \mathrm{SODA}: \beta_{\mathrm{u}}=6.32 \pm 1.92 \mathrm{~m} \cdot \mathrm{s}^{-1} / \mathrm{N} \cdot \mathrm{m}^{-2}, \mathrm{R}=0.13$. All correlations are significant at the $95 \%$ level.

Table 4 shows the mean zonal SST gradients in the ATL3 region required to compute the zonal advective feedback term, and the total ZAF in each reanalysis. All reanalysis but K7 have a positive value for the ZAF term. This happens because it displays a positive mean zonal SST gradient in the ATL3 region, as opposed to what is expected in this region. Since the regression coefficients are positive, this results in a negative ZAF term (see equation 15). All other reanalysis show a positive ZAF, since this feedback acts to enhance the SST anomalies. Similar values were obtained by Lübbecke and McPhaden (2013). 


\begin{tabular}{ccc}
\hline & $\langle\mathrm{dT} / \mathrm{dx}\rangle_{\mathrm{E}}$ & $\mathrm{ZAF}$ \\
\hline CFSR & -10.26 & $0.06 \pm 0.03$ \\
ECDA & -4.22 & $0.09 \pm 0.02$ \\
GECCO2 & -11.86 & $0.23 \pm 0.04$ \\
GODAS & -0.79 & $0.02 \pm 0.00$ \\
K7 & 25.70 & $-0.47 \pm 0.09$ \\
ORAS4 & -12.96 & $0.33 \pm 0.06$ \\
SODA & -7.63 & $0.07 \pm 0.03$ \\
\hline & ENS. MEAN & $0.05 \pm 0.09$ \\
\hline
\end{tabular}

Table 4: Zonal mean SST gradient in the ATL3 region $\left(10^{-8 \circ} \mathrm{C} / \mathrm{m}\right)$ and total ZAF in each reanalysis $\left(\mathrm{yr}^{-1}\right)$.

Ekman feedback (EF). In addition to the effect of ATL3 SST anomalies on zonal equatorial wind anomalies $\left(\mu_{\mathrm{a}}\right)$, the EF term also considers the influence of such wind anomalies on upwelling in the ATL3 region (multiplied by -1; see equation 19). The regressions between zonal equatorial winds anomalies and upwelling anomalies in the ATL3 region are shown in Figure 27. Strong correlations are observed in GECCO2 $(\mathrm{R}=0.64), \mathrm{K} 7(\mathrm{R}=0.66)$ and ORAS4 $(\mathrm{R}=0.55)$. All correlations are significant at the $95 \%$ level, except for SODA, for which it is significant at the $90 \%$ level only. SODA also has the smallest correlation $(\mathrm{R}=0.15)$ between zonal wind and upwelling anomalies and the smallest regression coefficient $\left(\beta_{\mathrm{w}}=4.72 \pm 2.83\right.$ $\left.10^{-5} \mathrm{~m} \cdot \mathrm{s}^{-1} /\left(\mathrm{N} \cdot \mathrm{m}^{-2}\right)\right)$. ORAS4 has the second smallest coefficient $\left(\beta_{\mathrm{w}}=5.47 \pm 0.75\right.$ $\left.10^{-5} \mathrm{~m} \cdot \mathrm{s}^{-1} /\left(\mathrm{N} \cdot \mathrm{m}^{-2}\right)\right)$. The value of $\beta_{\mathrm{w}}$ is similar in all other products, ranging from $7.88 \times 10^{-5}$ to $9.66 \times 10^{-5} \mathrm{~m} \cdot \mathrm{s}^{-1} /\left(\mathrm{N} \cdot \mathrm{m}^{-2}\right)$. Lübbecke and McPhaden (2013) found a range of $2.8-13.5 \times 10^{-5} \mathrm{~m} \cdot \mathrm{s}^{-1} /\left(\mathrm{N} \cdot \mathrm{m}^{-2}\right)$, although the correlations found were less statistically significant. 

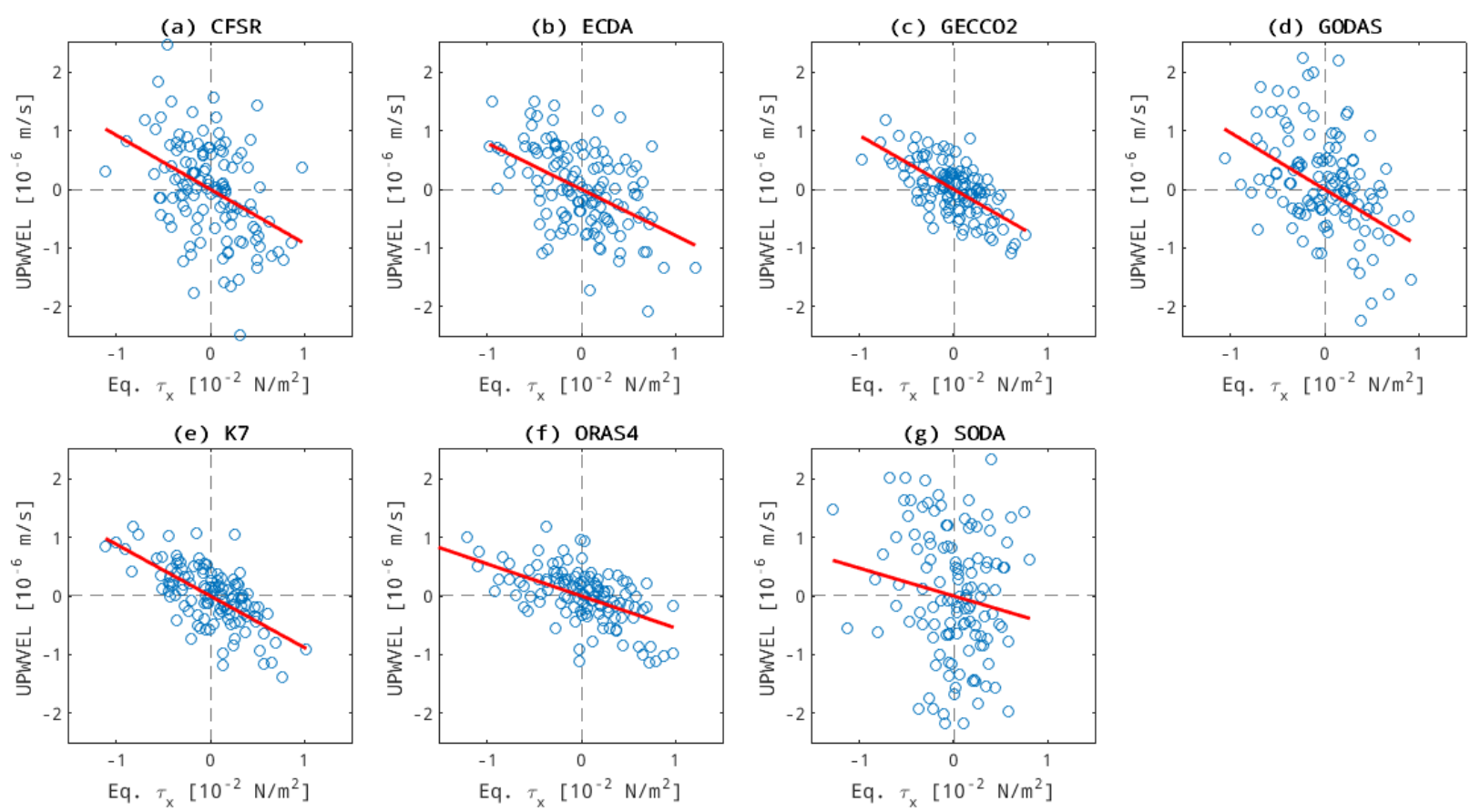

Figure 27 Cold tongue upwelling response to zonal wind stress, estimated from regression between mean equatorial zonal wind stress anomalies and ATL3 upwelling anomalies (multiplied by -1). (a) CFSR: $\beta_{\mathrm{w}}=9.24 \pm 1.8510^{-5} \mathrm{~m} \cdot \mathrm{s}^{-1} /\left(\mathrm{N} \cdot \mathrm{m}^{-2}\right), \mathrm{R}=0.41 ;$ (b) ECDA: $\beta_{\mathrm{w}}=7.88 \pm 1.3210^{-5}$ $\mathrm{m} \cdot \mathrm{s}^{-1} /\left(\mathrm{N} \cdot \mathrm{m}^{-2}\right), \mathrm{R}=0.47$; (c) GECCO2: $\quad \beta_{\mathrm{w}}=9.17 \pm 0.9810^{-5} \mathrm{~m} \cdot \mathrm{s}^{-1} /\left(\mathrm{N} \cdot \mathrm{m}^{-2}\right), \mathrm{R}=0.64$; (d) GODAS: $\beta_{\mathrm{w}}=9.66 \pm 2.1310^{-5} \mathrm{~m} \cdot \mathrm{s}^{-1} /\left(\mathrm{N} \cdot \mathrm{m}^{-2}\right), \mathrm{R}=0.38 ;$ (e) $\mathrm{K} 7: \beta_{\mathrm{w}}=8.82 \pm 0.9110^{-5}$ $\mathrm{m} \cdot \mathrm{s}^{-1} /\left(\mathrm{N} \cdot \mathrm{m}^{-2}\right), \mathrm{R}=0.66$; (f) ORAS4: $\beta_{\mathrm{w}}=5.47 \pm 0.7510^{-5} \mathrm{~m} \cdot \mathrm{s}^{-1} /\left(\mathrm{N} \cdot \mathrm{m}^{-2}\right), \mathrm{R}=0.55 ;(\mathrm{g})$ SODA: $\beta_{\mathrm{w}}=4.72 \pm 2.8310^{-5} \mathrm{~m} \cdot \mathrm{s}^{-1} /\left(\mathrm{N} \cdot \mathrm{m}^{-2}\right), \mathrm{R}=0.15$. Correlations are significant at the $95 \%$ level for all reanalyses except SODA, for which it is significant at the $90 \%$ level only.

The mean vertical temperature gradient in the ATL3 region, averaged from the thermocline up to the surface is shown in table 5, for each reanalysis, as well as the resulting total EF. The reanalyses agree well on the mean vertical temperature gradient. EF is strongest in ECDA and ORAS4 (1.20 and $1.21 \mathrm{yr}^{-1}$, respectively), twice as strong as in CFSR and SODA (0.61 and $\left.0.64 \mathrm{yr}^{-1}\right)$, for which EF is smallest. Nevertheless, EF is greater than ZAF in all reanalyses. These values are considerably larger than that found by Lübbecke and McPhaden (2013), due to larger vertical temperature gradients obtained. The fact that the vertical velocities are calculated via the horizontal velocity fields (if not provided) could also be responsible for the differences with respect to Lübbecke and McPhaden (2013). 


\begin{tabular}{ccc}
\hline & $\langle\mathrm{dT} / \mathrm{dz}\rangle_{\mathrm{E}}$ & $\mathrm{EF}$ \\
\hline CFSR & -0.06 & $0.38 \pm 0.07$ \\
ECDA & -0.07 & $0.88 \pm 0.00$ \\
GECCO2 & -0.05 & $0.77 \pm 0.02$ \\
GODAS & -0.06 & $0.77 \pm 0.04$ \\
K7 & -0.05 & $0.67 \pm 0.01$ \\
ORAS4 & -0.07 & $0.80 \pm 0.01$ \\
SODA & -0.06 & $0.42 \pm 0.19$ \\
\hline & ENS. MEAN & $0.67 \pm 0.07$ \\
\hline
\end{tabular}

Table 5: Vertical mean SST gradient in the ATL3 region and from the mean thermocline depth to the surface $\left({ }^{\circ} \mathrm{C} / \mathrm{m}\right)$ and total $\mathrm{EF}$ in each reanalysis $\left(\mathrm{yr}^{-1}\right)$.

Thermocline feedback (TF). The thermocline feedback takes into account the effect of ATL3 SST on zonal equatorial winds $\left(\mu_{\mathrm{a}}\right)$, their impact on zonal thermocline slope $\left(\beta_{h}\right)$ and the impact of the resulting subsurface temperature anomalies on SSTs $\left(a_{h}\right)$.

The regressions performed between equatorial zonal wind stress anomalies and the zonal thermocline slope are shown in Figure 28. Here thermocline slope is defined as the difference between thermocline depth in ATL3 and WATL, so that a positive anomaly in thermocline slope indicates the eastern thermocline is deeper (positive anomaly in the east) and the western is shallower (negative anomaly). In this case, the zonal thermocline slope is smoother. Likewise, a negative thermocline slope anomaly indicates the zonal slope is steeper. CFSR and SODA have the smallest correlations (0.38 and 0.46 , respectively). All other products display larger correlations, ranging from 0.66 (ECDA) to 0.79 (K7 and ORAS4). In spite of that, the regression coefficients found are similar among all products, ranging from $7.98 \times 10^{2} \mathrm{~m} /\left(\mathrm{N} \cdot \mathrm{m}^{-2}\right)(\mathrm{CFSR})$ to $10.48 \times 10^{2} \mathrm{~m} /\left(\mathrm{N} \cdot \mathrm{m}^{-2}\right)(\mathrm{K} 7)$. 

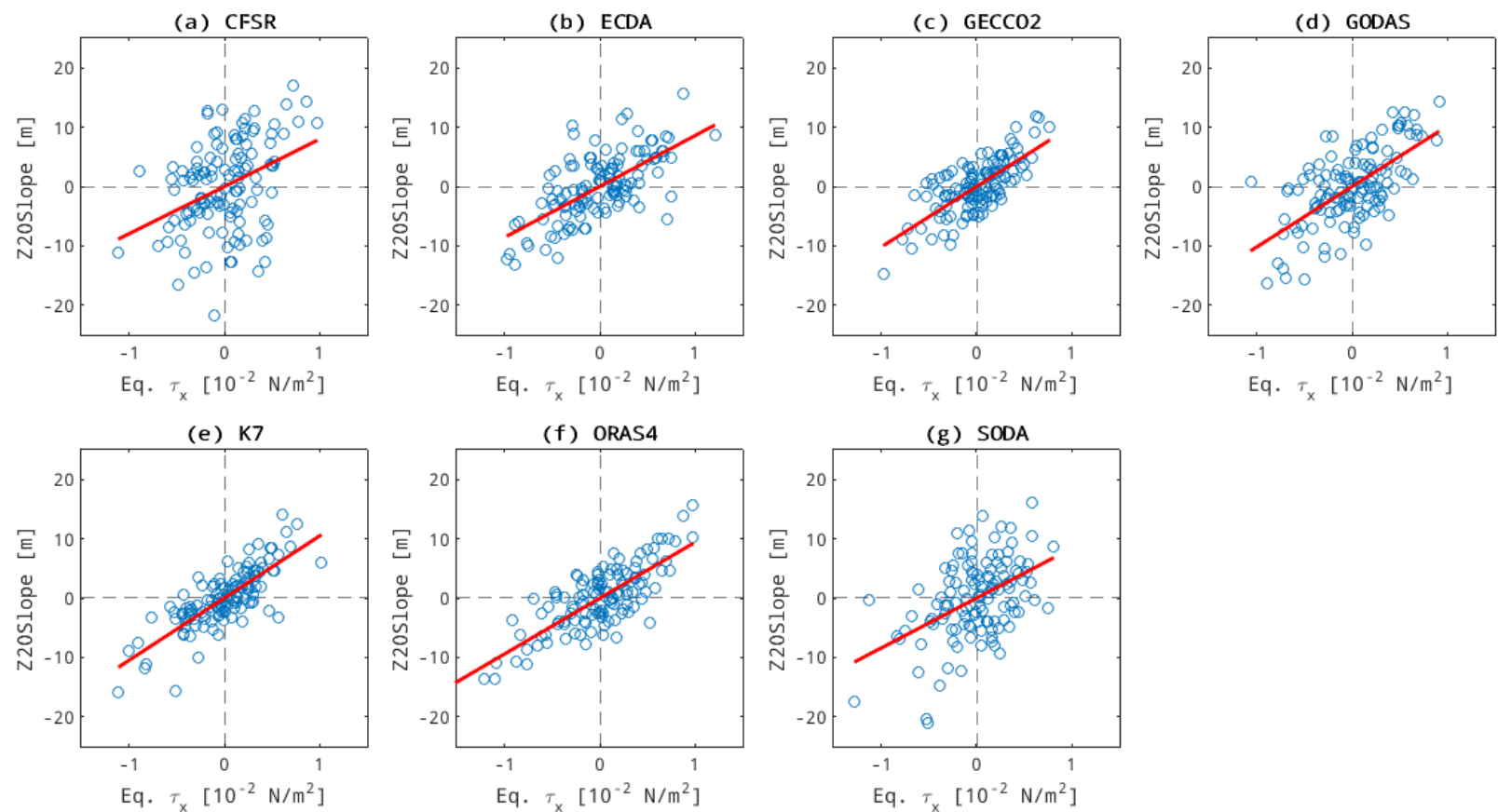

Figure 28 Thermocline slope response to zonal wind stress, estimated from regression between mean equatorial zonal wind stress anomalies and the difference between ATL3 and WATL anomalous thermocline depths. (a) CFSR: $\beta_{\mathrm{h}}=7.98 \pm 1.7410^{2} \mathrm{~m} /\left(\mathrm{N} \cdot \mathrm{m}^{-2}\right), \mathrm{R}=0.38$; (b) ECDA: $\beta_{\mathrm{h}}=8.59 \pm 8.7210^{2} \mathrm{~m} /\left(\mathrm{N} \cdot \mathrm{m}^{-2}\right), \mathrm{R}=0.66 ;(\mathrm{c})$ GECCO2: $\beta_{\mathrm{h}}=10.19 \pm 8.7910^{2} \mathrm{~m} /\left(\mathrm{N} \cdot \mathrm{m}^{-2}\right)$, $\mathrm{R}=0.72 ;(\mathrm{d})$ GODAS: $\beta_{\mathrm{h}}=10.19 \pm 1.1010^{2} \mathrm{~m} /\left(\mathrm{N} \cdot \mathrm{m}^{-2}\right), \mathrm{R}=0.64 ;$ (e) $\mathrm{K} 7: \beta_{\mathrm{h}}=10.48 \pm 0.74$ $10^{2} \mathrm{~m} /\left(\mathrm{N} \cdot \mathrm{m}^{-2}\right), \mathrm{R}=0.79 ;$ (f) ORAS4: $\beta_{\mathrm{h}}=9.42 \pm 0.6510^{2} \mathrm{~m} /\left(\mathrm{N} \cdot \mathrm{m}^{-2}\right), \mathrm{R}=0.79 ;(\mathrm{g})$ SODA: $\beta_{\mathrm{h}}=8.40 \pm 1.4410^{2} \mathrm{~m} /\left(\mathrm{N} \cdot \mathrm{m}^{-2}\right), \mathrm{R}=0.46$. All correlations are significant at the $95 \%$ level.

The regressions between ATL3 thermocline depth anomalies and anomalous subsurface temperatures in this region are displayed in Figure 29. Mean anomalous subsurface temperatures are multiplied by $\langle\mathrm{H}(\overline{\mathrm{w}})\rangle_{\mathrm{E}}$, where $\mathrm{H}()$ is the Heaviside function and $\overline{\mathrm{w}}$ is the climatological vertical current, so that only upwelling is taken into consideration (see Equation 21). Correlations are very high in all products, ranging from 0.85 (SODA) to 0.95 (GECCO2). Regression slopes vary from $6.89 \times 10^{-2}$ ${ }^{\circ} \mathrm{C} / \mathrm{m}\left(\right.$ GECCO2) to $10.97 \times 10^{-2}{ }^{\circ} \mathrm{C} / \mathrm{m}(\mathrm{ECDA})$. 

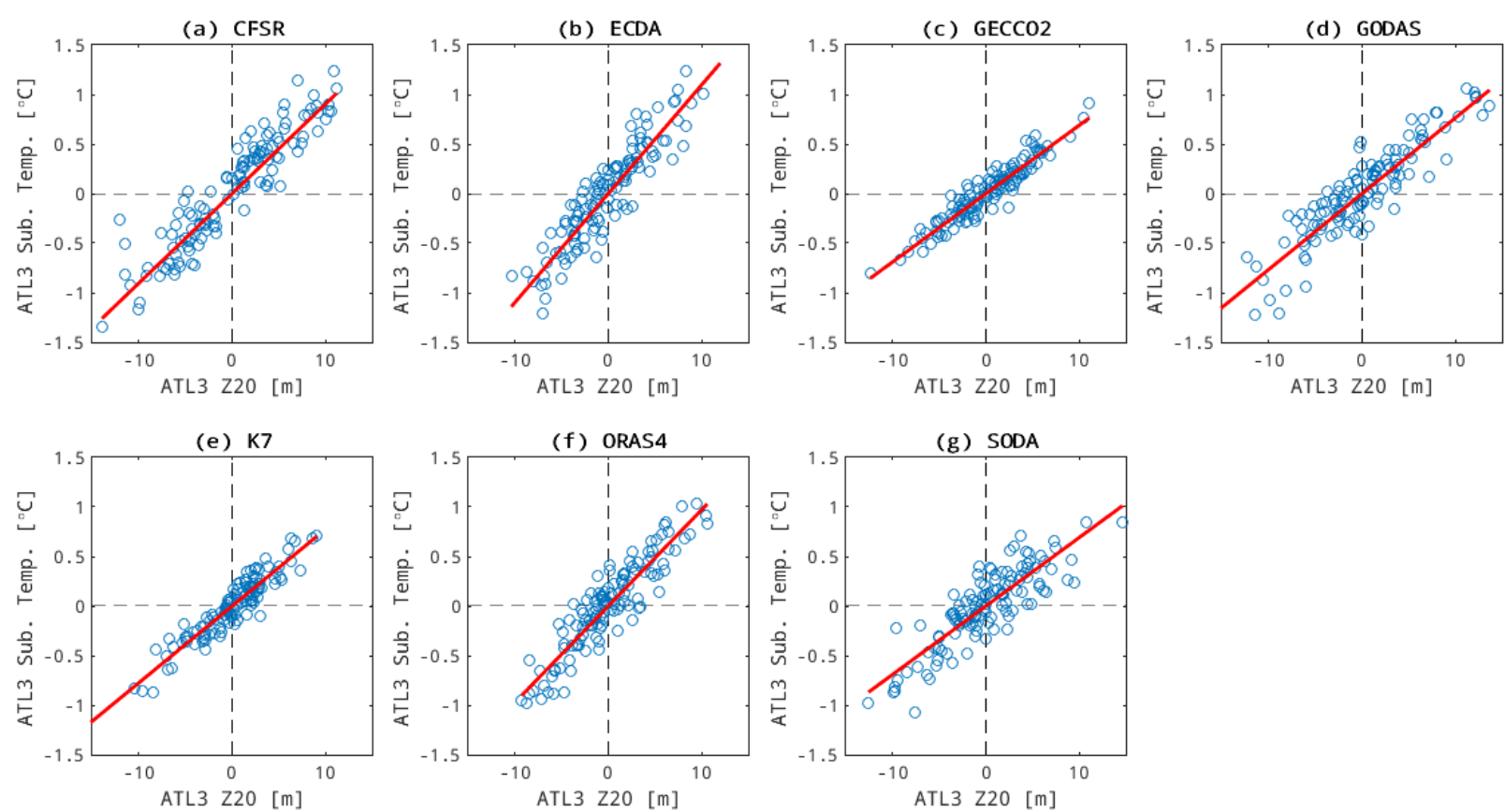

Figure 29 Subsurface temperature anomalies response to anomalous thermocline depth in the ATL3 region. (a) CFSR: $\mathrm{a}_{\mathrm{h}}=9.03 \pm 0.3210^{-2}{ }^{\circ} \mathrm{C} / \mathrm{m}, \mathrm{R}=0.93$; (b) ECDA: $\mathrm{a}_{\mathrm{h}}=10.97 \pm 0.4310^{-2}$ ${ }^{\circ} \mathrm{C} / \mathrm{m}, \mathrm{R}=0.92$; (c) GECCO2: $\mathrm{a}_{\mathrm{h}}=6.89 \pm 0.2110^{-2}{ }^{\circ} \mathrm{C} / \mathrm{m}, \mathrm{R}=0.95 ;$ (d) GODAS: $\mathrm{a}_{\mathrm{h}}=7.64 \pm 0.32$ $10^{-2}{ }^{\circ} \mathrm{C} / \mathrm{m}, \mathrm{R}=0.91 ;(\mathrm{e}) \mathrm{K} 7: \mathrm{a}_{\mathrm{h}}=7.75 \pm 0.2610^{-2}{ }^{\circ} \mathrm{C} / \mathrm{m}, \mathrm{R}=0.94$; (f) ORAS4: $\mathrm{a}_{\mathrm{h}}=9.71 \pm 0.3910^{-2}$ ${ }^{\circ} \mathrm{C} / \mathrm{m}, \mathrm{R}=0.91 ;(\mathrm{g})$ SODA: $\mathrm{a}_{\mathrm{h}}=6.91 \pm 0.3910^{-2}{ }^{\circ} \mathrm{C} / \mathrm{m}, \mathrm{R}=0.85$. All correlations are significant at the $95 \%$ level.

The total TF for each reanalysis is shown in table 6 , as well as the mean upwelling in the upper layer needed to compute the feedback term (see equation 15). In contrast to the results obtained by Lübbecke and McPhaden (2013) for SODA v2.0.2-4 and for a model output, the TF is not found to be the dominant positive feedback in all of the reanalyses. This is only observed in ECDA, ORAS4 and SODA. For CFSR and GODAS the values obtained for TF and EF are similar. Although the mean TF found among the reanalyses is larger than the mean EF, their error intervals overlap $\left(0.83 \pm 0.18 \mathrm{yr}^{-1}\right.$ for $\mathrm{TF}$ against $0.67 \pm 0.07 \mathrm{yr}^{-1}$ for $\left.\mathrm{EF}\right)$. 


\begin{tabular}{ccc}
\hline & $\langle\mathrm{H}(\overline{\mathrm{w}}) \overline{\mathrm{w}}\rangle_{\mathrm{E}}$ & $\mathrm{TF}$ \\
\hline CFSR & 3.25 & $0.35 \pm 0.23$ \\
ECDA & 3.03 & $1.38 \pm 0.43$ \\
GECCO2 & 2.94 & $0.60 \pm 0.15$ \\
GODAS & 3.25 & $0.76 \pm 0.24$ \\
K7 & 3.23 & $0.96 \pm 0.22$ \\
ORAS4 & 2.67 & $1.53 \pm 0.35$ \\
SODA & 1.07 & $0.25 \pm 0.09$ \\
\hline & ENS. MEAN & $0.83 \pm 0.18$ \\
\hline
\end{tabular}

Table 6: Mean upwelling in the ATL3 region $\left(10^{-6} \mathrm{~m} / \mathrm{s}\right)$ and total $\mathrm{TF}\left(\mathrm{yr}^{-1}\right)$.

Total Bjerknes Feedback Index $\left(\mathrm{I}_{\mathrm{BJ}}\right)$. The individual components and the total Bjerknes Feedback Index are summarized in Figure 30 and in table 7. The sum of all feedback terms yields a negative $\mathrm{I}_{\mathrm{BJ}}$ in all reanalysis, which agrees with previous studies that show the Atlantic Equatorial Mode is damped (Zebiak, 1993; Keenlyside and Latif, 2007; Jansen et al., 2009; Lübbecke and McPhaden, 2013). The greatest negative contribution comes from DD, in all reanalyses, as opposed to the predominant TD found by Lübbecke and McPhaden (2013). There is a large spread in ZAF, with the standard error surpassing the ensemble mean. The relative importance of the EF and TF terms varies among the reanalyses, with TF being strongest in ECDA, K7 and ORAS4, EF being strongest in GECCO2 and SODA, and EF and TF being similar in CFSR. The most damped total feedback was found for CFSR $\left(-1.66 \pm 0.40 \mathrm{yr}^{-1}\right)$ and the least for GODAS $\left(-0.64 \pm 0.39 \mathrm{yr}^{-1}\right)$. The ensemble mean $\mathrm{I}_{\mathrm{BJ}}$ was $-1.19 \pm 0.13 \mathrm{yr}^{-1}$.

\begin{tabular}{cccccccc}
\hline CFSR & ECDA & GECCO2 & GODAS & K7 & ORAS4 & SODA & ENS. MEAN \\
\hline$-1.66 \pm 0.32$ & $-0.93 \pm 0.40$ & $-1.00 \pm 0.25$ & $-0.64 \pm 0.28$ & $-1.42 \pm 0.27$ & $-1.21 \pm 0.36$ & $-1.45 \pm 0.29$ & $-1.19 \pm 0.13$ \\
\hline
\end{tabular}

Table 7: Total $\mathrm{I}_{\mathrm{BJ}}$ for each reanalysis and their ensemble mean $\left(\mathrm{yr}^{-1}\right)$. 
(a) Dynamical damping

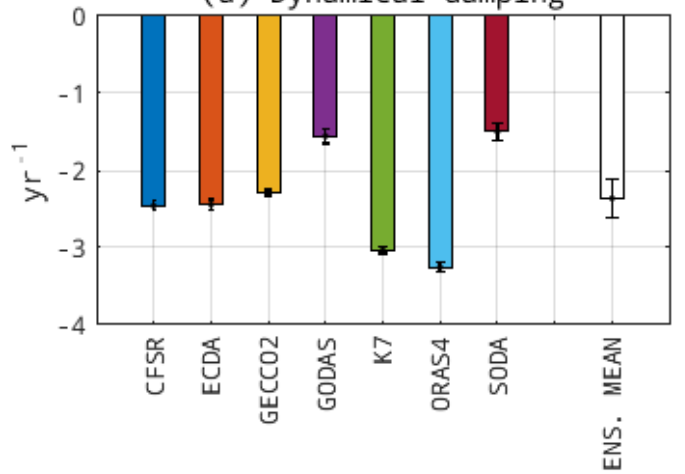

(c) Zonal advective feedback
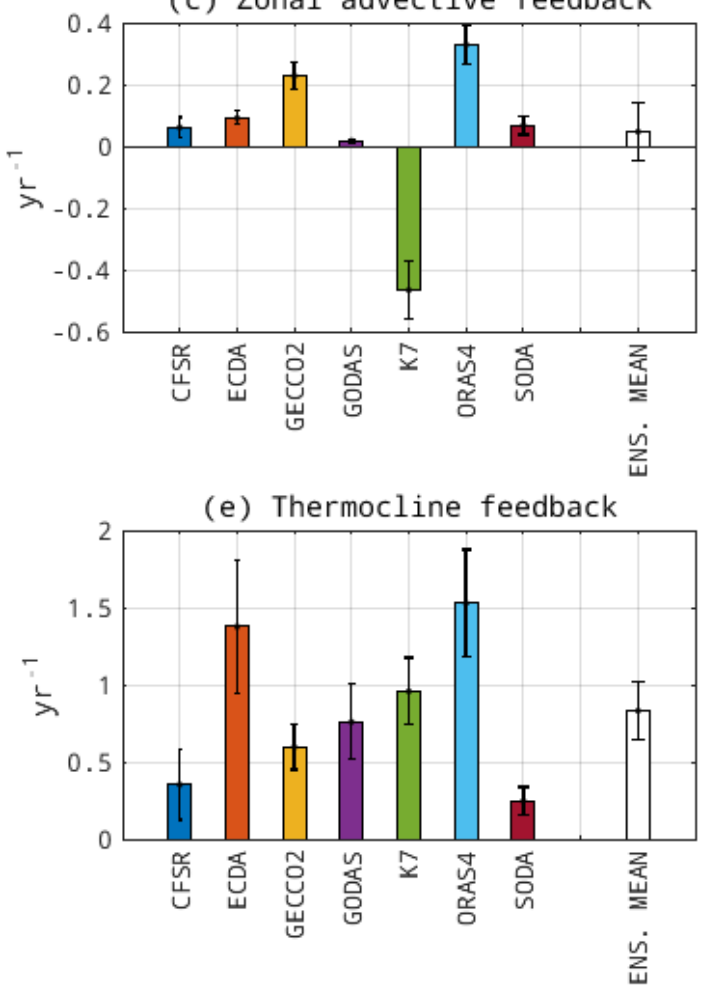

(b) Thermal damping

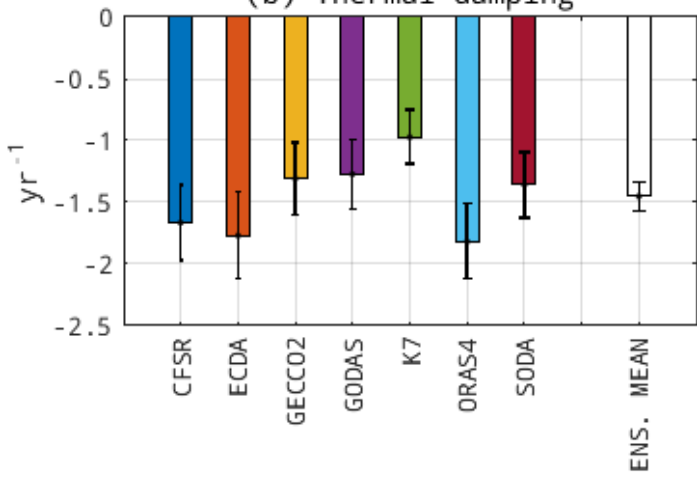

(d) Ekman feedback

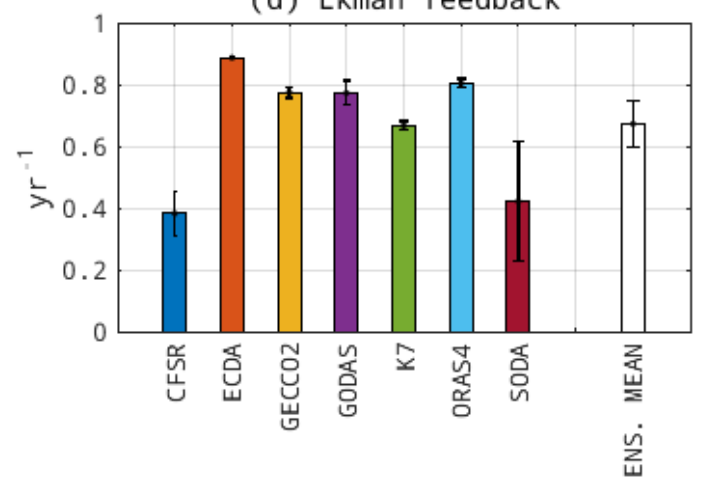

(f) Bjerknes Feedback Index

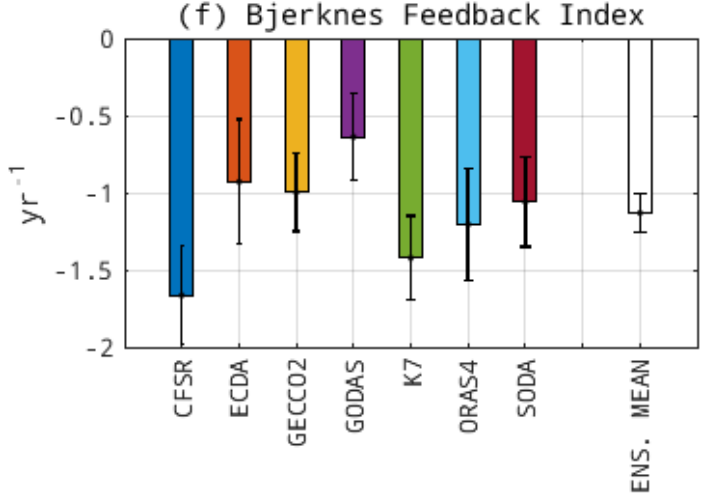

Figure 30 Dynamical damping (a), thermal damping (b), zonal advective feedback (c), Ekman feedback (d), thermocline feedback (e) and total Bjerknes Feedback Index (f), for each reanalysis and their ensemble mean. Error bars for the ensemble mean show the ensemble's standard error. 


\section{Changes over the past decades}

In this section we investigate the long term trends in the climate indices defined in section 3.4, considering the 20th century reanalyses. Potential associated changes in the Bjerknes Feedback are assessed for the periods 1950-1980, 1980-2000 and 2000-2010.

\subsection{Anomaly time series}

\subsubsection{Sea surface temperature, zonal wind stress and thermocline depth}

The time series for ATL3 SST anomalies, mean equatorial zonal wind stress anomalies and ATL3 Z20 anomalies are shown in Figures 31, 32 and 33, respectively. The series are shown for the ensemble of reanalysis products described in the previous section for the period 1980-2010 and for the 20th century reanalyses (CHOR and 20CR), considering the period 1950-2010. This period is chosen due to the increased number of observations available from 1950 onward (Yang et al., 2017). All anomalies are calculated based on 1980-2010 climatology.

The spread of the reanalyses for ATL3 SST anomalies in 1980-2010 is very small. The series for CHOR matches well the series for the ensemble mean for their common period and their temporal standard deviations are similar $\left(0.36^{\circ} \mathrm{C}\right.$ for $\mathrm{CHOR}$ and $0.43^{\circ} \mathrm{C}$ for the ensemble mean). Increasing trends in 1980-2010 are observed in all reanalyses of the ensemble, all of which are significant at the $95 \%$ level. The mean trend found for this period is $0.0136 \pm 0.002{ }^{\circ} \mathrm{C} \mathrm{mon}^{-1}$. An increasing trend in 1950-2010 is also observed in $\operatorname{CHOR}\left(0.0120 \pm 0.001{ }^{\circ} \mathrm{C} \mathrm{mon}^{-1}\right)$, significant at the $95 \%$ level. This is consistent with observational results obtained by Tokinaga and Xie (2011) and Servain et al. (2014). Both studies find warming trends in eastern equatorial Atlantic in the last decades (1950-2009 and 1976-2012). 


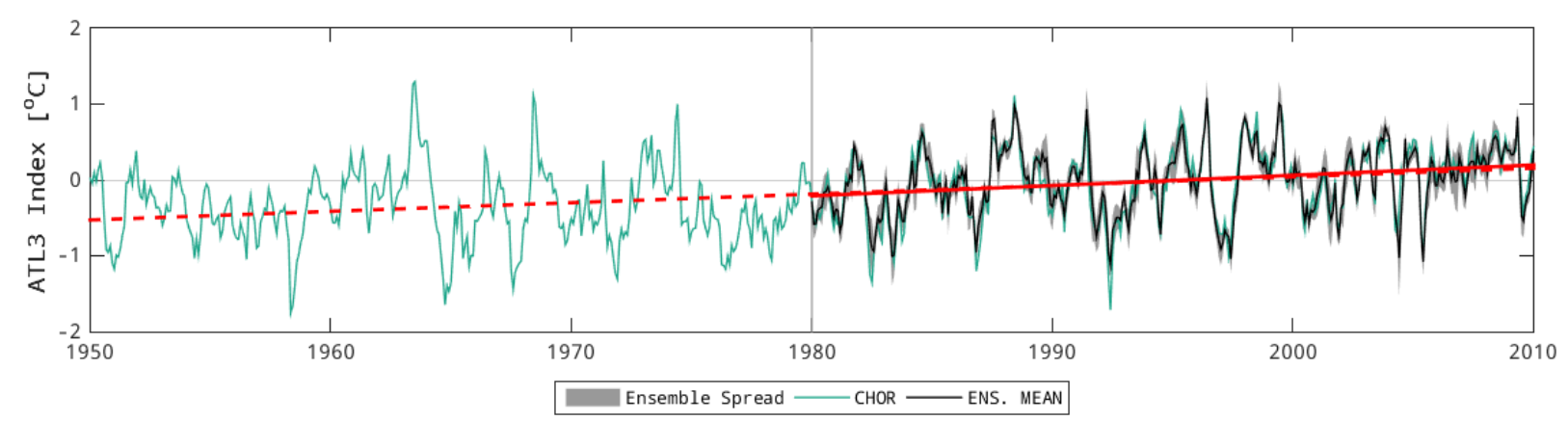

Figure 31 Time series of ATL3 SST anomalies for 1950-1980 (CHOR) and 1980-2010 (reanalyses ensemble). All reanalyses for the 1980-2010 period show an increasing trend in ATL3 SST anomalies (mean trend $0.0136 \pm 0.002{ }^{\circ} \mathrm{C} \mathrm{mon}^{-1}$, solid red line), significant at the $95 \%$ level. A $0.0120 \pm 0.001$ ${ }^{\circ} \mathrm{C}$ mon $^{-1}$ trend is observed for CHOR in 1950-2010 (dotted red line).

Although more interannual variability is observed for zonal wind stress (Figure 32) the spread of the ensemble is small. The anomaly series for CHOR in 19802010 is also very close to that of the ensemble mean, and both display the same standard deviation in this period $\left(0.004 \times 10^{-2} \mathrm{~N} \cdot \mathrm{m}^{-2}\right)$. CFSR, ECDA, GECCO2 and K7 show positive trends (i.e., weakening of the easterly winds) significant at the $95 \%$ level in $1980-2010\left(0.011 \pm 0.003 \times 10^{-2}, 0.007 \pm 0.003 \times 10^{-2}, 0.009 \pm 0.002 \times 10^{-2}\right.$ and $0.013 \pm 0.003 \times 10^{-2} \mathrm{~N} \cdot \mathrm{m}^{-2} \mathrm{mon}^{-1}$, respectively). These trends are consistent with the weakening of the Atlantic trade winds reported by Tokinaga and Xie (2011), but disagree with results obtained by Servain et al. (2014), who, conversely, found a strengthening trend in the last 50 decades. No trend is observed for GODAS, ORAS4 and SODA in the same period, nor in CHOR between 1950-2010.

There is good agreement overall among the reanalyses regarding ATL3 thermocline depths as well, although the ensemble spread is slightly larger. The standard deviation for CHOR for the 1980-2010 period is $5.6 \mathrm{~m}, 34 \%$ higher than that of the ensemble mean $(4.2 \mathrm{~m})$. Negative trends (i.e, shoaling of the thermocline) are observed in K7 $(-0.17 \pm 0.03 \mathrm{~m} / \mathrm{mon}, 95 \%$ level $)$, ORAS4 $(-0.12 \pm 0.03 \mathrm{~m} / \mathrm{mon}$, $95 \%$ level) and SODA $(-0.15 \pm 0.03 \mathrm{~m} / \mathrm{mon}, 95 \%$ level), while a positive trend (i.e., deepening of the thermocline) is observed in ECDA $(0.06 \pm 0.03 \mathrm{~m} / \mathrm{mon}, 90 \%$ level $)$, which is the only product to agree with the deepening of the thermocline in eastern equatorial Atlantic reported by Tokinaga and Xie (2011). No trend is observed in the other products, including CHOR. 


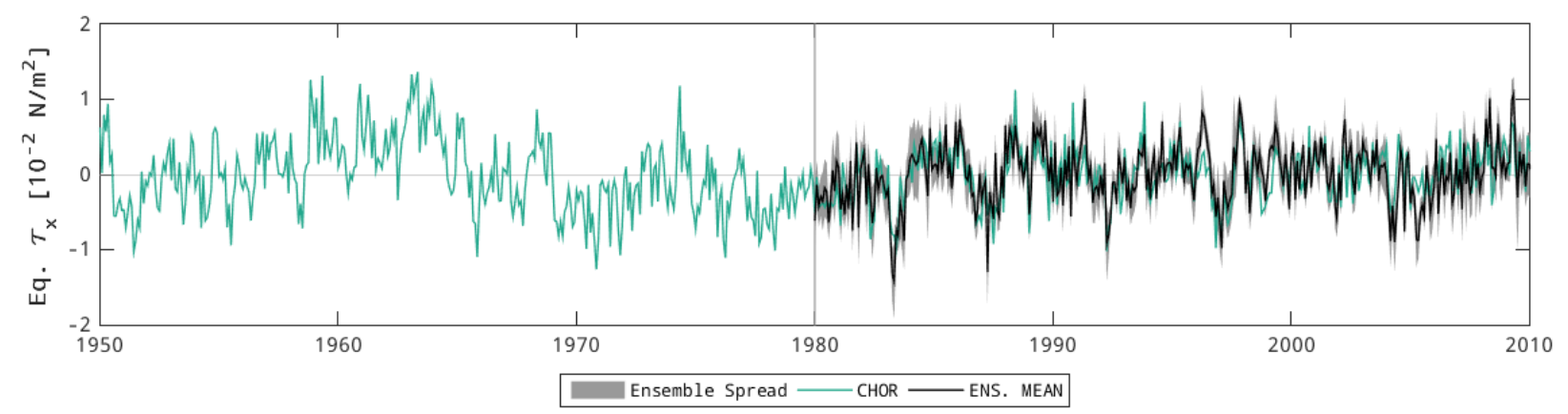

Figure 32 Time series of mean equatorial zonal wind stress anomalies for 1950-1980 (CHOR) and 1980-2010 (reanalyses ensemble). Positive trends (i.e., weakening of the trade winds) are observed in 1980-2010 in CFSR $\left(0.011 \pm 0.003 \times 10^{-2} \mathrm{~N} \cdot \mathrm{m}^{-2} \mathrm{mon}^{-1}\right)$, ECDA $\left(0.007 \pm 0.003 \times 10^{-2} \mathrm{~N} \cdot \mathrm{m}^{-2}\right.$ $\left.\mathrm{mon}^{-1}\right)$, GECCO2 $\left(0.009 \pm 0.002 \times 10^{-2} \mathrm{~N} \cdot \mathrm{m}^{-2} \mathrm{mon}^{-1}\right)$ and $\mathrm{K} 7\left(0.013 \pm 0.003 \times 10^{-2} \mathrm{~N} \cdot \mathrm{m}^{-2} \mathrm{mon}^{-1}\right)$, at the $95 \%$ significance level.

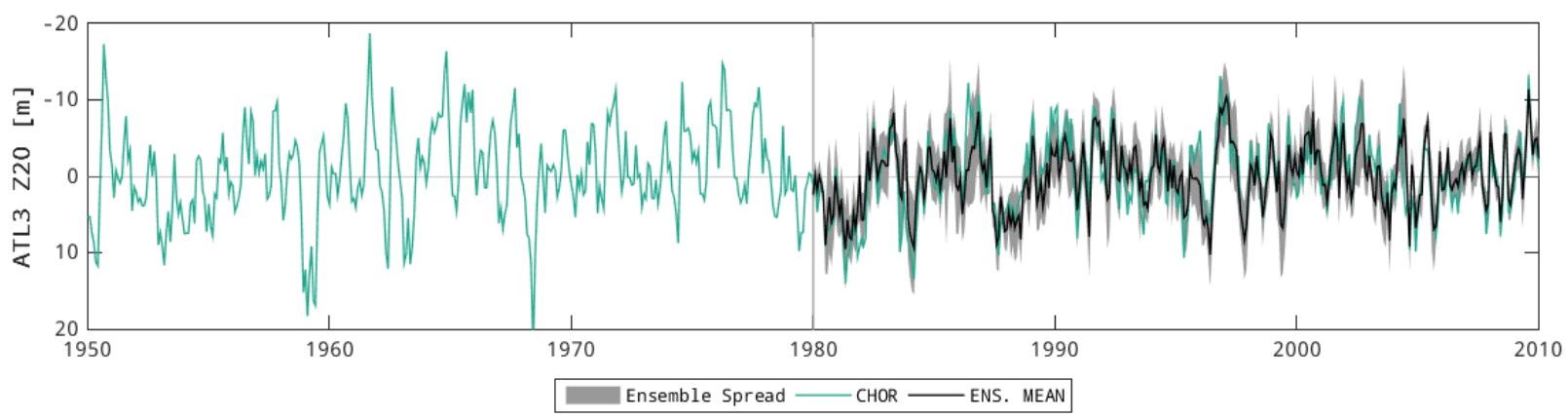

Figure 33 Time series of the ATL3 thermocline depth anomalies for 1950-1980 (CHOR) and 1980-2010 (reanalyses ensemble). Negative trends (i.e, shoaling of the thermocline) are observed in K7 $(-0.17 \pm 0.03 \mathrm{~m} / \mathrm{mon}$, ORAS4 $(-0.12 \pm 0.03 \mathrm{~m} / \mathrm{mon})$ and SODA $(-0.15 \pm 0.03 \mathrm{~m} / \mathrm{mon})$ at the $95 \%$ significance level, while a positive trend (i.e., deepening of the thermocline) is observed in ECDA $(0.06 \pm 0.03 \mathrm{~m} / \mathrm{mon})$, at the $90 \%$ level.

Despite the absence of linear trends among the products for zonal wind stress and thermocline depth, there is a consistent decrease in variability in MAM equatorial zonal wind stress (Figure 34b) and in JJA ATL3 thermocline depth (Figure 34c), in terms of root mean squared variances. CHOR shows a decrease in the moving 21-window standard deviation in these two parameters, particularly after 1980. Although the spread of their RMSV series is high and the time period is short, most of the reanalyses for 1980-2010 show a decrease in variance in 19902010. For ATL3 SSTs, a decrease in variability is observed in all reanalyses except GODAS from 1990 on (Figure 34a). Such decrease has also been shown to weaken precipitation interannual variability off the Guinean coast (Tokinaga and Xie, 2011). 

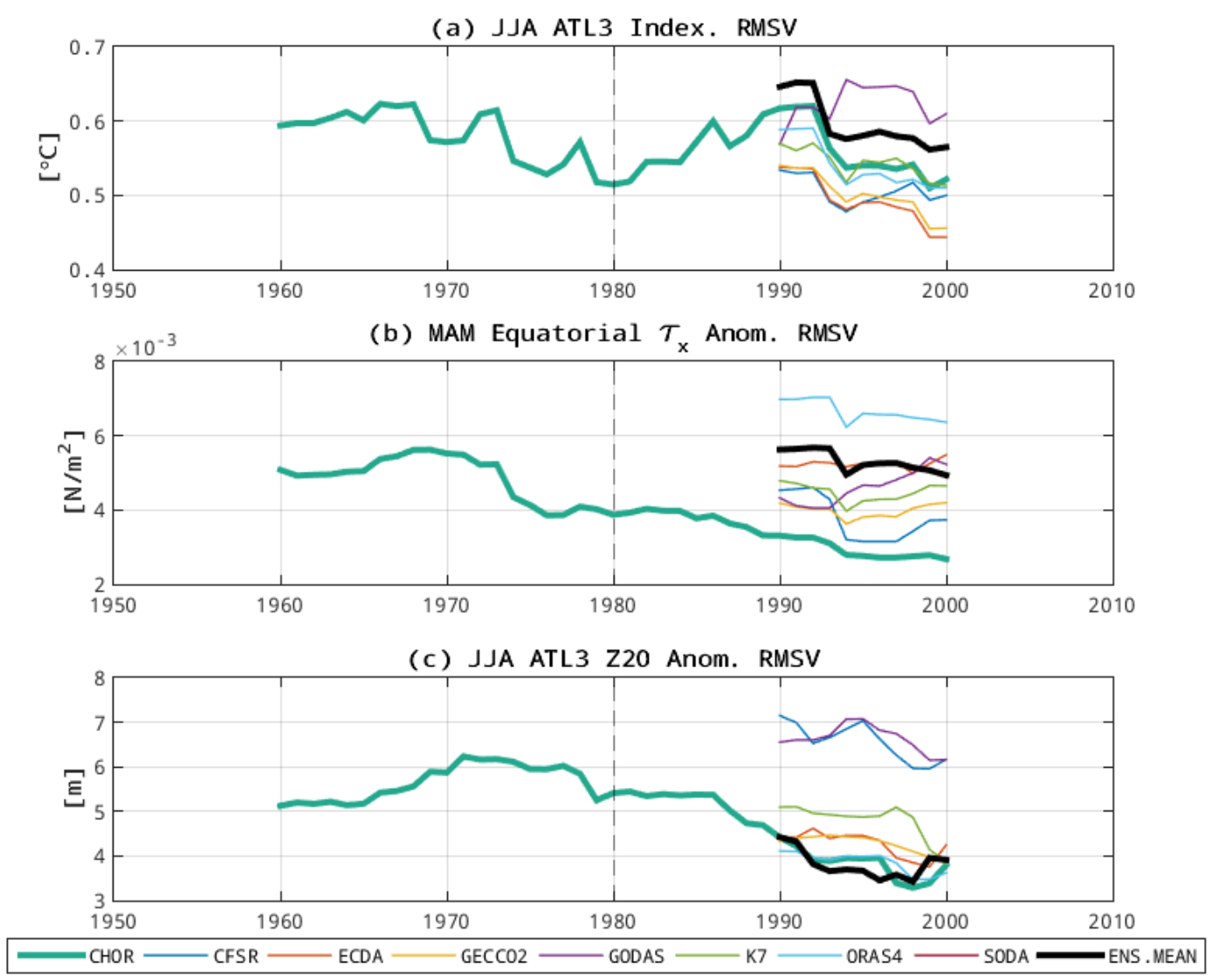

Figure 34 Root mean squared variances (21 yr window) for (a) JJA ATL3 SST anomalies, (b) MAM equatorial zonal wind stress anomalies and (c) JJA ATL3 thermocline depth anomalies.

\subsubsection{Net surface heat flux}

A comparison of the annual climatologies (1980-2010) of the net surface heat fluxes (NSHF) provided by TropFlux (Kumar et al., 2012) used with the ensemble of reanalyses for the 1980-2010 period and the one calculated using 20CR for CHOR are shown in Figure 35. The region of strongest NSHF is the ATL3 region in TropFlux (Figure 35c). This feature is also captured by the calculated NSHF (FIgure 35a), although it has weaker magnitude. This is due to a higher seasonal amplitude in the ATL3 region in 20CR (Figure 35b). 

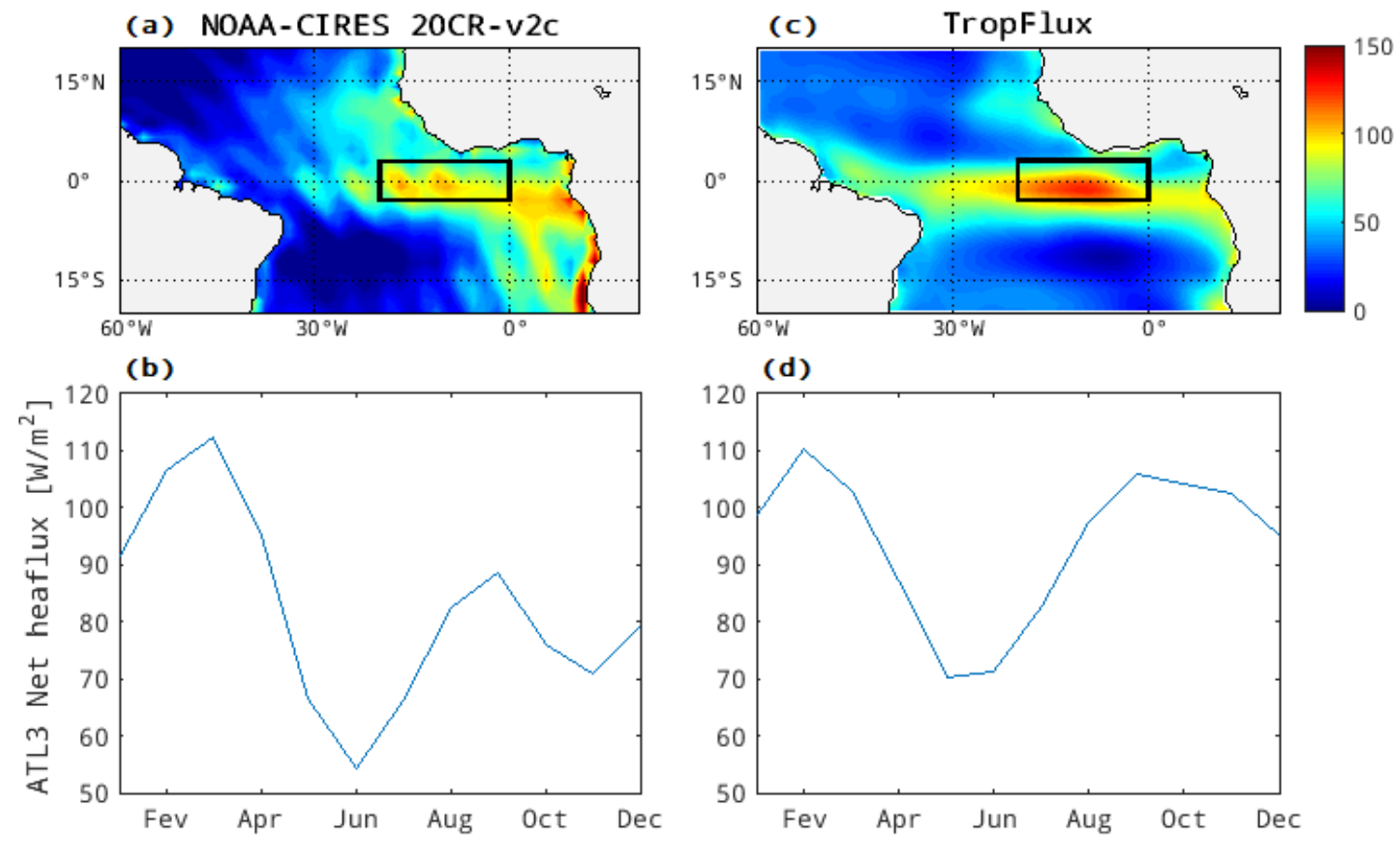

Figure 35 Annual climatology and seasonal cycles of NSHF in the ATL3 region for 20CR (a,b) and TropFlux (c,d), for the 1980-2010 period.

Figure 36 displays the NSHF anomaly series for TropFlux (1980-2010) and the anomaly series calculated using 20CR (1950-2010). The series obtained from 20CR correlates well with the series provided by TropFlux, but presents smaller interannual variability $\left(11.0 \mathrm{Wm}^{-2}\right.$ std against $14.6 \mathrm{Wm}^{-2}$ from TropFlux in 19802010). An increasing trend in 1950-2010 is observed in $20 \mathrm{CR}\left(0.06 \pm 0.02 \mathrm{~W} \cdot \mathrm{m}^{-2} / \mathrm{mon}\right.$, 95\% significance level), consistent with results obtained by Tokinaga and Xie (2011) in this period.

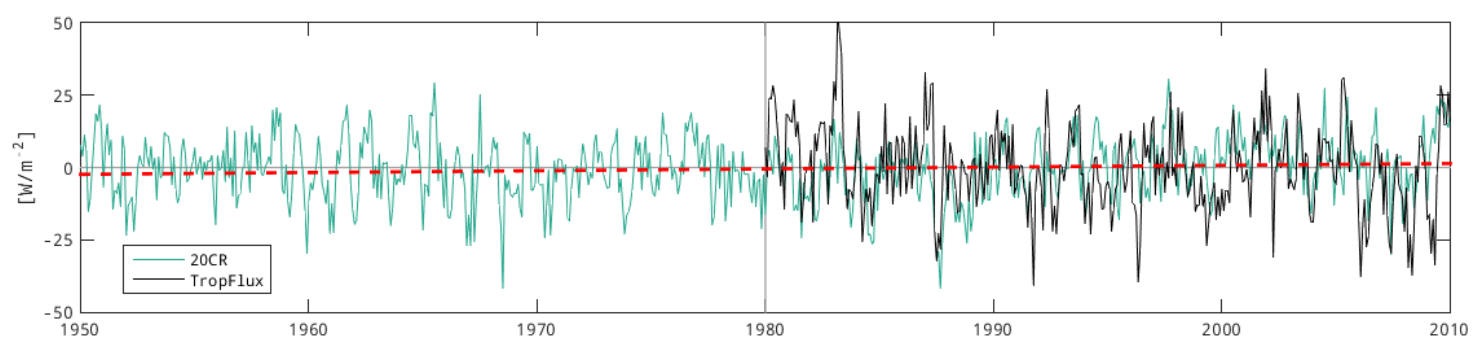

Figure 36 NSHF anomaly series in the ATL3 region for 20CR (green) and TropFlux (black). An increasing trend $\left(0.06 \pm 0.02 \mathrm{~W} \cdot \mathrm{m}^{-2} / \mathrm{mon}, 95 \%\right.$ confidence level) is observed in 20CR (red dotted line). 


\subsection{Changes in the Bjerknes Feedback}

\subsubsection{Differences between 1980-1999 and 2000-2010}

Figure 37 shows the differences in the spatial pattern of the Atlantic Equatorial Mode between 1980-1999 and 2000-2010, for the reanalysis ensemble mean. The correlation pattern is much weaker in 2000-2010, indicating there could be a shift in the equatorial mode in this period. This is consistent with the decrease observed in SST variability in the ATL3 region (Figure 34a). The pattern obtained for 1980-1999 is the same as for 1980-1989 (not shown), indicating the change is not a consequence of the different lengths of the time periods considered. These changes are assessed in terms of the $\mathrm{I}_{\mathrm{BJ}}$ and its components in the two periods, for each reanalysis and their ensemble mean. The ensemble values are also compared to those obtained for CHOR.
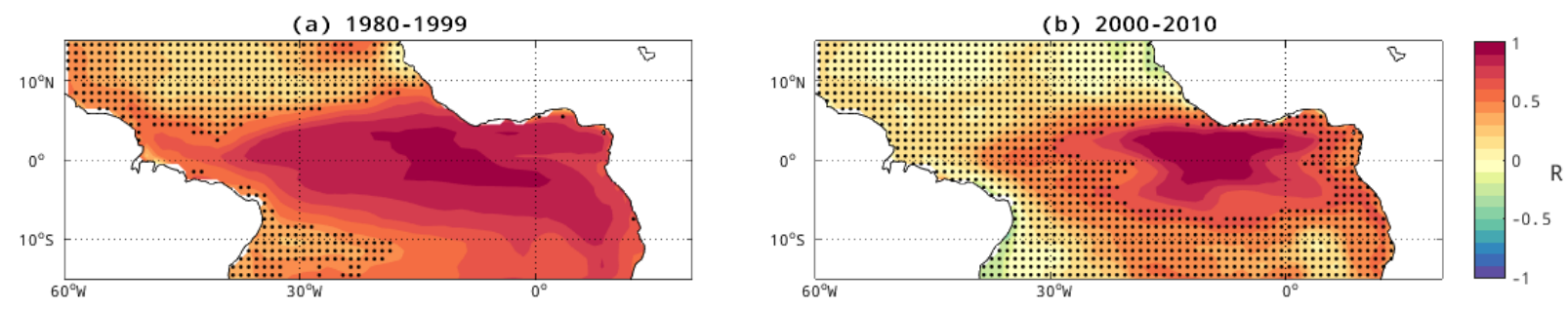

Figure 37 Spatial pattern of the Atlantic equatorial mode averaged in JJA for (a) 1980-1999 and (b) 2000-2010, for the ensemble mean. Stippling indicates regions where the correlations are not significant in at least 3 reanalyses, at the $95 \%$ level.

The comparison between $\mathrm{I}_{\mathrm{BJ}}$ and each of its components in 1980-1999 and 2000-2010 is shown in Figure 38. The total $\mathrm{I}_{\mathrm{BJ}}$ (Figure 38f) is more negative (i.e., the system is more damped) in all reanalyses in 2000-2010. The ensemble mean $\mathrm{I}_{\mathrm{BJ}}$ was found to be $-0.99 \pm 0.14 \mathrm{yr}^{-1}$ in $1980-1999$ and $-1.70 \pm 0.17 \mathrm{yr}^{-1}$ in $2000-2010$. The ensemble's standard error intervals from each period do not overlap. The ensemble means are also different at the 95\% significance level of a two-tailed student t-test. This reinforces the hypothesis that the system is more damped in the recent period. CHOR shows a more damped system in 1980-1999 than the ensemble $(-1.86 \pm 0.46$ $\left.\mathrm{yr}^{-1}\right)$. No significant difference is observed between CHOR and the ensemble in 2000-2010, though.

There are no visible changes in DD, with some products showing a stronger and others a weaker DD in 2000-2010. The error bars are overlapping in the ensemble 
and for all three components (zonal, meridional and vertical) the ensemble error of each period is larger than the difference between the time periods. The same happens for ZAF, with the ensemble standard error surpassing the ensemble mean. CHOR presents the same issue as K7, where a positive mean zonal SST gradient in the ATL3 region leads to an unrealistically negative ZAF. As for EF, all products display a weakening in 2000-2010, with the exception of SODA, which shows a strengthening. This is however within the error interval, which is quite large in 1980-1999. The difference in the EF term between the time periods in the ensemble $\left(-0.10 \mathrm{yr}^{-1}\right)$ is also similar to the standard error in 1980-1999 (0.09 $\left.\mathrm{yr}^{-1}\right)$.

A stronger TD term is observed in all products for this period, with nonoverlapping error bars in CFSR, ECDA and ORAS4. The ensemble mean shows a much stronger thermal damping in 2000-2010 (-2.22 $\left.\pm 0.31 \mathrm{yr}^{-1}\right)$ compared to 1980$1999\left(-1.15 \pm 0.06 \mathrm{yr}^{-1}\right)$. The error bars do not overlap and the difference between the time periods $\left(-1.0712 \mathrm{yr}^{-1}\right)$ is larger than the ensemble standard errors $(0.0603$ and $0.3065 \mathrm{yr}^{-1}$ ). A two-tailed student t-test confirms that the ensemble means are different in the different time periods, at the $99 \%$ significance level. CHOR displays a stronger TD in the recent period as well $\left(-1.36 \pm 0.47 \mathrm{yr}^{-1}\right.$ in 2000-2010 against $-0.61 \pm 0.28 \mathrm{yr}^{-1}$ in 1980-1999), although its error bars lie close to each other. Its TD is significantly weaker than the ensemble in both periods, with error bars not overlapping with those from the ensemble mean. This could be due to the different NSHF data sets used. 

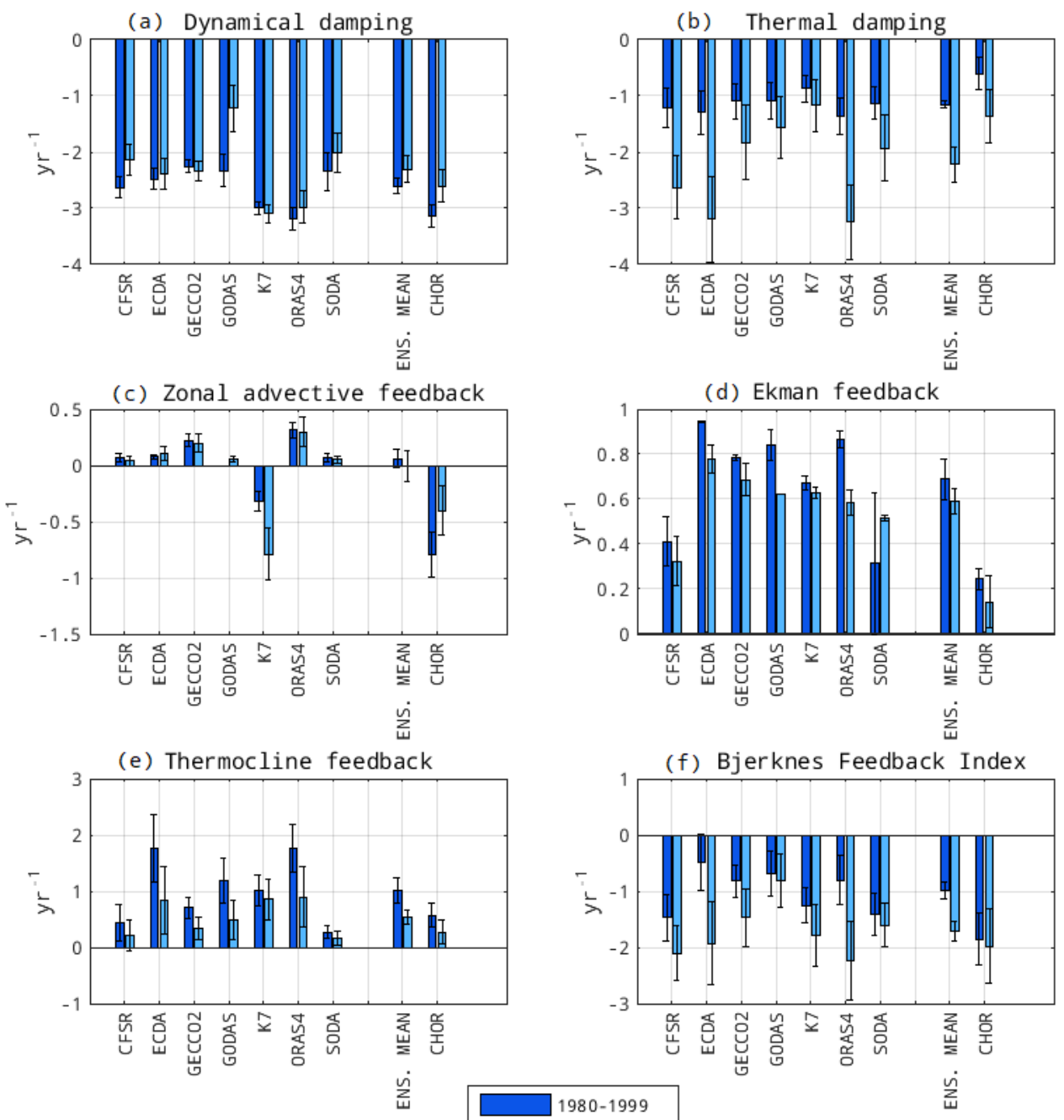

Figure 38 Dynamical damping (a), thermal damping (b), zonal advective feedback (c), Ekman feedback (d), thermocline feedback (e) and total Bjerknes Feedback Index (f), for 1980-1999 (dark blue) and 2000-2010 (light blue) for each reanalysis, their ensemble mean and for the 20th century ocean reanalysis (CHOR). The ensemble error bar represents the ensemble standard error.

As for TF (Figure 38e), all reanalysis products present a weakening in the last period and so does the ensemble mean $\left(0.54 \pm 0.12 \mathrm{yr}^{-1}\right.$ in 2000-2010 against $1.02 \pm 0.23 \mathrm{yr}^{-1}$ in 1980-1999). The standard error bars of the two periods are nonoverlapping and the student t-test results that the means are different, although at the $90 \%$ level.

A weaker TF is also present in CHOR $\left(0.27 \pm 0.21 \mathrm{yr}^{-1}\right.$ in $2000-2010$ against $0.57 \pm 0.20 \mathrm{yr}^{-1}$ in 1980-1999). The value found for 1980-1999 is lower than the one from the ensemble, with non-overlapping error bars, indicating the feedback represented by CHOR in this period is weaker. The difference between CHOR and 
the ensemble is not robust in 2000-2010, since the error bars overlap.

The parameters $\alpha, \mu_{\mathrm{a}}, \beta_{\mathrm{h}}$ and $\mathrm{a}_{\mathrm{h}}$, which are associated with TD and TF, are shown in Figure 39, for each time period. The parameter $\alpha$ is the linear regression coefficient between SST anomalies and NSHF anomalies in the ATL3 region. It corresponds to the TD term itself. The stronger thermal damping in 2000-2010 observed in Figures 39 and 38 is corroborated by the analysis of the spatial correlation patterns between TropFlux NSHF anomalies and the reanalyses ensemble mean SST anomalies for the two time periods (Figure 40). Consistent with the stronger thermal damping, there is a strengthening in the correlation pattern, with the region of 0.4 correlation covering a larger extent of the equatorial region in 2000-2010 than in 1980-1999.
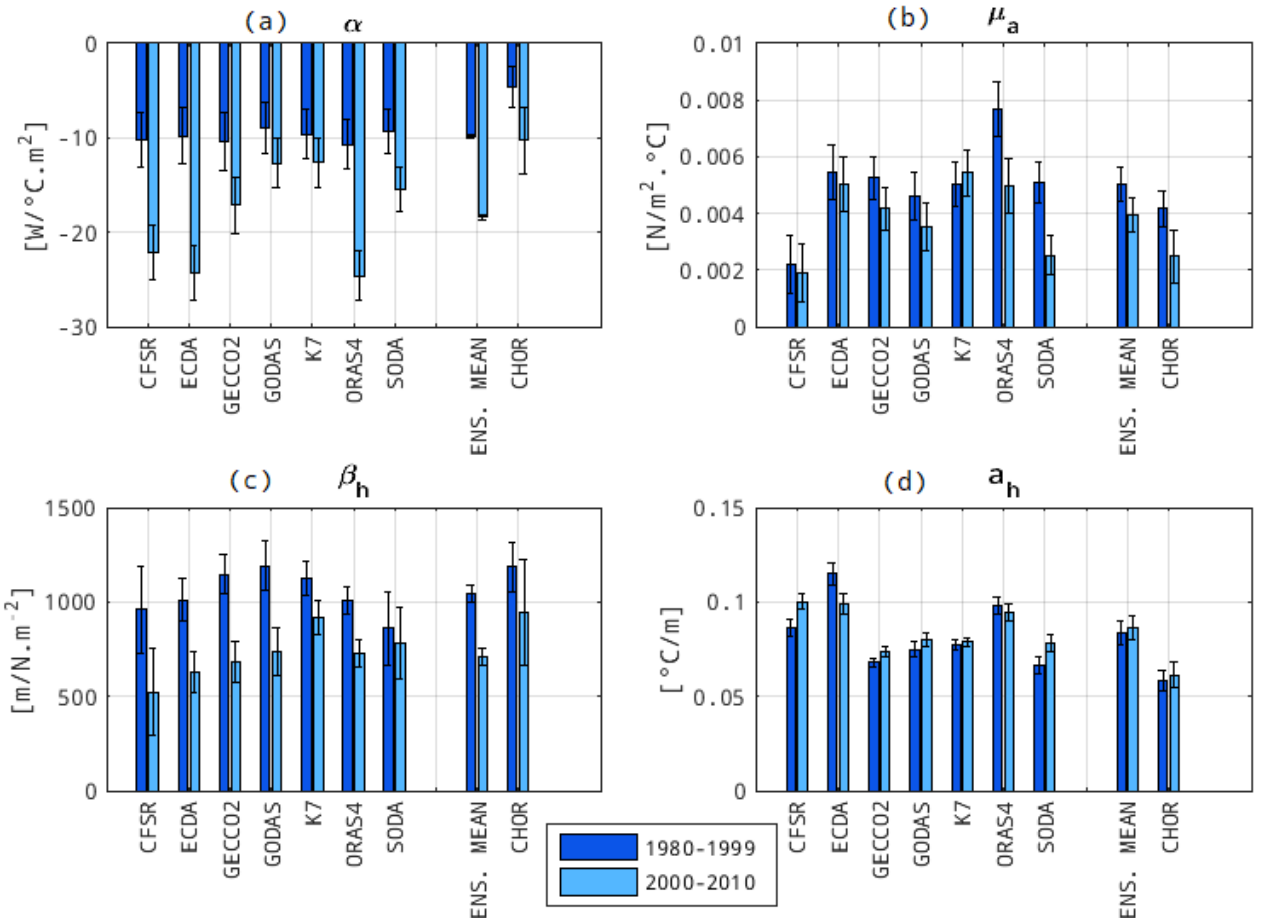

Figure 39 Regression parameters associated with TD and TF for 1980-1999 (dark blue) and 2000-2010 (light blue) for each reanalysis, their ensemble mean and for the 20th century ocean reanalysis (CHOR): thermal damping (a), equatorial zonal wind stress response to ATL3 SST anomalies (b), equatorial thermocline slope response to zonal wind stress anomalies (c) and SST response to subsurface temperature anomalies $(\mathrm{d})$. The error bars indicate the regression standard error for each reanalysis and the ensemble standard error for the ensemble mean. 

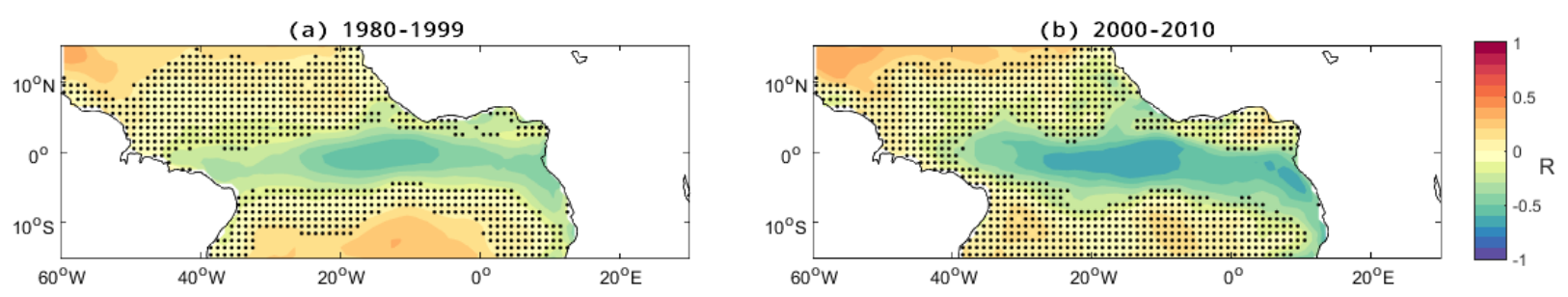

Figure 40 Pointwise correlation of the reanalyses ensemble mean SST anomalies against TropFlux NSHF anomalies, for (a) 1980-1999 and (b) 2000-2010. Stippling indicates regions where the correlations are not significant in at least 3 reanalyses, at the $95 \%$ level.

The other three parameters are required to compute TF. The term $\mu_{\mathrm{a}}$ shows a decrease in the recent period in all products except K7. However, the error bars of the ensemble mean overlap, indicating this difference is not robust. This is confirmed by a two-tailed t-test (90\% level). Some products show a decrease and others an increase in $a_{h}$ in 2000-2010, but the difference in the reanalysis ensemble mean between the two periods is not significant either. The same is observed in CHOR, whose values for both periods are similar, with overlapping error bars.

As for $\beta_{\mathrm{h}}$, a decrease in 2000-2010 is observed in all reanalyses, with nonoverlapping error bars in ECDA, GECCO2, GODAS and ORAS4, the same happening to the ensemble mean. Indeed, the correlation between mean equatorial wind stress anomalies and thermocline depth anomalies (Figure 41) shows a weaker pattern in 2000-2010, with the positive region more concentrated at the equator and displaying lower values for the regression coefficient. The negative region in the western Atlantic remains very similar. Therefore, the weaker thermocline feedback in the recent period could be associated with a weaker response of the thermocline slope to anomalous zonal wind stress in the equatorial region.
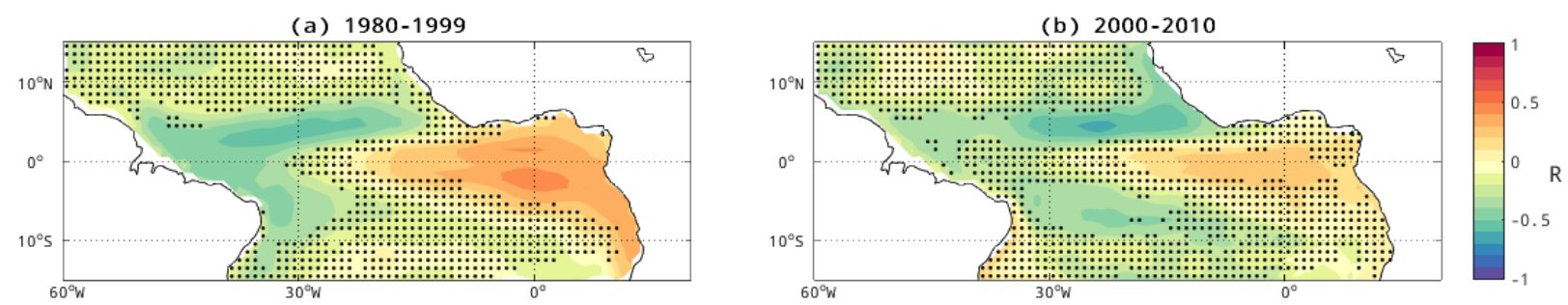

Figure 41 Correlation of mean equatorial zonal wind stress and thermocline depth (Z20), for the ensemble mean in (a) 1980-1999 and (b) 2000-2010. Stippling indicates regions where the correlations are not significant in at least 3 reanalyses, at the $95 \%$ level.

These results suggest that the more damped $\mathrm{I}_{\mathrm{BJ}}$ in 2000-2010 is related to a weaker thermocline feedback and a stronger thermal damping. This is consistent 
with results obtained by Tokinaga and Xie (2011), which associate the decrease in the ACT variability with a weaker thermocline feedback, due to a decreased zonal thermocline slope resulting from weaker trade winds, and increased upward net heat flux, leading to a stronger evaporative damping of SSTs. This also agrees with results obtained by Servain et al. (2014), who argue that long term SST warming in this region drives and increase in the surface latent heat flux.

Similarly, Lübbecke and McPhaden (2014) also report a weakening in the Bjerknes Feedback in the Pacific in the early XXI century. However, they found this weakening is attributed to a weaker thermocline feedback only, without any changes in thermal damping. The weaker TF in the Pacific results from a westward shift of the ascending branch of the Walker cell, leading to a westward confinement of wind stress response to eastern Pacific SST anomalies. In our results, no changes are observed in the correlation patterns between ATL3 SST anomalies and zonal wind stress. This further reinforces that despite its similarities with the Pacific Niño, other mechanisms impact the Atlantic equatorial mode and its variability.

\subsubsection{Differences between 1950-1979 and 1980-2010}

Considering the differences between the ensemble and the 20th century reanalysis in the Bjerknes Feedback Index terms in 1980-2010, in this section we assess potential changes in earlier decades (1950-1980).

The components and total $\mathrm{I}_{\mathrm{BJ}}$ in each period are shown in Figure 42. The DD term is stronger in 1980-2010, but its lower error bound $\left(-1.62 \mathrm{yr}^{-1}\right)$ is very close to the upper error bound in 1950-1979 $\left(-1.63 \mathrm{yr}^{-1}\right)$. The difference in DD is mainly due to the vertical damping $\left(\mathrm{DD}_{\mathrm{w}}\right)$ term, which ranges from -1.76 to -1.85 $\mathrm{yr}^{-1}$ in 1950-1979 and from -1.85 to $-1.96 \mathrm{yr}^{-1}$ in $1980-2010$. The difference in $\mathrm{DD}_{\mathrm{w}}$ between the time periods $\left(-0.10 \mathrm{yr}^{-1}\right)$ is larger than the errors in both periods $(0.04$ and $0.05 \mathrm{yr}^{-1}$ ), which suggests a stronger vertical dynamical damping in 1980-2010. As for the second negative term, TD, the associated errors are large and the error intervals in both periods overlap, despite it being weaker in 1980-2010.

Among the terms with positive contributions, TF is the only one that does not show any consistent changes, with the difference between the two time periods $\left(-0.16 \mathrm{yr}^{-1}\right)$ being similar to the errors $\left(0.17\right.$ and $\left.0.15 \mathrm{yr}^{-1}\right)$. The EF term is weaker 
in the recent period. It ranges from $0.45-0.46 \mathrm{yr}^{-1}$ in 1950-1979 and from 0.17 to $0.29 \mathrm{yr}^{-1}$ in $1980-2010$. ZAF is negative in both periods due to a large positive zonal SST gradient in the ATL3 region. The decrease in 1980-2010 indicates there could be a change in the regression coefficients.

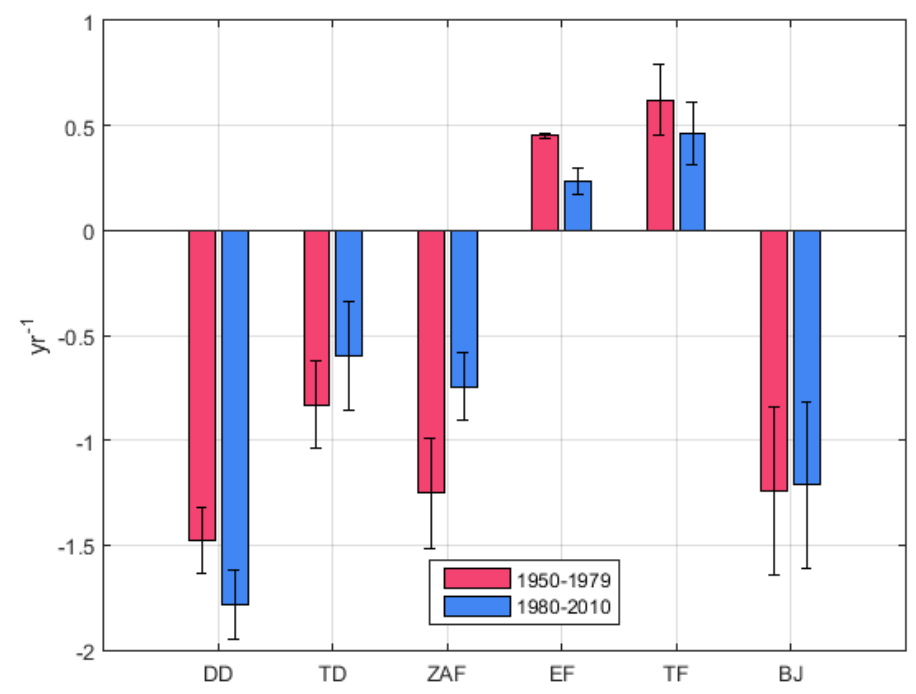

Figure 42 Individual terms and total Bjerknes Feedback Index for 1950-1979 (pink) and 1980-2010 (blue), obtained from the 20th century reanalysis (CHOR).

The regression coefficients associated with ZAF and EF are shown in Figure 43. A decrease in the recent period is observed in all of them, with $\mu_{\mathrm{a}}$ going from $5.2 \pm 0.7 \times 10^{-3}$ to $4.0 \pm 0.5 \times 10^{-3} \mathrm{~N} \cdot \mathrm{m}^{-2} /{ }^{\circ} \mathrm{C}, \beta_{\mathrm{u}}$ from $15.97 \pm 1.07$ to $14.07 \pm 1.2$ $\mathrm{m} \cdot \mathrm{s}^{-1} / \mathrm{N} \cdot \mathrm{m}^{-2}$ and $\beta_{\mathrm{w}}$ from $-7.02 \pm 0.96 \times 10^{-5}$ to $-4.58 \pm 1.76 \times 10^{-5} \mathrm{~m} \cdot \mathrm{s}^{-1} / \mathrm{N} \cdot \mathrm{m}^{-2}$. However, the error bars overlap for $\beta_{\mathrm{u}}$ and $\beta_{\mathrm{w}}$. For $\mu_{\mathrm{a}}$ the lower error bound for 1950-1979 is the same as the upper error bound for 1980-2010 (0.045 $\left.\mathrm{yr}^{-1}\right)$. The correlation pattern between ATL3 SST anomalies and zonal wind stress in the equatorial region (Figure 44) displays some differences between the two periods. The region of positive correlations is more confined in the equator in 1980-2010 and the region of negative correlations off the coast of Africa observed in 1950-1979 vanishes almost completely in the second period. However, the differences are mostly meridional and the correlations in the averaging equatorial region used to compute $\mu_{\mathrm{a}}$ are similar in both periods, suggesting there is no shift in this parameter. 

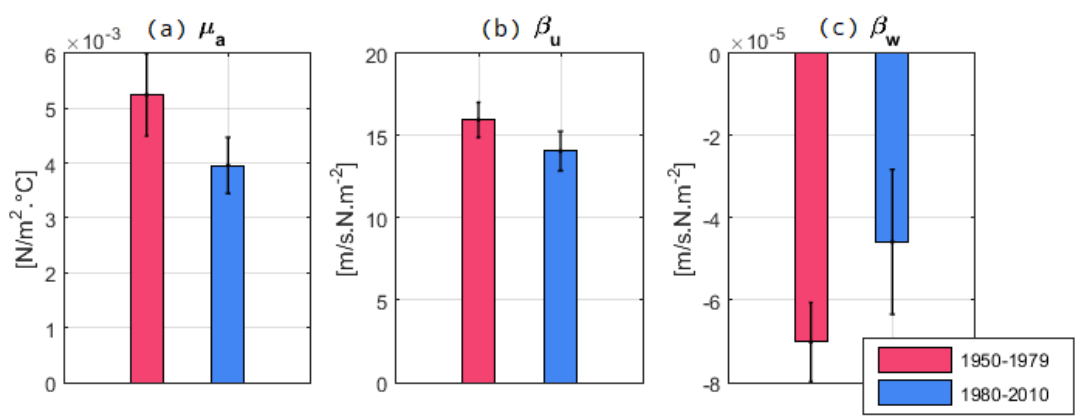

Figure 43 Regression parameters associated with ZAF and EF in 1950-1979 (pink) and 19802010 (blue) for the 20th century ocean reanalysis (CHOR): equatorial zonal wind stress response to ATL3 SST anomalies (a) and ATL3 zonal current (b) and upwelling (c) responses to zonal wind stress anomalies. The error bars indicate the regression standard error.
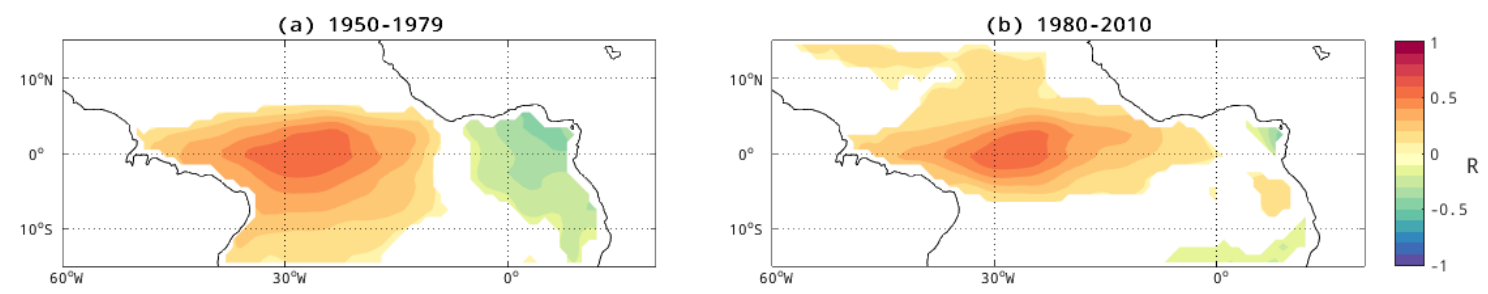

Figure 44 Correlation of mean ATL3 SST anomalies and zonal wind stress anomalies elsewhere in the basin, for CHOR in (a) 1950-1979 and (b) 1980-2010. Only correlations significant at the $95 \%$ level are shown. 


\section{Summary and conclusions}

In this study we assessed the climatological behavior and the mechanisms responsible for interannual variability in the Tropical Atlantic as represented in a group of seven reanalyses from the Ocean Reanalysis Intercomparison Project (ORA-IP - Balmaseda et al., 2013) for the period 1980-2010. The changes in such mechanisms are quantified in terms of the Bjerknes Feedback Index and the underlying long term trends, also considering a 20th century ocean reanalysis (CHOR Yang et al., 2017) for 1950-2010.

For the reanalyses ensemble spanning the period 1980-2010, significant differences were found among the different products regarding their representation of the mean state (climatology). The largest spreads in SST are observed in the EEA, particularly in JJA, when the cold tongue peaks. A consistent outlier is K7, which not only shows SSTs higher than the mean in the equatorial Atlantic $\left(0.5-1^{\circ} \mathrm{C}\right)$, but also displays higher subsurface temperatures and a deeper thermocline in all seasons. An even larger spread is observed for equatorial averaged zonal wind stress, with GECCO2 being an outlier in all seasons, displaying weaker easterly winds than the upper bound of the spread. Unlike the SSTs, however, the spread observed is the same throughout the year. The most disagreement among the reanalysis products regarding wind stress is observed in the southwestern tropical Atlantic. Considering the equatorial $\left(3^{\circ} \mathrm{N}-3^{\circ} \mathrm{S} ; 40^{\circ} \mathrm{W}-0^{\circ}\right)$ surface currents, a stronger $\mathrm{SEC}$ is observed in GODAS and K7, while in SODA (v3.4.1) the EUC extends all the way up to the surface, causing the surface currents in this region to be unrealistically eastward, which was also observed by Lübbecke and McPhaden (2013) for SODA's version $2.0 .2-4$.

As a result from these differences, variability in the representation of the components of the Bjerknes Feedback Index is observed among the reanalyses. The spatial correlations between SST and zonal wind stress anomalies, zonal wind stress and thermocline depth anomalies and subsurface temperatures and SST anomalies show that the Bjerknes Feedback is well represented in the different reanalysis products for the Equatorial Atlantic, although with varying intensity. The quantification of the feedback's intensity in each product is performed by computing the Bjerknes Feedback Index, for the period 1980-2010. 
The total index is negative in all products (ensemble mean $-1.19 \pm 0.13$ $\mathrm{yr}^{-1}$ ), which indicates that the Atlantic Equatorial Mode is damped, in agreement with previous results (e.g., Zebiak, 1993; Keenlyside and Latif, 2007; Lübbecke and McPhaden, 2013). The negative contributions to the total index come from the TD and DD terms. The first was very similar in all products (ensemble mean $-1.44 \pm 0.12$ $\mathrm{yr}^{-1}$ ). There was more disagreement among the reanalyses with respect to DD. Since the mean currents are averaged in the ATL3 region and from the surface to Z20, the zonal contribution is expected to be positive, because zonal velocities in this region are westward (Stramma and Schott, 1999) and therefore contribute to enhance an eastern SST anomaly. However, GECCO2, ORAS4 and SODA display negative zonal contributions due to a shallower EUC. Despite this, the total dynamical damping term is negative in all reanalyses and nearly twice as large as TD (ensemble mean $-2.47 \pm 0.21 \mathrm{yr}^{-1}$ ), with the upwelling term being dominant. This contrasts with the results obtained by Lübbecke and McPhaden (2013) who found that TD is the dominant negative term. These differences could be related to the fact that while the authors average the ATL3 mean currents from the surface to a mixed layer depth of $32 \mathrm{~m}$ (mean ATL3 mixed layer depth obtained from the NEMO-ORCA05 simulation) here we adopt the depth of the $20^{\circ} \mathrm{C}$ isotherm as the vertical limit of the averaging region, which is located near the center of the thermocline in the tropical regions (Yang and Wang, 2009).

Among the positive terms, the largest contributions come from EF (ensemble mean $-0.67 \pm 0.07 \mathrm{yr}^{-1}$ ) and TF (ensemble mean $-0.83 \pm 0.18 \mathrm{yr}^{-1}$ ). Their relative importance vary depending on the reanalysis product. In all of the reanalyses ZAF is the smallest positive term. However, in $\mathrm{K} 7$ this term is negative due to the warmer equatorial Atlantic SSTs and positive zonal SST gradient in the ATL3 region. Out of all seven reanalyses, SODA displayed the weakest correlations overall among the variables of interest.

A weakening of the ACT in the last six decades was reported by Tokinaga and Xie (2011), associated with weaker interannual variability and a weaker thermocline feedback driven by weaker trade winds, which in turn are a result of higher SSTs in the EEA. In our results, a consistent warming of the ACT is observed for all 7 reanalyses of the ensemble for 1980-2010 and for CHOR in 1970-2010, indicated 
by the positive trends in the anomaly time series of the ATL3 index. A variability decrease of the cold tongue SSTs in JJA is also observed.

There is less consistency among results regarding zonal wind stress and thermocline depth trends though, with some not showing any significant trends or trends of different signs. However, both ATL3 thermocline depth and equatorial averaged zonal wind stress displayed decreases in variability in the recent period.

In addition, the spatial pattern of the Equatorial Atlantic Mode showed a robust weakening in 2000-2010 compared to 1980-1999. Indeed, the computation of the $\mathrm{I}_{\mathrm{BJ}}$ yielded a more damped index for the recent period $\left(-1.70 \pm 0.17 \mathrm{yr}^{-1}\right.$ in 2000-2010 against $-0.99 \pm 0.14 \mathrm{yr}^{-1}$ in 1980-1999, for the ensemble mean), as a result of the stronger thermal damping $\left(-2.22 \pm 0.31 \mathrm{yr}^{-1}\right.$ in 2000-2010 against $-1.15 \pm 0.06$ $\mathrm{yr}^{-1}$ in 1980-1999) and a weaker thermocline feedback (-2.22 $\pm 0.31 \mathrm{yr}^{-1}$ in 2000-2010 against $-1.15 \pm 0.06 \mathrm{yr}^{-1}$ in 1980-1999). The stronger thermal damping is a response to the warming of the ACT, as it was shown by Servain et al. (2014). The weaker thermocline feedback, on the other hand, is found to be related to a weaker response of the equatorial thermocline slope to anomalous equatorial zonal wind stress. Similar results are obtained by Lübbecke and McPhaden (2014) for the Pacific, which in turn associate the weaker response to the westward confinement of the equatorial zonal wind stress response to eastern Pacific SST anomalies. In our results, however, no changes in the response of wind stress to ATL3 SST anomalies were found, indicating that other mechanisms must be at play in the Atlantic. Therefore, more studies are necessary to fully understand what is driving such changes.

It was also attempted to quantify changes in the Bjerknes Feedback using the 20th Century Reanalysis product for 1950-1980. However, no significant changes were found between this period the 1980-2010 period. Considering the high variability of the $\mathrm{I}_{\mathrm{BJ}}$ terms among the different data sets analyzed, these results further reinforce that one single reanalysis product is insufficient to assess changes in the Bjerknes Feedback in the Atlantic. In order to minimize uncertainty, an ensemble of data products is necessary. 


\section{References}

Amaya, D. J., M. J. DeFlorio, A. J. Miller, and S.-P. Xie (2017, Sep). WES feedback and the Atlantic Meridional Mode: observations and CMIP5 comparisons. Climate Dynamics 49(5), 1665-1679.

An, S.-I. and H. Bong (2016, Aug). Inter-decadal change in El Niño-Southern Oscillation examined with Bjerknes stability index analysis. Climate Dynamics 47(3), 967-979.

Balas, N., S. E. Nicholson, and D. Klotter (2007). The relationship of rainfall variability in West Central Africa to sea surface temperature fluctuations. International Journal of Climatology 27(10), 1335-1349.

Balmaseda, M., F. Hernandez, A. Storto, M. Palmer, O. Alves, L. Shi, G. Smith, T. Toyoda, M. Valdivieso, B. Barnier, D. Behringer, T. Boyer, Y.-S. Chang, G. Chepurin, N. Ferry, G. Forget, Y. Fujii, S. Good, S. Guinehut, K. Haines, Y. Ishikawa, S. Keeley, A. Köhl, T. Lee, M. Martin, S. Masina, S. Masuda, B. Meyssignac, K. Mogensen, L. Parent, K. Peterson, Y. Tang, Y. Yin, G. Vernieres, X. Wang, J. Waters, R. Wedd, O. Wang, Y. Xue, M. Chevallier, J.-F. Lemieux, F. Dupont, T. Kuragano, M. Kamachi, T. Awaji, A. Caltabiano, K. Wilmer-Becker, and F. Gaillard (2015). The Ocean Reanalyses Intercomparison Project (ORA-IP). Journal of Operational Oceanography 8(sup1), s80-s97.

Balmaseda, M. A., K. Mogensen, and A. T. Weaver (2013). Evaluation of the ECMWF ocean reanalysis system ORAS4. Quarterly Journal of the Royal Meteorological Society $139(674), 1132-1161$.

Bamston, A. G., M. Chelliah, and S. B. Goldenberg (1997). Documentation of a highly ENSO-related SST region in the Equatorial Pacific: Research note. Atmosphere-Ocean 35(3), 367-383.

Behringer, D. W. (2007). The Global Ocean Data Assimilation System at NCEP. 11th Symp. on Integrated Observing and Assimilation Systems for Atmosphere, Oceans and Land Surface, 14-18. 
Berrisford, P., D. Dee, K. Fielding, M. Fuentes, P. Kallberg, S. Kobayashi, and S. Uppala (2009). The ERA-Interim Archive. ERA report series 1(1), 1-16.

Binet, D., B. Gobert, and L. Maloueki (2001). El Niño-like warm events in the Eastern Atlantic (6 $\left.{ }^{\circ} \mathrm{N}, 20^{\circ} \mathrm{S}\right)$ and fish availability from Congo to Angola (1964-1999). Aquatic Living Resources 14(2), 99 - 113.

Bjerknes, J. (1969). Atmospheric Teleconnections from the Equatorial Pacific. Monthly Weather Review 97(3), 163-172.

Brierley, C. and I. Wainer (2018). Interannual Variability in the Tropical Atlantic from the Last Glacial Maximum into Future Climate Projections simulated by CMIP5 / PMIP3. (August).

Brown, E., A. Colling, D. Park, J. Phillips, D. Rothery, and J. Wright (2001). Chapter 5 - Other major current systems. In E. Brown, A. Colling, D. Park, J. Phillips, D. Rothery, and J. Wright (Eds.), Ocean Circulation (Second Edition) (Second Edition ed.)., pp. 143 - 189. Oxford: Butterworth-Heinemann.

Carton, J. A., X. Cao, B. S. Giese, and A. M. D. Silva (1996). Decadal and Interannual SST Variability in the Tropical Atlantic Ocean. Journal of Physical Oceanography 26(7), 1165-1175.

Carton, J. A., G. A. Chepurin, and L. Chen (2018). SODA3: A New Ocean Climate Reanalysis. Journal of Climate 31(17), 6967-6983.

Carton, J. A. and Z. Zhou (1997). Annual cycle of sea surface temperature in the Tropical Atlantic Ocean. Journal of Geophysical Research: Oceans 102(C13), 27813-27824.

Chiang, J. C. H. and D. J. Vimont (2004). Analogous Pacific and Atlantic Meridional Modes of Tropical Atmosphere-Ocean Variability. Journal of Climate 17(21), 4143-4158.

Chung, C. E. and V. Ramanathan (2006). Weakening of North Indian SST Gradients and the Monsoon Rainfall in India and the Sahel. Journal of Climate 19(10), 2036-2045. 
Compo, G. P., J. S. Whitaker, P. D. Sardeshmukh, N. Matsui, R. J. Allan, X. Yin, B. E. Gleason, R. S. Vose, G. Rutledge, P. Bessemoulin, S. Brönnimann, M. Brunet, R. I. Crouthamel, A. N. Grant, P. Y. Groisman, P. D. Jones, M. C. Kruk, A. C. Kruger, G. J. Marshall, M. Maugeri, H. Y. Mok, Ø. Nordli, T. F. Ross, R. M. Trigo, X. L. Wang, S. D. Woodruff, and S. J. Worley (2011). The Twentieth Century Reanalysis Project. Quarterly Journal of the Royal Meteorological Society 137(654), 1-28.

Deppenmeier, A. L., R. J. Haarsma, and W. Hazeleger (2016). The Bjerknes Feedback in the Tropical Atlantic in CMIP5 models. Climate Dynamics 47(7-8), 2691-2707.

Deser, C., M. A. Alexander, S.-P. Xie, and A. S. Phillips (2010). Sea Surface Temperature Variability: Patterns and Mechanisms, Volume 2.

Ding, H., N. S. Keenlyside, and M. Latif (2010). Equatorial Atlantic interannual variability: Role of heat content. Journal of Geophysical Research: Oceans 115(C9).

Enfield, D. B. (1996). Relationships of inter-American rainfall to Tropical Atlantic and Pacific SST variability. Geophysical Research Letters 23(23), 3305-3308.

Foltz, G. R., M. J. McPhaden, and R. Lumpkin (2012). A Strong Atlantic Meridional Mode Event in 2009: The Role of Mixed Layer Dynamics. Journal of Climate $25(1), 363-380$.

Frankignoul, C. and E. Kestenare (2002, Oct). The surface heat flux feedback. Part I: estimates from observations in the Atlantic and the North Pacific. Climate Dynamics 19(8), 633-647.

Frankignoul, C., E. Kestenare, M. Botzet, A. F. Carril, H. Drange, A. Pardaens, L. Terray, and R. Sutton (2004, Apr). An intercomparison between the surface heat flux feedback in five coupled models, COADS and the NCEP reanalysis. Climate Dynamics 22(4), 373-388.

Goldenberg, S. B., C. W. Landsea, A. M. Mestas-Nuñez, and W. M. Gray (2001). The Recent Increase in Atlantic Hurricane Activity: Causes and Implications. Science 293(5529), 474-479. 
Haarsma, R. J. and W. Hazeleger (2007). Extratropical Atmospheric Response to Equatorial Atlantic Cold Tongue Anomalies. Journal of Climate 20(10), 20762091.

Hoyos, C. D., P. A. Agudelo, P. J. Webster, and J. A. Curry (2006). Deconvolution of the Factors Contributing to the Increase in Global Hurricane Intensity. Science 312(5770), 94-97.

Jansen, M. F., D. Dommenget, and N. Keenlyside (2009). Tropical Atmosphere-Ocean Interactions in a Conceptual Framework. Journal of Climate 22(3), $550-567$.

Jin, F.-F. (1997). An Equatorial Ocean Recharge Paradigm for ENSO. Part I: Conceptual Model. Journal of the Atmospheric Sciences 54(7), 811-829.

Jin, F.-F. and S.-I. An (1999). Thermocline and Zonal Advective Feedbacks Within the Equatorial Ocean Recharge Oscillator Model for ENSO. Geophysical Research Letters $26(19)$.

Jin, F. F., S. T. Kim, and L. Bejarano (2006). A coupled-stability index for ENSO. Geophysical Research Letters 33(23), 2-5.

Keenlyside, N. S. and M. Latif (2007). Understanding Equatorial Atlantic Interannual Variability. Journal of Climate 20(1), 131-142.

Kim, S. T., W. Cai, F.-F. Jin, and J.-Y. Yu (2014, Jun). ENSO stability in coupled climate models and its association with mean state. Climate Dynamics 42(11), 3313-3321.

Kim, S. T. and F.-F. Jin (2011, Apr). An ENSO stability analysis. Part II: results from the twentieth and twenty-first century simulations of the CMIP3 models. Climate Dynamics 36(7), 1609-1627.

Köhl, A. (2015). Evaluation of the GECCO2 ocean synthesis: Transports of volume, heat and freshwater in the Atlantic. Quarterly Journal of the Royal Meteorological Society 141(686), 166-181. 
Kumar, B. P., J. Vialard, M. Lengaigne, V. S. Murty, and M. J. McPhaden (2012). TropFlux: Air-sea fluxes for the global tropical oceans: description and evaluation. Climate Dynamics 38(7-8), 1521-1543.

Lau, K.-M. and S. Yang (2002). Walker Circulation. Encyclopedia of Atmospheric Sciences.

Li, T. and S. G. H. Philander (1997). On the Seasonal Cycle of the Equatorial Atlantic Ocean. Journal of Climate 10(4), 813-817.

Losada, T., B. Rodríguez-Fonseca, S. Janicot, S. Gervois, F. Chauvin, and P. Ruti (2010, Jul). A multi-model approach to the Atlantic Equatorial Mode: impact on the West African Monsoon. Climate Dynamics 35(1), 29-43.

Lübbecke, J. F. and M. J. McPhaden (2013). A comparative stability analysis of Atlantic and Pacific Niño Modes. Journal of Climate 26(16), 5965-5980.

Lübbecke, J. F. and M. J. McPhaden (2014). Assessing the twenty-first century shift in ENSO variability in terms of the Bjerknes stability index. Journal of Climate $27(7), 2577-2587$.

Masuda, S., T. Awaji, N. Sugiura, J. P. Matthews, T. Toyoda, Y. Kawai, T. Doi, S. Kouketsu, H. Igarashi, K. Katsumata, H. Uchida, T. Kawano, and M. Fukasawa (2010). Simulated Rapid Warming of Abyssal North Pacific Waters. Science 329(5989), 319-322.

Melice, J.-L. and J. Servain (2003, Mar). The tropical Atlantic meridional SST gradient index and its relationships with the SOI, NAO and Southern Ocean. Climate Dynamics 20(5), 447-464.

Nobre, P. and J. Shukla (1996). Variations of Sea Surface Temperature, Wind Stress, and Rainfall over the Tropical Atlantic and South America. Journal of Climate 9(10), 2464-2479.

Philander, S. G. (2001). Atlantic Ocean Equatorial Currents. Encyclopedia of Ocean Sciences, 188-191. 
Rasmusson, E. M. and T. H. Carpenter (1982). Variations in Tropical Sea Surface Temperature and Surface Wind Fields Associated with the Southern Oscillation/El Niño. Monthly Weather Review 110(5), 354-384.

Richter, I., S. K. Behera, Y. Masumoto, B. Taguchi, H. Sasaki, and T. Yamagata (2012). Multiple causes of interannual sea surface temperature variability in the equatorial Atlantic Ocean. Nature Geoscience 6(3), 43.

Saha, S., S. Moorthi, H. L. Pan, X. Wu, J. Wang, S. Nadiga, P. Tripp, R. Kistler, J. Woollen, D. Behringer, H. Liu, D. Stokes, R. Grumbine, G. Gayno, J. Wang, Y. T. Hou, H. Y. Chuang, H. M. H. Juang, J. Sela, M. Iredell, R. Treadon, D. Kleist, P. Van Delst, D. Keyser, J. Derber, M. Ek, J. Meng, H. Wei, R. Yang, S. Lord, H. Van Den Dool, A. Kumar, W. Wang, C. Long, M. Chelliah, Y. Xue, B. Huang, J. K. Schemm, W. Ebisuzaki, R. Lin, P. Xie, M. Chen, S. Zhou, W. Higgins, C. Z. Zou, Q. Liu, Y. Chen, Y. Han, L. Cucurull, R. W. Reynolds, G. Rutledge, and M. Goldberg (2010). The NCEP climate forecast system reanalysis. Bulletin of the American Meteorological Society 91(8), 1015-1057.

Saunders, M. A. and A. S. Lea (2008, Jan). Large contribution of sea surface warming to recent increase in Atlantic hurricane activity. Nature 451, $557 \mathrm{EP}-$.

Servain, J., G. Caniaux, Y. K. Kouadio, M. J. McPhaden, and M. Araujo (2014, Dec). Recent climatic trends in the Tropical Atlantic. Climate Dynamics 43(11), 3071-3089.

Servain, J., G. Clauzet, and I. C. Wainer (2003). Modes of Tropical Atlantic climate variability observed by PIRATA. Geophysical Research Letters 30(5), n/a-n/a.

Servain, J., I. Wainer, J. P. McCreary, and A. Dessier (1999). Relationship between the equatorial and meridional modes of climatic variability in the Tropical Atlantic. Geophysical Research Letters 26(4), 485-488.

Smirnov, D. and D. J. Vimont (2011). Variability of the Atlantic Meridional Mode during the Atlantic Hurricane Season. Journal of Climate 24 (5), 1409-1424.

Stramma, L. and F. Schott (1999). The mean flow field of the Tropical Atlantic 
Ocean. Deep Sea Research Part II: Topical Studies in Oceanography 46(1), 279 303.

Taschetto, A. S. (2001). O impacto dos gases estufa nas variáveis de superfície armar através de um modelo acoplado de circulação geral. Dissertação de mestrado, Instituto Oceanográfico, Universidade de São Paulo.

Tokinaga, H. and S.-P. Xie (2011). Weakening of the Equatorial Atlantic cold tongue over the past six decades. Nature Geoscience 4(4), 222-226.

Vecchi, G. A. and B. J. Soden (2007). Increased Tropical Atlantic wind shear in model projections of global warming. Geophysical Research Letters $34(8)$.

Vimont, D. J. and J. P. Kossin (2007). The Atlantic Meridional Mode and hurricane activity. Geophysical Research Letters 34(7).

Wainer, I. and J. Soares (1997, 02). North Northeast Brazil rainfall and its decadal-scale relationship to wind stress and sea surface temperature. Geophysical Research Letters - GEOPHYS RES LETT 24, 277-280.

Xie, S.-P. (1994). On the Genesis of the Equatorial Annual Cycle. Journal of Climate 7(12), 2008-2013.

Xie, S.-P. and J. A. Carton (2013). Tropical Atlantic Variability: Patterns, Mechanisms, and Impacts, pp. 121-142. American Geophysical Union (AGU).

Xie, S.-P., C. Deser, G. A. Vecchi, J. Ma, H. Teng, and A. T. Wittenberg (2010). Global Warming Pattern Formation: Sea Surface Temperature and Rainfall. Journal of Climate 23(4), 966-986.

Xue, Y., M. A. Balmaseda, T. Boyer, N. Ferry, S. Good, I. Ishikawa, A. Kumar, M. Rienecker, A. J. Rosati, and Y. Yin (2012). A Comparative Analysis of UpperOcean Heat Content Variability from an Ensemble of Operational Ocean Reanalyses. Journal of Climate 25(20), 6905-6929.

Yadav, R. K., G. Srinivas, and J. S. Chowdary (2018). Atlantic Niño modulation of the Indian Summer Monsoon through the Asian Jet. Climate and Atmospheric Science 1(1), 23. 
Yang, C., S. Masina, and A. Storto (2017). Historical ocean reanalyses (1900-2010) using different data assimilation strategies. Quarterly Journal of the Royal Meteorological Society 143(702), 479-493.

Yang, H. and F. Wang (2009). Revisiting the Thermocline Depth in the Equatorial Pacific. Journal of Climate 22(13), 3856-3863.

Zebiak, S. E. (1993). Air-Sea Interaction in the Equatorial Atlantic Region. Journal of Climate 6(8), 1567-1586.

Zhang, S., M. J. Harrison, A. Rosati, and A. Wittenberg (2007). System Design and Evaluation of Coupled Ensemble Data Assimilation for Global Oceanic Climate Studies. Monthly Weather Review 135(10), 3541-3564.

Zhu, J., B. Huang, and M. Balmaseda (2012, 08). An ensemble estimation of the variability of upper-ocean heat content over the Tropical Atlantic Ocean with multi-ocean reanalysis products. Climate Dynamics 39, 1001-1020. 